\title{
Caring and Unpaid Work in Ireland
}

Helen Russell, Raffaele Grotti, Frances McGinnity and Ivan Privalko

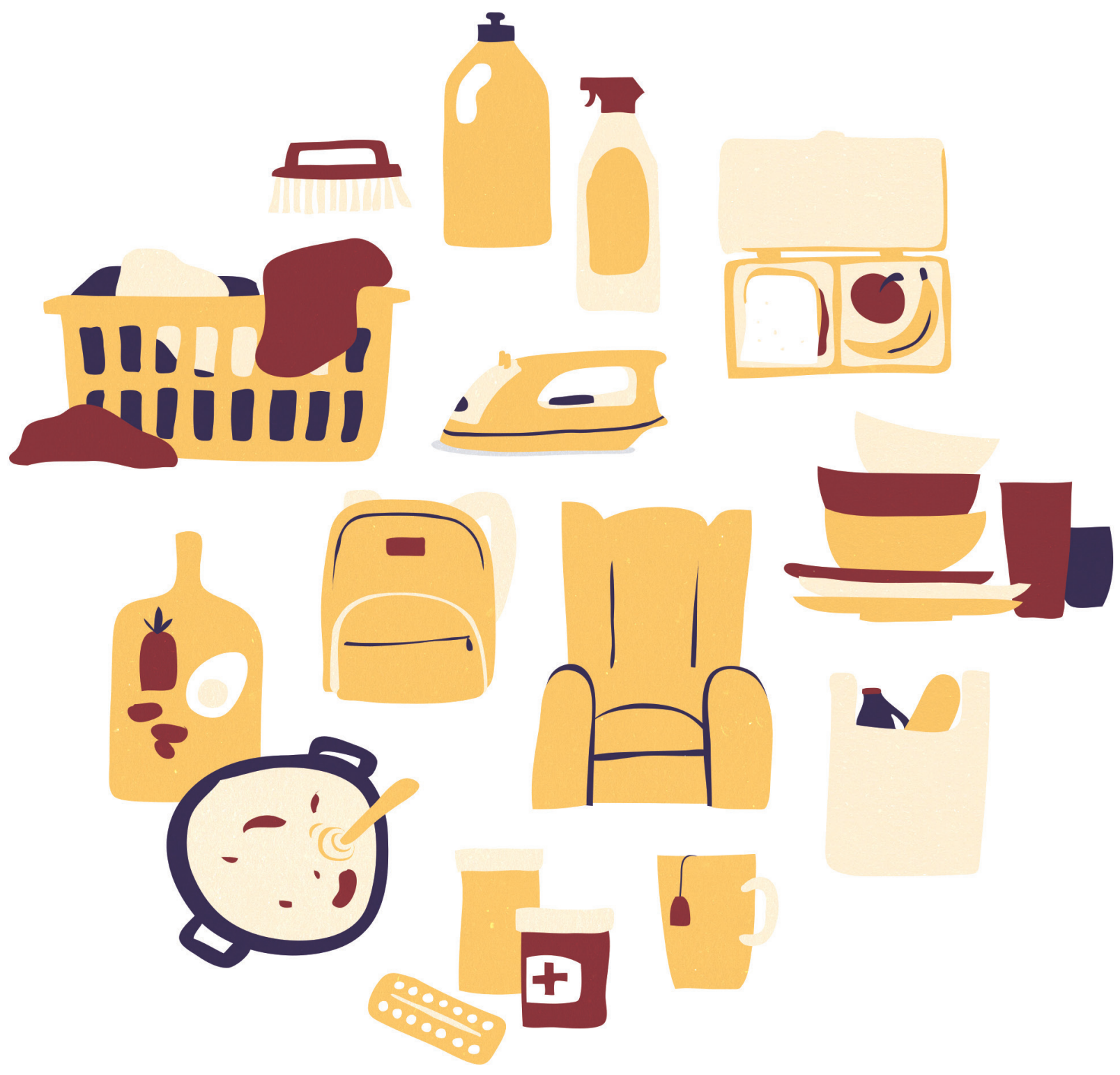

Coimisiún na hÉireann um Chearta an Duine agus Comhionannas

Irish Human Rights and Equality Commission

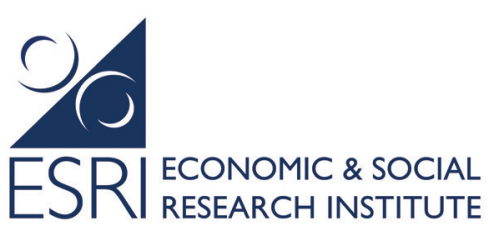




\section{Caring and Unpaid Work in Ireland}

Helen Russell, Raffaele Grotti, Frances McGinnity and Ivan Privalko 
This report was written by Helen Russell, Raffaele Grotti, Frances McGinnity and Ivan Privalko. It was prepared for the Irish Human Rights and Equality Commission by the Economic and Social Research Institute as part of the Research Programme on Human Rights and Equality. The report has been peer-reviewed prior to publication. The views expressed in this report are those of the authors and do not necessarily represent those of the Economic and Social Research Institute or the Irish Human Rights and Equality Commission.

The Irish Human Rights and Equality Commission was established under statute on 1 November 2014 to protect and promote human rights and equality in Ireland, to promote a culture of respect for human rights, equality and intercultural understanding, to promote understanding and awareness of the importance of human rights and equality, and to work towards the elimination of human rights abuses and discrimination.

The Economic and Social Research Institute (ESRI) is an independent research institute working towards a vision of 'Informed policy for a better Ireland'. The ESRI seeks to support sustainable economic growth and social progress in Ireland by providing a robust knowledge base capable of providing effective solutions to public policy challenges.

Available to download from www.esri.ie and www.ihrec.ie

(C) 2019. Copyright is held jointly by the Economic and Social Research Institute and the Irish Human Rights and Equality Commission.

Irish Human Rights and Equality Commission, 16-22 Green Street, Dublin 7.

The Economic and Social Research Institute, Whitaker Square, Sir John Rogerson's Quay, Dublin 2

ISBN 978-0-7070-0489-1

DOI https://doi.org/10.26504/bkmnext382

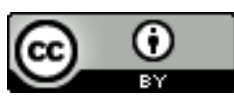

This Open Access work is licensed under a Creative Commons Attribution 4.0 International License (https://creativecommons.org/licenses/by/4.0/), which permits unrestricted use, distribution, and reproduction in any medium, provided the original work is properly credited. 


\section{FOREWORD}

I am very pleased to introduce Caring and Unpaid Work in Ireland, the sixth in a series of pieces of research conducted by the Economic and Social Research Institute as part of the Irish Human Rights and Equality Commission's Research Programme on Human Rights and Equality.

This piece of research is particularly timely, coming as it does during a period where the contribution made to our society by those involved in caring and unpaid work is being actively examined in political, policy and civil society circles. This can be seen not only in the ongoing discussion around reform of Article 41.2 of the Constitution, but also in the context of Government commitments to better facilitate caring and unpaid work through planned reform of parental and family leave provisions.

The results presented in this study are an important contribution to this discussion, and demonstrate not only the scale of care and other unpaid work carried out in Ireland, but the considerable work that remains to be done in order for that work to be better recognised and supported.

Drawing from data from the European Quality of Life Survey, which examine frequency of involvement in childcare, adult care, housework and cooking, this research provides further evidence of the heavily gendered nature of caring and unpaid work in Ireland - something which the Commission has highlighted previously in its reporting to the United Nations Committee on the Elimination of All Forms of Discrimination Against Women.

The data reveal that Ireland has the third highest rate of unpaid work for both women and men, and that the gap between men and women, at 15 hours per week, places Ireland very far down the league table within the EU28.

This study also makes clear that over half of those carrying out unpaid care work are juggling these responsibilities with employment, and that women are overrepresented in the cohort of employees who avail of reduced hours in order to facilitate care and unpaid work. 
While we have seen advances in recent years, including increased participation by women in the workplace, we have yet to see adequate supports for caring and unpaid work. Nor, crucially, have we yet seen adequate measures to reconfigure the gendered nature of care work, and to create the conditions to encourage men to take on more such work.

I hope this study will provide some of the insights required to assist policymakers in Ireland to create a new paradigm, where caring and unpaid work is recognised, truly valued, and equally shared.

I would like to convey my thanks to the authors of this report, Helen Russell, Raffaele Grotti, Frances McGinnity and Ivan Privalko.

Emily Logan

Chief Commissioner

Irish Human Rights and Equality Commission 



\section{THE AUTHORS}

Helen Russell is an Associate Research Professor at the ESRI and an Adjunct Professor of Sociology at TCD. Raffaele Grotti was a Post-doctoral Research Fellow at the ESRI and is currently a Research Fellow at the European University Institute (Italy). Frances McGinnity is an Associate Research Professor at the ESRI and an Adjunct Professor of Sociology at TCD. Ivan Privalko is a Post-doctoral Research Fellow at the ESRI.

\section{ACKNOWLEDGEMENTS}

We gratefully acknowledge the funding received from the Irish Human Rights and Equality Commission (IHREC) to support this research programme. We would like to thank Cliona Doherty (IHREC), Iris Elliott (IHREC) and Gráinne Collins (NDA) for their input and constructive comments as members of the research programme steering group. The report also benefited greatly from the comments of two ESRI reviewers, and an external expert reviewer, as well as Professor Emer Smyth, who acted as editor of the report. Lastly, we thank Eurofound for providing the European Quality of Life Survey. 



\section{TABLE OF CONTENTS}

GLOSSARY

VII

EXECUTIVE SUMMARY IX

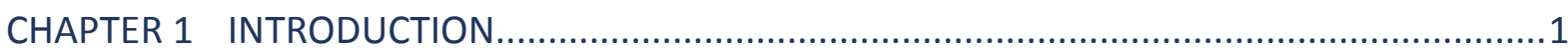

1.1 Introduction: why is unpaid work important? .....................................1

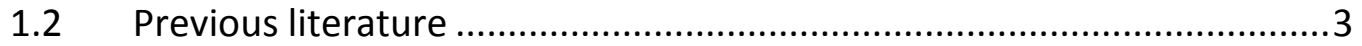

1.3 Policy context in Ireland ....................................................................10

1.4 Labour market context: paid employment...........................................16

1.5 Previous evidence on unpaid work in Ireland ...................................18

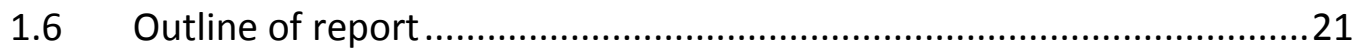

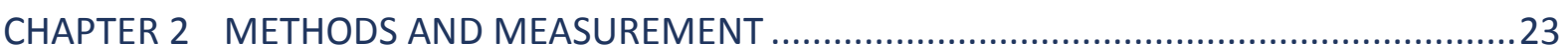

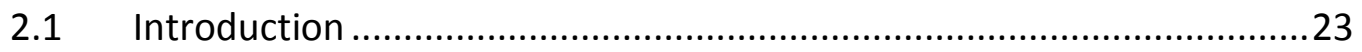

2.2 Defining and measuring unpaid labour ..............................................23

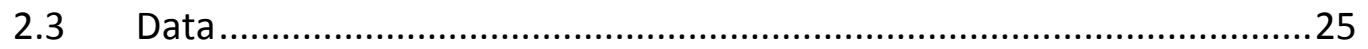

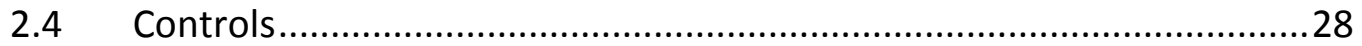

CHAPTER 3 LEVEL OF INVOLVEMENT IN UNPAID ACTIVITIES IN IRELAND ..........................31

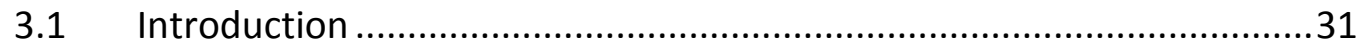

3.2 Who is caring? Involvement in caring activities ..................................32

3.3 Weekly hours spent on caring activities ...........................................34

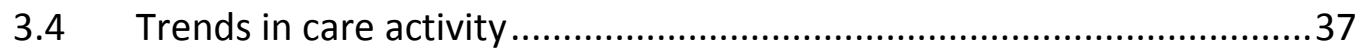

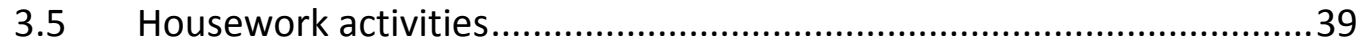

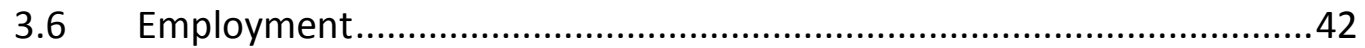

3.7 Comparison with 2005 Time-Use Survey.............................................44

3.8 How does Ireland compare to elsewhere in Europe? ..........................45

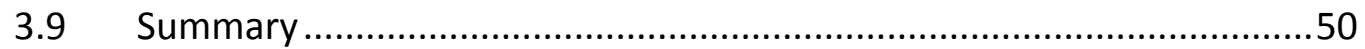


CHAPTER 4 MODELLING THE FACTORS THAT INFLUENCE TIME SPENT ON CARING, HOUSEWORK AND TOTAL UNPAID LABOUR

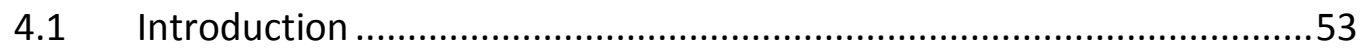

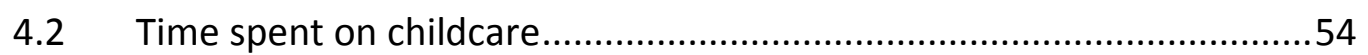

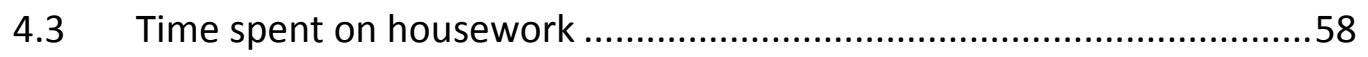

4.4 Time spent on total unpaid work …................................................61

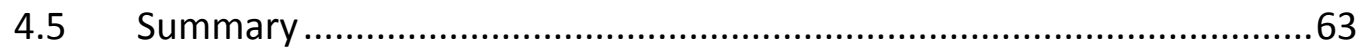

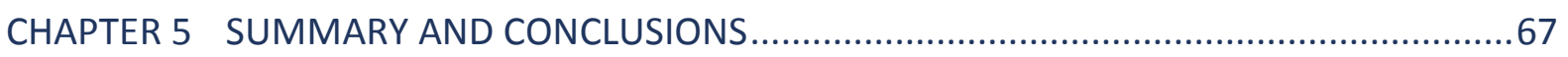

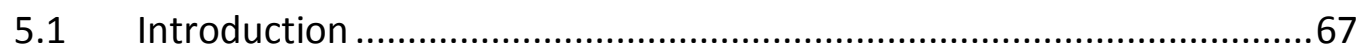

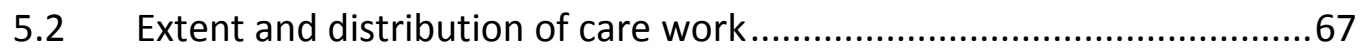

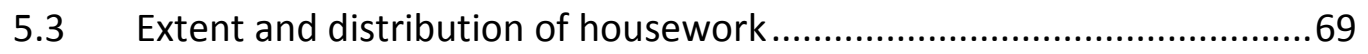

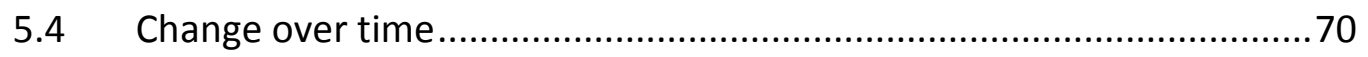

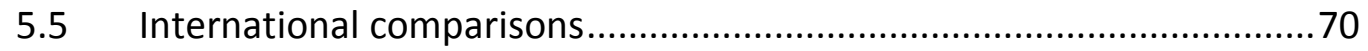

5.6 Limitations and implications for data collection ................................71

5.7 Implications for economic evaluations of care .....................................72

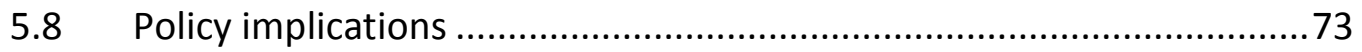




\section{LIST OF TABLES}

Table 1.1 Number of claimants of Carer's Allowance and Carer's Benefit ..................... 15

Table 2.1 Sample size and response rates European Quality of Life Survey .................. 26

Table 2.2 Types of unpaid/domestic labour measured in the EQLS ............................. 27

Table 2.3 Summary and distribution of control measures.......................................... 30

Table 3.1 Employment rate and hours of paid work by gender (Ireland 2003-2016) .... 43

Table 3.2 Estimates of mean weekly hours spent on care and housework, EQLS and National Time-use Survey compared ..................................................... 45

Table 4.1 Zero-inflated negative binomial model of care hours, marginal effects.......... 56

Table 4.2 Zero-inflated negative binomial model of housework hours, marginal

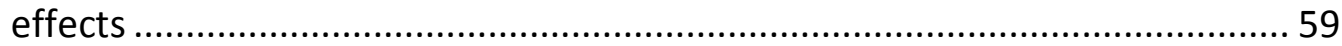

Table 4.3 Zero-inflated negative binomial model of unpaid hours, marginal effects ..... 61

Table A3.1 Employment rates by gender over time (Ireland 2003-2016)....................... 87

Table A3.2 Mean weekly hours spent on childcare activity ............................................ 88

Table A3.3 Mean weekly hours spent on adult care .................................................... 88

Table A3.4 Involvement in housework activity every day............................................ 88 


\section{LIST OF FIGURES}

Figure 1.1 Employment rates men and women in Ireland 1993-2017, ages 15-64 years.

Figure 1.2 Proportion of women in home duties 1998-2017 (15 years and over) .......... 20

Figure 1.3 Care hours for adult care by gender (Census 2016) ................................... 21

Figure 3.1 Daily childcare by gender and age in Ireland, 2003-2016 pooled ................... 32

Figure 3.2 Daily adult care by gender and age in Ireland, 2003-2016 pooled ................. 33

Figure 3.3 Daily involvement in any care activity by gender and age, 2003-2016 pooled

Figure 3.4 Average time spent on care work, for whole population and regular carers, Ireland (2007, 2011, 2016, pooled)

Figure 3.5 Mean and median hours spent on child and adult care for those regularly caring (2007, 2011 and 2016 pooled)

Figure 3.6 Proportion of men and women involved in care activity every day, Ireland, 2003 to 2016 38

Figure 3.7 Daily involvement in housework by gender and age group 40

Figure 3.8 Mean and median hours spent on housework across whole population (Ireland, 2007, 2011 and 2016 pooled)

Figure 3.9 Daily involvement in housework in Ireland: change over time. 42

Figure 3.10 Employment status of those providing care every day...... 44

Figure 3.11 Women: modelled unpaid work hours by country, 2016

Figure 3.12 Men: modelled unpaid work hours by country, 2016. 48

Figure 3.13 Modelled gender gap in unpaid work hours across Europe 50

Figure 4.1 Modelled weekly care time (child and adult care) by gender and hours of paid work 57

Figure 4.2 Modelled housework time for men and women by employment hours. 60

Figure 4.3 Modelled hours of total unpaid work by gender and paid employment. 63 


\section{GLOSSARY}

Adult care Unpaid care of an older person or a person with a disability.

Carer Any person who provides regular unpaid care 'at least once a week' to children, to an older person or to a person with a disability. It does not include paid carers.

Childcare Unpaid care and education of children. Excludes caring undertaken as paid work.

EQLS European Quality of Life Survey.

Formal care Care provided in a formal setting by waged workers. Formal care can be provided by the State or the market.

Housework Unpaid domestic tasks, including cooking (added to the EQLS in 2007).

Informal care Care that is provided on an unpaid basis by family or friends.

Margins Marginal effects for categorical variables (like countries) measure the effect of the variable on the predicted values of an outcome (such as unpaid work time) when other factors are held constant.

Multivariate Multivariate analysis examines the impact of one factor (such as gender) on analysis/ another (such as time spent providing childcare), after taking into account

statistical models

QNHS the differences (such as time spent at work). For instance, multivariate analysis allows us to ask whether men's patterns of care are similar to women's once we consider men's tendency to work longer hours in paid employment.

Quarterly National Household Survey (recently renamed the Labour Force Survey).

Statistical An estimate of the relationship between variables like time spent caring and significance gender is statistically significant if the $p$-value associated with the estimate is less than 0.05 . A p-value is the probability of gaining an estimate as extreme as the one recorded, in a scenario where no relationship exists between measures. A value of .05 means there is less than a 5 per cent chance that the difference found is due to chance.

Total care Combined total of time spent on unpaid childcare and adult care.

Total unpaid Combined total of time spent on care and housework. work

Zero-inflated Negative Binomial Model (ZINB)
A method of regression analysis which is used for count variables and takes two factors into account. First, skewed distributions with excessive zero values. Second, over-dispersed outcomes where the variance is higher than the mean value of an outcome. 



\section{EXECUTIVE SUMMARY}

Care and other unpaid work provides an important contribution to the welfare of individuals, families and society. Yet in contrast to paid work, participation in these activities and the time people spend on them is rarely measured. While the need for care is universal, labour market trends and demographic trends have changed the shape of these demands. For example, increased life expectancy increases the need for care of older people, while growing female participation in employment over the last two decades in Ireland has altered the availability of someone in the home to provide care. The division of paid and unpaid work is strongly gendered, but comparative analysis shows how the extent of gender equality in unpaid work varies across countries and is influenced, in part, by the policy configuration in place. Comparative studies suggest that Ireland is closest to the 'modified male breadwinner' policy regime, where there has been a shift from the traditional male breadwinner approach, particularly in terms of women's increased participation in paid work. However supports for caring are comparatively low; combining paid work and caring remains challenging; and policies to encourage men to take on caring responsibilities are underdeveloped.

In this study we focus on childcare, care of older adults or those with a disability, and housework, and set out to ask the following questions:

- What is the level of involvement in caring and other unpaid household work in Ireland?

- How does the time spent on care and housework vary by gender, age, education level and household composition?

- How has involvement and time spent on these activities changed over time among women and men?

- How does the situation in Ireland compare to elsewhere in the EU?

We draw on data from the European Quality of Life Survey (EQLS), which are collected across the EU every five years by the European Foundation for the Improvement of Working and Living Conditions. The findings are based on questions about frequency of involvement 
in childcare, adult care, and housework/cooking, and self-reports of the time spent on these activities per week in the period 2003 to 2016.

\section{KEY FINDINGS: UNPAID CARING}

Pooling data across years we find that 45 per cent of women and 29 per cent of men provide care for others on a daily basis (childcare and/or adult care). Overall, we find that 55 per cent of those regularly providing care are in employment: 45 per cent in the case of women and 72 per cent in the case of men.

Daily involvement in care of children is more common across the population than care of adults: 33 per cent compared to 8 per cent. These participation patterns influence the average time spent on care, as the majority do not record any time on care activities.

The average time spent on care across the whole population is 16 hours per week; 10.6 hours for men and 21.3 hours for women. Among those providing regular childcare i.e. at least once a week, the mean weekly time is 35.2 hours per week: 42.6 hours for women and 25.2 hours for men.

The average time commitment and the gender gap in weekly hours are lower in the case of adult care. Among those providing regular adult care the mean time commitment is $\mathbf{1 9 . 4}$ hours per week; 19.8 hours per week among female carers and 18.8 hours among male carers. The provision of care to older or disabled adults every day is most common for those women aged 50 to 64 years, but for men such care peaks in the over 65 age group.

We use statistical models to examine how care time is influenced by factors such as hours of employment, age, education, age of children, partnership status, and partner's employment. Holding all these factors constant, women perform an average of 7.2 hours more hours of care work per week than men. The strongest predictors of care time are gender, age of youngest child, and for women, participation in paid employment. Men's care hours do not differ by employment status and are less strongly linked to children's age than women's care hours. Among those not in employment or working part-time there is a large difference in the care hours of women and men. There is no significant gender difference in care time among those employed full-time. 


\section{KEY FINDINGS: HOUSEWORK}

The EQLS also asks respondents about their participation and time spent on housework. Women in Ireland report doing an average of just under 20 hours of housework per week, and men report an average of seven hours. Time spent on housework is related to a similar set of factors as care, though the strength of their influence differs. Family structure is again important. Having pre-school children increases housework by 7.9 hours per week, when other relevant factors are controlled. We find that the effect of children on housework time is stronger for women than men, adding 11.0 hours and 6.5 hours respectively, compared to those with no children. The effect of having a partner on the level of housework time differs for women and men. Having a partner, either employed or non-employed, increases time spent on housework for women. For men, having a partner who is not in employment lowers time spent on housework (compared to single men). This suggests that a traditional gendered allocation of housework persists in many households.

While time on housework is related to hours of employment for both women and men, at each level of paid work, women do significantly more housework than men.

\section{CHANGE OVER TIME}

The repeated nature of the EQLS allows us to examine change over time. Men's time spent on unpaid work time (care plus housework) increased significantly between 2007 and 2011 but returned to the 2007 levels in 2016. This increase was partly due to decreases in paid employment during the recession, but was noticeable even when employment was taken into account, suggesting drops in income may also have resulted in a shift towards selfprovision of meals, care and other services. The time trends indicate a recessionary shock rather than a long-term change in men's unpaid work.

\section{IRELAND IN INTERNATIONAL PERSPECTIVE}

We compare levels of unpaid work across the EU28 in 2016 holding constant the distribution of other relevant factors, namely level of paid employment, age, education, partner status and age of children. Even in models taking these compositional differences into account, Ireland has the third highest weekly hours of unpaid work for both men and 
women across the EU28. This is likely to reflect high demand for caring in Ireland, with relatively low State involvement in support for caring.

The gender gap in unpaid work time in Ireland is seventh highest amongst the EU28. The other countries with a wide gender gap include a number of Southern countries (Italy, Greece and Malta) and Eastern European countries (e.g. Poland). These countries have been identified as having systems where the provision of care falls primarily on the family (Saraceno and Keck, 2011). The gender gap in caring is narrowest in the Scandinavian countries. These countries have welfare/gender regimes that are closer to the dual earner/dual caregiver model, and offer the most consistent policy configuration for promoting gender equality. These comparisons suggest that the Irish policy regime continues to support a gendered allocation of unpaid care. Further research is necessary to explore more detailed policy processes (social services, family policies, tax/welfare policies, employment policies, etc.) that influence these cross-national differences but is beyond the scope of the current study.

\section{FUTURE RESEARCH AND DATA NEEDS}

Recognition of the value of unpaid work depends first on its measurement. The figures presented in the report provide the basis for carrying out an estimate of the economic value of unpaid work using established techniques (see Hanly and Sheerin, 2017, for an estimate of the labour cost value of adult care in Ireland).

The EQLS asks respondents to estimate the total amount of time they have spent on care and housework per week. These data fill an important gap in the evidence on unpaid work in Ireland but such estimates may be prone to error. Time-use surveys, in which respondents complete detailed activity diaries, provide the most accurate accounts of time spent on unpaid work activities but no such national survey has been carried out in Ireland since 2005. Given the increasing public focus on this important issue a new time-use survey for Ireland is now urgently needed. 


\section{POLICY IMPLICATIONS}

Irish social policy has been characterised as being a Liberal modified male breadwinner regime, in that provision of care services (e.g. childcare, care for older people) by the State is relatively low, leaving households to provide these services themselves or to source them from the market if they can pay. While support for childcare services has increased significantly in recent years, and leave schemes have been developed and enhanced over the last two decades, the levels of support for combining paid and unpaid work are still well behind the provision in Scandinavian and some continental European states, and lag behind the dramatic rise in women's paid employment in Ireland (Russell et al., 2017a).

In order to move to a situation where caring and household work is both valued and more equally shared between men and women there is a need for changes in social and employment policies that support carers, facilitate the combination of care and employment and at the same time encourage greater male participation in care.

Employer policies are crucial in allowing individuals to combine work and care; previous research has shown that men's access to flexible working arrangements is low (Russell et al., 2009a). Yet the majority of (daily) carers are combining employment and care. The value of income supports is critical for full-time carers who do not have access to market income in the household, for example, those in receipt of one-parent family payments or Carer's Allowance.

Many authors have argued that the distribution of caring tasks between women and men is vital to understanding persistent gender difference in the labour market and the allocation of resources in society (see Chapter 1 ). Caring responsibilities are a key component of gender inequality in the labour market, in terms of access to employment, hours of work, promotion prospects, wages and working conditions. Without greater equality in terms of unpaid work, gender equality in the labour market is unlikely to be achieved.

Steps are currently underway to run a referendum on removing or replacing Article 41.2 of the Constitution, which refers to women's place in the home. This has prompted a broader discussion on the value of care and unpaid work in the home (Oireachtas Joint Committee on Justice and Equality, 2018). The results presented in this study contribute to this debate 
by highlighting the substantial scale of care and other housework that is carried out informally in households, and the characteristics of those providing care. The study also highlights that the value and distribution of this work is an important question for Irish society to consider. 


\section{CHAPTER 1}

\section{Introduction}

\section{$1.1 \quad$ INTRODUCTION: WHY IS UNPAID WORK IMPORTANT?}

The care and household work that is provided between and within households is an important component of the welfare of society. ${ }^{1}$ The needs of citizens are met through a combination of state, market and family provision. While the level of state and market involvement in the provision of services and resources is routinely measured, the level of unpaid care and other services provided within families is much less visible and more rarely quantified, chiefly because it does not involve an exchange of money. Yet unpaid caring and housework clearly contribute to the living standards, well-being and human development of a society (Folbre, 2015). Indeed Folbre $(2006 ; 2015)$ cogently argues that by not valuing unpaid work in National Accounts of economic activity, we miss an important part of the picture; the total work that is done in countries. Market transactions represent only a subset of the goods and services in any society and yet market activity such as paid work is crucially reliant on unpaid work being done to support it.

The issue of the value of unpaid work in the home has received renewed attention due to deliberations around Article 41.2 of the Irish Constitution and whether it should be deleted or replaced. The Article refers to the contribution of women to the State, 'through her life in the home', and obliges the State to 'endeavour' to support mothers not to have to work outside the home; it has been contentious for some time. While much of the debate about the article has criticised the provision as sexist and anachronistic, others have noted that the aspiration to value care work is an important one (Oireachtas Joint Committee on Justice and Equality, 2018). As Murphy (2011) points out, the cost in not caring consists of not only repairing the social dysfunction caused by inadequate care, but also in the lower quality of our collective lives. In the context of these discussions, it is useful to interrogate the nature and distribution of unpaid care in Ireland and how this has changed over time. The level and

1 By care, we mean the unpaid and informal production of value in the home for the benefit of children, older adults, and adults with a disability 
distribution of unpaid care is also important for the quality of life of carers and those in receipt of care.

Demographic and labour market changes also lead to changes in the demand for different forms of care. Population ageing trends and a policy shift towards care in the community for older and disabled adults mean that there is an increasing demand for adult care in the community, both formal and informal (Hanly and Sheerin, 2017). The shifting patterns of female employment, which were particularly dramatic in Ireland in recent decades (Russell et al., 2017a), mean that caring is increasingly combined with paid work. This has implications for the services and supports needed by parents and those caring for older adults or those with a disability.

There is an important gender dimension to this issue of valuing care work in that the bulk of unpaid care and housework has been provided by women, while men have traditionally supplied the greater part of paid work time. Despite changes in gender roles and a narrowing gender gap in employment rates, gender differences in care work within the household remain pronounced (Blossfeld and Drobnic 2001; Bianchi et al., 2006; Gershuny, 2018).

Indeed many authors have argued that the distribution of caring tasks between women and men is vital to understanding wider gender difference in the labour market and resources in society (Blau et al., 1992; England, 2006; Bianchi and Milkie, 2010). Caring responsibilities are a key component of gender equality in the labour market, in terms of access to employment, hours of work, promotion prospects, wages and working conditions. Breaks in employment for caring are a key component of the gender wage gap, in Ireland as well as internationally (Blau and Kahn, 2000; McGuinness et al., 2009). Part-time work, which is often undertaken to accommodate caring responsibilities, is typically associated with lower wages and poorer promotion prospects than full-time work (Gregory, 2010; Bergin et al., 2012 for Ireland). Women's lower earnings in employment and shorter working lives also bring lower lifetime earnings, reduced pension entitlements and greater risk of poverty in old age (Gregory, 2010). 
The first step in valuing unpaid work is to measure it. In this study we draw on the European Quality of Life Survey (EQLS) to investigate the distribution of unpaid work, which is carried out by the European Foundation every five years, most recently in 2016. In the report unpaid work is defined as including care of children, care of older people or those with a disability, and housework. ${ }^{2}$ Using these data and applying statistical models, this study aims to address the following questions:

- What is the level of involvement in caring and other unpaid household work in Ireland?

- How does the time spent on care and housework vary by gender, age, education level and household composition?

- How has involvement and time spent on these activities changed over time among women and men?

- How does the situation in Ireland compare to elsewhere in the EU?

This chapter provides the context for the empirical analysis which follows. Section 1.2 summarises previous literature, first reviewing different explanations for how unpaid work is allocated in societies (1.2.1). Different states reward and value care work in different ways, and this has a crucial impact on how much unpaid work is done within families and by whom. Section 1.2.2 discusses different policy configurations and how Ireland fits in, and then in Section 1.3 we review in more detail past and current policies in the area of childcare and adult care in Ireland. Section 1.4 discusses the labour market context, in particular the long-term increase in women's labour market participation, but also the boom and recession. Section 1.5 discusses previous evidence of unpaid work in Ireland.

\subsection{PREVIOUS LITERATURE}

\subsubsection{Explanations for the allocation of unpaid labour}

A number of theoretical perspectives, drawn from both economics and sociology, dominate the literature on gender differences in unpaid work across society and across time. This brief

2 The concepts of care and unpaid work are discussed in more detail in Chapter 2 and the precise question wording in the survey is presented. 
overview is not designed to be comprehensive but rather give a flavour of the different factors that play a role in understanding how paid and unpaid work is allocated in society.

\section{Economic theories of allocation: specialisation and bargaining}

The specialisation perspective is informed by Becker's very influential 'new home economics' theory (Becker, 1991). Becker argues that the fact that husbands are traditionally responsible for 'breadwinning' or paid work and wives traditionally responsible for homemaking arises from the choices and preferences of rational actors who seek to maximise the welfare or utility of the household. If one partner earns more for any given hour spent in paid work this will lead to a specialisation of roles, where one partner invests more time in producing income and the other will spend more time in non-market work. Yet while in all countries women do more unpaid work than men, patterns vary across countries and across time: state policy is found to influence the context and extent to which 'specialisation' takes place, as discussed in Section 1.2.2.

Other authors reject the notion that there is consensus or agreement in the household and assume that partners have potentially conflicting interests (Brines, 1994). According to economic bargaining models, how unpaid work is allocated reflects power relations between men and women. The level of resources each partner brings to the relationship determines how much paid and unpaid work is done by each partner. As unpaid work is seen as less attractive than paid work, the models suggest that the partner with greater resources (economic advantage within the partnership and better alternatives to the relationship) will use these resources to avoid unpaid work. Studies find partial support for bargaining; relative income matters in most cases, so women within couples decrease their housework as their earnings increase, with some notable exceptions (Bittman et al., 2003). Once again the national context can influence the resources that men and women possess (the differences between men's and women's wages; women's choices and constraints regarding labour market participation), or their alternatives to marriage (for example the legal and cultural context of marital separation) and hence the allocation of paid and unpaid work (Breen and Cooke, 2005). 


\section{The time availability perspective}

In the time availability perspective, the emphasis is on time constraints. The division of labour is rationally allocated on the basis of (1) the amount of unpaid work to be done and (2) the amount of time available to each partner. Hence, we would expect time in unpaid work be strongly related to how much paid employment individuals are doing and the number of children or adults needing care. While research findings tend to support this perspective, results also show that these factors (paid employment hours and the number and ages of children, for example) have a much stronger effect on women's unpaid labour than men's (Bianchi et al., 2000).

This perspective would strongly suggest that an increase in paid work by women over time would see a fall in their unpaid work time. Similarly a fall in paid work, as happens during an economic recession, might result in an increase in unpaid work. For example if a parent loses their job, they may become a full-time carer for their pre-school child because of time availability and cost.

\section{Gender and gender role attitudes}

Feminist researchers have challenged the idea that the allocation of unpaid labour is simply about resources, time availability, or rational choices, and they stress the role of gender. The 'doing gender' approach sees housework as a symbolic enactment of gender relations. In other words, men and women display their 'proper' gender roles by the amount of housework they perform (West and Zimmerman, 1987). This explains some results that are inconsistent with the time availability perspective, for example the finding that nonemployed/unemployed men do much less housework than their employed wives, even though they have more time available. And at a societal level, the role of gender helps explain the fact that rapid increases in paid employment by women in societies are not always accompanied by an increase in unpaid work by men (Gershuny et al., 2005). Women continue to do more unpaid work as being a 'good' mother, wife or daughter depends on this. Chesley and Flood (2017) use the American Time Use Survey to show how stay-athome mothers perform more childcare than fathers who take a similar role. They argue that gender normative tasks persist, even when economic positions between mothers and fathers differ. 
A related approach places more emphasis on gender role attitudes, suggesting that those who hold more egalitarian gender attitudes will distribute unpaid labour more equally. Previous research finds some support for this, although, once again, attitudes are more relevant for women than for men; wives tend to be more affected by husbands' attitudes than vice versa (Shelton and John, 1996; Bianchi et al., 2000). But it is difficult to determine the link between attitudes and behaviour, since individuals may adjust their attitudes to be consistent with their behaviour; that is, how much paid and unpaid work they are actually doing. Nevertheless, one might expect that the dominant gender ideology in a country in relation to the role of men, women, wives and husbands and mothers and fathers is also relevant to the household division of labour (Geist and Cohen, 2011).

In Ireland recent changes in what are seen as 'appropriate' roles for men and women are relevant here. Using data from the International Social Survey Programme from 1988 until 2012, Russell et al. (2017) show that over this period there was a clear increase in support for the employment of mothers in Ireland. Fine-Davis (2016) argues that attitudes have changed more in the area of mothers' employment than attitudes to caring. She notes that while gender role attitudes have changed dramatically in Ireland over the last 40 years, in 2010 there was still an underlying ambivalence around male involvement in caring and 'vestiges of traditional views of caring' (ibid, p60). This also extended to the area of housework. A majority of respondents in Ireland agreed with the statement 'while men recognise that women have to spend less time on housework, they don't recognise that they have to contribute more than they used to', though a much greater proportion of women agreed with this statement than men. Gender role attitudes also tend to vary across age groups and between those with different socio-economic backgrounds or education level (Fine-Davis, 2016; O’Sullivan, 2007).

Of course, individual women may also differ in the importance they attach to employment and to the aspects of employment that they most value, and thus the jobs they choose, or whether they work at all (Hakim, 2002). It is difficult to assess how much weight to give individual preferences, given that they may be strongly influenced by constraints, like financial constraints and childcare costs. Yet the idea that individual tastes and preferences play a role in any individual's paid and unpaid work hours, given these constraints, is 
plausible, although of course individual preferences will also be related to the normative climate in society around gender roles and mothers' employment, as discussed above.

These perspectives present different accounts of how and why unpaid work is allocated. Emphases differ, but a clear thread running through the accounts is that state policy is important for understanding the allocation of paid and unpaid work. Section 1.2.2 discusses international literature on state supports and policies regarding caring, Section 1.3 presents policy supports in Ireland.

\subsubsection{Variation in how states support unpaid work}

Social policy researchers have developed welfare regime typologies to summarise the distinctive approaches to the organisation of employment, social support and care across European societies. In an influential contribution, Esping-Andersen (1990), focused on the balance between state, market and family, and highlighted how different policy configurations influence the extent to which individuals can maintain a livelihood without the market ('decommodification'). In his typology, the social democratic (Scandinavian) regime is characterised by universal benefits, a weakening of the market influence and a strong commitment to full employment. In conservative-corporatist regimes of continental Europe, benefits are earnings-linked and differentiated by class and status. In liberal welfare states, typified by the United States but also including the UK, the market dominates and there is a heavy reliance on residual means-tested benefits and high social class inequality. Ireland is usually classified as a liberal regime according to this typology.

While in principle this work considered state, market and family, feminists criticised EspingAndersen's initial typology for downplaying the role of the family. ${ }^{3}$ Feminist welfare state theorists have developed our understanding of the role of the family in providing welfare and care and on the gender dimensions of welfare regimes (Daly, 1996; Lewis, 1992; Orloff, 1993). These authors focus attention on 'defamilialisation', that is the degree to which care policies promote independence from family support. This implies the movement of care work traditionally performed inside the home to the formal sector, either the market or the state.

3 In later work Esping-Andersen further developed his ideas on the family and gender equality, partly in response to this criticism (see for example Esping-Andersen, 2009). 
From a gender equality perspective, some commentators argue that gender equality can best be achieved through full-time employment, thus policies should focus on strengthening/increasing women's employment and a move away from the traditional male breadwinner model (Blau and Kahn, 2013). Yet despite the positive implications of the 'universal breadwinner model' in terms of increased autonomy and choice for women, others argue that such a model limits gender equality to the labour market and neglects the persistence of imbalances in the gender division of unpaid work (Ciccia and Bleijenbergh, 2014). Other authors stress that care is deeply embedded in social relations, and not all caring can or should be reduced to a 'commodity' on the market (Lynch and Lyons, 2008; Murphy, 2011).

Fraser (1994) has argued we need time to care, and the policy goal should enable both men and women to care. Fraser (1994) identified four different models of social citizenship: the male breadwinner model, where men do paid work and women care; the 'universal breadwinner', with high employment of both men and women; the 'care parity' model where caregiving grants access to social rights and some income, but care is still feminised and undervalued compared to paid work; and the 'universal caregiver' model where both women and men can combine care and paid work. The universal caregiver (Fraser, 1994) or dual earner/dual caregiver model (Gornick and Meyers, 2009) represents an alternative vision of a gender egalitarian society which values paid and unpaid work equally, and supports the redistribution of unpaid labour between a wide range of actors (men, women, families, the state and the market). This requires a fundamental reorganising of paid work, to allow time for men and women to care. This model might not yet exist, although Scandinavian countries are generally considered to provide the most fully developed examples (Gornick and Meyers, 2009).

Saraceno and Keck (2011) point out that many of these models concentrate on the care of (small) children, ignoring the fact that care needs do not stop at early childhood. It is thus important to focus on policy provision for adults. They offer a detailed analysis of policies in 24 European countries, of which Ireland is one, and seek to identify the policy rationales in countries. Dimensions they identify as being particularly relevant from a gender equality perspective are: 
1. The degree to which policies allow women with family responsibilities to remain in the labour market and thus be financially independent;

2. The degree to which policies acknowledge caring for dependent family members (children or dependent adults) as an activity giving an entitlement to financial support;

3. The degree to which policies support men's uptake of care responsibilities.

They also consider the implications of fiscal policies, income transfers and the combination of policies. The Nordic countries offer the most consistent policy configuration for promoting gender equality, by supporting families to care for children through generous leave schemes, with father quotas, and well-developed services for care of both young children and older adults. A second approach is typified by countries such as Germany and Austria, where mothers are encouraged to stay in the labour market through long paid parental leave, but childcare provision is much weaker. Care services for adults are reduced, but care allowances are paid to recipients to purchase care. This approach acknowledges the value of caring, but has some negative implications for women's labour market participation. A third approach gives a large amount of scope for what the authors term 'familialism by default'. In these countries policy supports, either services or leave allowances, are weak, and policy offers no incentives for a gender rebalancing of childcare. Greece, Italy and Poland display this pattern most clearly. This is the least promising from a gender equality perspective (Saraceno and Keck, 2011). A final group of countries are classified as 'internally divergent' between supporting a dual earner model and a modified male breadwinner/female carer model, and Ireland is one of these, though perhaps leaning more towards the modified male breadwinner model.

Leave provision for caring for children in Ireland is relatively low, though leave for care of dependent adults is more generous, at least in comparative terms. Compared to other countries, childcare service provision was very low indeed (though changing, see below) and provision is quite low for adult care. Rebalancing of parental leave is also low, and fiscal policy (for example through taxation) tends to support male breadwinner households. This analysis highlights just how complex policy configurations can be, that they can be 
contradictory in how they operate, and also that no country conforms exactly to a typology/ideal type. It is perhaps thus more illuminating to focus on policy principles.

In her analysis, Murphy (2011) argues that historically Ireland adopted a relatively strong male breadwinner model. Indeed the male breadwinner/female carer ideology is codified in Article 41.2 of the Constitution. Although changing, Murphy (2011) argues that present Irish policy still reflects the male breadwinner position through the tax system, certain welfare benefits and low support for childcare in comparative context. Policy supports for caring in Ireland, or lack of them, are the subject of Section 1.3.

\subsection{POLICY CONTEXT IN IRELAND}

How does the Irish State support its citizens in caring and in combining care work and employment? In Section 1.3.1 we examine policies in the area of childcare and in Section 1.3.2 we examine supports for those providing adult care. The focus is on leave schemes, including any possibility for or requirement for parents to share leave; care services; cash transfers paid for caring; and tax credits. Formal caring supports differ as to whether the care they support is in a home-based setting or in a community-based centre/residential setting, or a mixture of both. This is particularly relevant for supports for care of adults.

\subsubsection{Support for caring for children}

Government support for the care of children in Ireland has been guided by a number of competing objectives; supporting child development, female employment (and gender equality), social inclusion/poverty reduction, and high birth rates (McGinnity et al., 2013). Significantly, until recent years, the Government tried to steer a course that was neutral in terms of providing support for care in the home (by parents) and care outside the home, and resisted direct investment in universal childcare services. ${ }^{4}$

\section{Family leave schemes}

Family leave is linked to the birth of a child and takes the form of maternity leave, paternity leave and parental leave. The duration of maternity leave - 26 weeks paid leave and 16

$4 \quad$ A key element of this principle was that raising the universal child benefit was designated as an important element of the 'childcare strategy', though this benefit is paid to all parents, irrespective of childcare use. 
weeks unpaid leave - now compares reasonably well to other European countries, though the relatively low maximum threshold means that the replacement rate for maternity benefit in Ireland falls well below the level found in a number of comparable EU countries (Blum et al., 2018). Parental leave for both parents has been extended to 18 weeks per child but is unpaid; fathers' entitlement to paid leave is confined to two weeks of paternity leave. $^{5}$

Across Europe there has been a trend towards a blurring of the differences between maternity, paternity and parental leaves, and when the amount and value of paid leave across these different schemes are combined, Ireland falls in the lowest of three groups of 43 countries, and well below the highest performing countries (Blum et al., 2018). The comparative evidence suggests that where fathers take parental leave this can lead to greater sharing of care for children by gender, and that take-up for fathers is strongly related to payment (Blum et al., 2018). Take-up of unpaid parental leave is very low among fathers in Ireland. ${ }^{6}$ There is currently no statutory entitlement to work part-time for parents (or other carers) in Ireland, though such a scheme exists in a number of EU countries. ${ }^{7}$

\section{Childcare provision}

The second pillar of support for combining work and care is childcare. Historically there has been a very low level of State investment in childcare in Ireland and the system combines market provision with community provision supported by the government but no direct State provision. A number of investments have improved childcare provision somewhat over the last decade, including the introduction of the Early Childhood Care and Education Scheme $(E C C E)^{8}$ and the new affordable childcare scheme ${ }^{9}$ which represent a clear shift in

5 In a family crisis, due to illness or injury of a close family member, an employee in Ireland can take a maximum of three days 'force majeure leave' per year. Force majeure is paid and protects workers from unfair dismissal. A close family member is defined as someone in the immediate family of the worker, or a person in a domestic dependency with the worker.

6 By nine months, around 12 per cent of fathers who responded in the Growing Up in Ireland study had taken parental leave, and the majority (74 per cent) of those who did take leave took two weeks or less (McGinnity et al., 2013).

7 Since 2013 there is a right to request a change in working patterns or hours for a set period on return from parental leave, though it can be turned down.

8 The ECCE, funded by the Department of Children and Youth Affairs, provides two years of childcare and early education for children aged three or older. 
policy intent and focus (Russell et al., 2018). Nevertheless, families still face a high burden of costs. International comparisons show that the cost for formal childcare for pre-school children in Ireland was second highest for lone parents and third highest for couple households in OECD countries (OECD, 2017). A recent ESRI study found that parents were paying an average of 12 per cent of disposable household income for childcare costs of one three-year-old child (Russell et al., 2018). The study also clearly demonstrated that the amount that families pay for childcare influences maternal employment, and that higher costs are associated with a subsequent reduction in mothers' paid working hours. Against this backdrop of low State support, recent research has suggested that there is a high level of unmet need in Ireland for formal childcare supports, particularly among disadvantaged families (Grotti et al., 2019).

\section{Taxation and welfare system}

There are a number of elements within the current tax and welfare systems which support full-time care or domestic roles. A partial move towards tax individualisation in the early 2000s addressed the high marginal tax rates faced by secondary earners within couples, who are predominantly women (Doorley, 2018). Partial individualisation of income taxes lead to a greater share of net income for working women. This incentivised and increased women's employment and working hours. The change also decreased their childcare hours, without yielding a corresponding rise in male childcare hours (Doorley, 2018, p.17).

Despite the change, the taxation system remains only partially individualised and it is still possible to share part of the tax allowance ${ }^{10}$ between couples when one partner does not participate in paid employment (Doorley, 2018, p.6). The tax allowance is linked to marriage/partnership rather than to participation in care but is a de facto support for this role within couples.

$9 \quad$ The Affordable Childcare Scheme will provide financial support (through both universal and targeted subsidies) to parents who use formal childcare services. The scheme is due to be open for applications in October 2019.

10 Non-employed partners (who are typically women) are able to transfer 32 per cent of their standard rate band to a working partner. 


\section{Lone parents allowance}

Ireland's One-Parent Family Payment (OFP) scheme underwent significant reform between 2012 and 2015, mostly in terms of eligibility. Previously, parents were entitled to the payments until the child was 18 (or 22 if they remained in education), but by 2015 parents were only entitled to payment until their child was aged seven (Regan et al., 2018, p.1). The reforms aimed to 'reduce long-term social welfare dependency, and associated poverty, by ending the expectation that lone parents will remain outside of the workforce indefinitely' (Indecon, 2017). However, recent research by the ESRI found that the policy changes negatively affected the incomes of lone parents and had a stronger effect on employed lone parents: this group saw a 2 per cent decline in income, which could be directly attributed to the OFP reforms (Regan et al., 2018).

\section{Single Person Child Carer Credit}

This tax credit came into effect in 2014. It aims to support single parents who are primary caregivers, and who are in employment. Single parents may claim the credit even if they receive support from the other parent, who is not present in the home. It is valued at $€ 1,650$ per year at the time of writing.

\subsubsection{State supports for those caring for older adults or those with disabilities}

Ageing demographics are increasing the demand for caring in Ireland, both formal and informal. Since 2001, Ireland's Primary Care Strategy has emphasised a shift away from hospital care towards community care (Department of Health, 2014). This change, while broadly consistent with the wishes of those receiving care, relies on significant informal care provided by family and community (Hanly and Sheerin, 2017).

By 2007 estimates, 9 per cent of those aged over 65 and living at home rely on formal care, while 23 per cent rely on informal care (Gannon and Davin, 2010). ${ }^{11}$ Formal care is defined as professional home visits to those receiving care, paid for by 'national insurance systems or directly by individuals', while informal care is care provided by family or friends (Gannon and Davin 2010, p.501). The same figures for France show 23 per cent receive formal care

11 The figures exclude those in full-time residential care. The remaining 68 per cent of over 65 -year-olds are not in receipt of care. 
and 17 per cent receive informal care, revealing the extent of Ireland's reliance on informal care. The provision of formal residential or long-term care also shapes the demand for informal care. Wren et al. (2017) note that 4.5 per cent of the population aged over 65 are in long-term or intermediate residential care. The authors also note that older men are more likely to be cared for at home than older women, which suggests that a greater demand for informal care falls to female partners.

Providing such informal care has potential consequences for labour market participation (Heger, 2014; Bolin et al., 2008). King and Pickard (2013) find that female carers aged 50 and over have a greater chance of moving out of employment than women without informal care obligations. Research also suggests that providing ten hours of care per week increases a carer's likelihood of leaving work, whereas previous authors have put this effect at 20 hours per week (Carmichael et al., 2010). Some of the negative effects of caregiving on employment were found to differ depending on whether the carer and the person receiving care lived together (Michaud et al., 2010). The relationship can also work the other way around; that is that changes in work demands lead to a decrease in the probability of providing informal care, especially among women aged 40-64 (He and McHenry, 2016). This is especially true when informal care is particularly time-intensive.

Current policy approaches to support informal carers in Ireland primarily consist of direct income supports, though carer's leave is an option for full-time carers on a temporary basis. The Carer's Leave Act 2001 provides a minimum of 13 weeks leave (but no more than 104 weeks); it is open to employees who wish to leave work temporarily to provide full-time care. ${ }^{12}$ Carer's leave is unpaid, but allows participants to apply for income support in the form of Carer's Benefit or Carer's Allowance. ${ }^{13}$ The former is open to workers with enough PRSI contributions, the latter is a means-tested payment.

Carer's Benefit is paid to carers relative to the number of people they care for. Carers are also entitled to standard child dependant allowances, in common with other welfare

12 Carers can attend an educational or training course or take up voluntary work for a maximum of 15 hours a week. See: www.citizensinformation.ie/en/employment/employment_rights_and_conditions/leave_and_holidays/c arers_leave_from_employment.html 
payments (Hoyer and Reich, 2017). Those who do not qualify for Carer's Benefit can apply for a Carer's Allowance, subject to a means test.

Based on the study of Hoyer and Reich (2017), the welfare payments for adult care in Ireland appear on a par with other countries regarding generosity and duration. The maximum duration of carer's leave is similar to Belgium and France, and longer than a comparative leave in Denmark (six months). The maximum payments for carers in Ireland are also relatively generous compared to countries like Estonia and France (unpaid), but not as generous as most Scandinavian countries though the study does not calculate comparative replacement rates. However, on other measures, the Irish model is similar to other liberal welfare states. It has a strong reliance on informal care with fewer options for formal care. ${ }^{14}$ State support for those who wish to receive care in their own home is limited. For example, the HSE offers home-care packages that include home-help hours, nursing services, and therapeutic services (Hanly and Sheerin, 2017). Wren et al. (2017) highlight that there is a significant level of unmet demand for home-care packages and predict that an increase in demand of 66 per cent up to 2030. This unmet need means additional informal care is needed to close the gap.

This configuration offers little support for those wishing to combine adult care and part-time work, and so pushes workers to full-time care (King and Pickard, 2013), which disproportionally affects women (Sarasa, 2007).

TABLE 1.1 NUMBER OF CLAIMANTS OF CARER'S ALLOWANCE AND CARER'S BENEFIT

\begin{tabular}{|l|r|r|r|r|}
\hline & $\mathbf{2 0 0 8}$ & $\mathbf{2 0 1 1}$ & \multicolumn{1}{|c|}{$\mathbf{2 0 1 4}$} & \multicolumn{2}{|c|}{2017} \\
\hline Carer's Allowance (carers) & 43,569 & 51,666 & 59,380 & 75,264 \\
\hline Carer's Benefit (carers) & 2,249 & 1,637 & 1,769 & 2,762 \\
\hline Total & 45,818 & 53,303 & 61,149 & 78,026 \\
\hline Total number of those receiving care & 76,736 & 86,760 & 97,288 & 123,958 \\
\hline
\end{tabular}

Source: Department of Employment Affairs and Social Protection 2016.

14 Bettio and Plantenga (2008), place Ireland at around the mid-point for residential services for older adults across the EU15 countries and in the top six for community care based on the number of full-time personnel per 100 people over 65. The figures appear to date from the mid-1990s. The lowest level of support are recorded the Southern European countries (Spain, Italy, Greece, Portugal). 
Table 1.1 shows that the total number of those in receipt of carers' welfare payments increased steadily each year as did the numbers in receipt of care. The table also shows that the great majority of claimants (96 per cent in 2017) receive the means-tested Carer's Allowance rather than Carer's Benefit. Department of Employment Affairs and Social Protection (2016: p.48) statistics also show that 76 per cent of those receiving Carer's Allowance were women, while 24 per cent were men.

The figures above reflect wider trends in Ireland's demographics. Ireland's growth in life expectancy and its expansion of health services has improved the lives of many. However while increased longevity is a positive trend, in Ireland as in most countries, it brings with it significant challenges. For men, life expectancy increased from 73 in 1995-1997 to 78 in 2010-2012. For women, life expectancy increased from 78 to 83 in the same periods (Central Statistics Office). Demographic change, a rising dependency ratio, and a fall in formal services all contribute to a rise in the need for informal care (Family Carers Ireland, 2017).

\section{Carers tax allowance}

Those providing care are also entitled to income supports via specific tax credits. The Home Carer's Tax Credit is a given to married couples or civil partners where one spouse cares for a dependent person. Here, the home carer's income must be below $€ 7,200$. A reduced credit applies to carers whose income is between $€ 7,200$ and $€ 9,600$. A 'dependent person' is defined as a child for whom child benefit is payable, a person aged 65 or over, or a person with a disability who requires care.

For 2018 , the full tax credit was $€ 1,200$ while the reduced tax credit was calculated as half the difference above the $€ 7,200$ limit. The tax credit does not apply if the carer's income is in excess of $€ 9,600$. As a result, carers may have an incentive to limit their working hours in order to qualify for additional tax credits.

\subsection{LABOUR MARKET CONTEXT: PAID EMPLOYMENT}

Participation in caring and domestic work is influenced by both short- and long-term changes in paid employment. The long-term trend of increasing female labour market 
participation is likely to have significant implications for the levels and distribution of unpaid work, as noted above.

FIGURE 1.1 EMPLOYMENT RATES MEN AND WOMEN IN IRELAND 1993-2017, AGES 15-64 YEARS

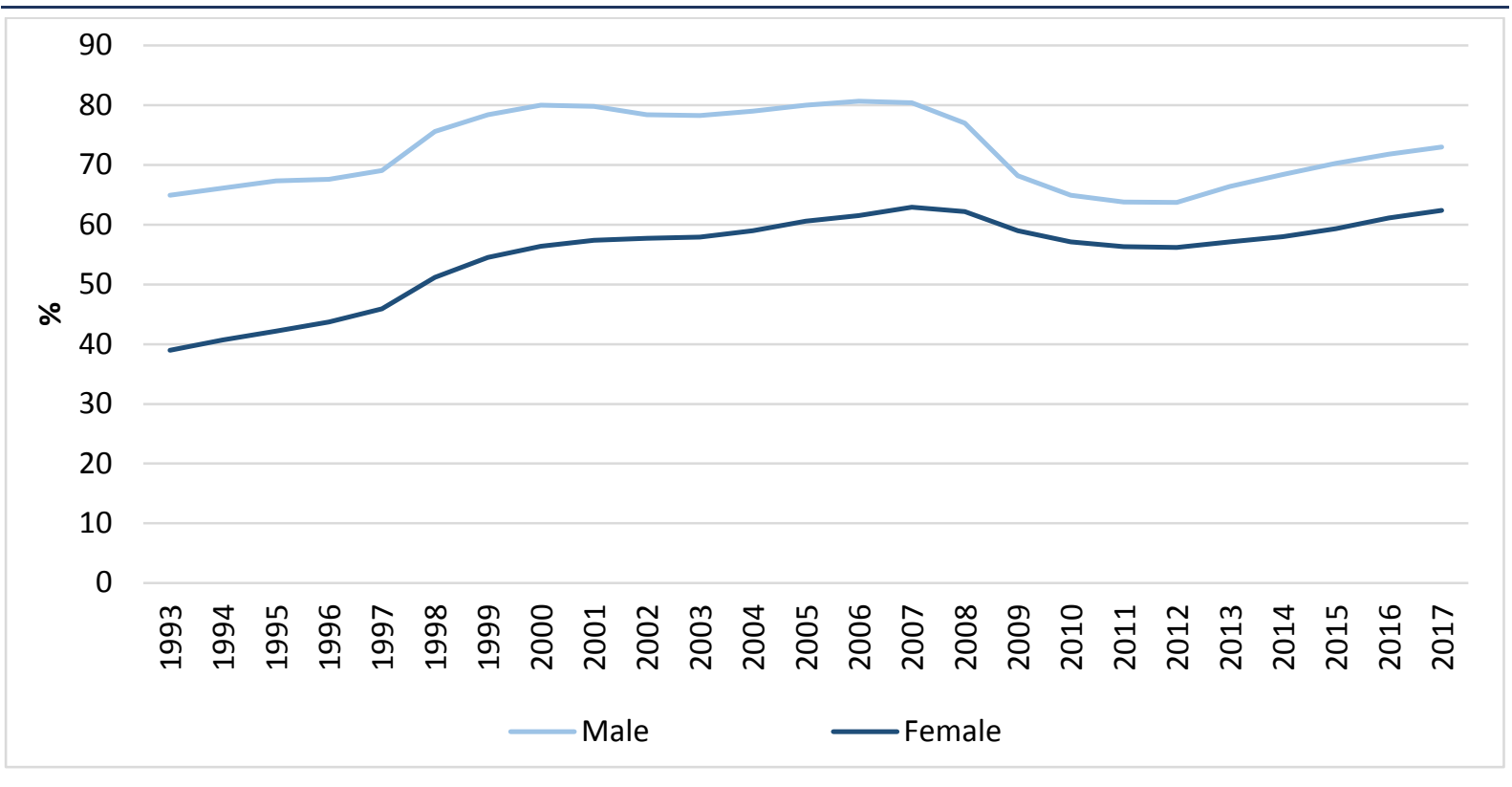

Source: QHNS. Proportion of total resident population aged 15-64 that are in employment.

In Ireland women's employment increased rapidly in last part of the twentieth century and the early 2000s, rising from 39 per cent in 1993 to 63 per cent in 2007 (see Figure 1.1). By 2007 female participation in the labour market in Ireland had also converged with the EU average (Russell et al., 2009b). Labour market participation increased even among those with very significant care demands. The participation rate among mothers of children aged under five rose from 54 per cent in 1998 to 60 per cent in 2007 (Russell et al., 2009b). The latest figures show that 61 per cent of women with children under the age of 14 were in employment in Ireland in 2014 (OECD, Family statistics database).

\section{Cyclical changes: boom and bust}

The study spans a period of immense labour market change in Ireland, 2003 to 2016. In the first part of the period employment grew rapidly, especially in the construction sector. The financial crisis hit in late 2008 and the labour market impacts in Ireland were also rapid and severe. Employment levels fell sharply and the unemployment rate grew from 4.6 per cent in 2006 to a peak of 15 per cent in 2012. The unemployment crisis in Ireland was particularly concentrated among men, meaning that the gender gap in paid employment was at its 
narrowest in this period (Kelly et al., 2016). Household incomes also fell sharply in the recession. Average disposable household income fell by 14 per cent from peak (2007) to trough (2012) (Savage et al., 2015), while levels of deprivation, economic stress and levels of indebtedness rose rapidly (Maître et al., 2014).

The bust and boom of the Irish labour market has implications for the levels and distribution of unpaid work. From a time availability perspective we would expect high levels of paid employment to crowd out other forms of labour such as caring and housework, while low levels of paid employment would allow greater scope for involvement in these activities. The economic crisis is also likely to have influenced the financial incentives attached to paying for such services or providing them within the household (or between households). We would expect housework to be more responsive to changes in general demand for paid work, since the opportunity to undertake housework is available to all, whereas the need to provide care for children or older/disabled adults does not affect all households.

However as the discussion of the role of gender in the allocation of unpaid work highlighted, the allocation of caring and housework tasks is not simply a matter of economic rationality, and is strongly influenced by social norms about who should undertake these roles. Studies from the recessions in the 1980s found that unemployed men were reluctant to take on domestic work, as this threatened their sense of masculinity, which was already damaged by the loss of the provider role (Morris, 1995). It therefore remains to be seen whether the economic crisis in Ireland was associated with a shift in both the level of caring and domestic work and the gender gap therein. We examine this question in Chapter 4.

\subsection{PREVIOUS EVIDENCE ON UNPAID WORK IN IRELAND}

While time-use diaries are common phenomena in many countries, only one nationally representative time-use survey of adults has been carried out in Ireland. This was carried out by the ESRI in 2005 with support from the Department of Justice and Equality (previously known as the Department of Justice, Equality and Law Reform) (see McGinnity et al., 2005 for details). The survey showed that the quantity of unpaid work was very substantial indeed and that its distribution was strongly gendered. The study found that one-third of the population participated in caring activities on weekdays and weekends; 
48 per cent of women and 23 per cent of men (McGinnity and Russell, 2008). Participation in housework was much more widespread with 70 per cent of respondents participating on weekdays and 74 per cent on weekend days. Again there were strong gender differences: 89 per cent of women participated in housework on weekdays compared to 51 per cent of men. On weekend days the proportion of men participating in housework increased to 62 per cent while women's participation level stayed the same as on weekdays.

Due to the higher levels of participation the average time spent on housework was higher than that for care. On weekdays individuals spent an average of 1 hour 33 minutes on care and 1 hour 53 minutes on housework. On the weekends the figures were 1 hour 40 minutes for care and 2 hours 5 minutes for housework. If we estimate a weekly figure from these results, ${ }^{15}$ the average weekly care time was 11.1 hours on care and 13.6 hours on housework. This is for the whole population, those participating in care and housework and those not participating.

In addition to gender the strongest predictors of unpaid work time were age of youngest child, marital status, and time in paid employment. Those in the 25-44 age group had the highest unpaid workload holding other factors constant. The study also found that women's unpaid work time was more responsive to the presence of children and their paid work time than men's (a finding that is replicated in international research; Bianchi et al., 2000). Moreover a partner added more to women's workload than men's. Education did not have an independent effect when employment time was controlled (McGinnity and Russell, 2008).

Additional but less detailed information on caring is available in the Quarterly National Household Survey and the Census, both collected by the CSO. The decline in the full-time domestic role among women in Ireland has been dramatic. In early 1998, 40 per cent of women in Ireland described their principal economic status as 'home duties'; by 2017 this had fallen to 22 per cent of women. In absolute numbers, this reflected a fall from 584,900 women to 417,300 women (see Figure 1.2).

15 We calculate a weekly figure by multiplying the weekday figure by 5 and the weekend figure by 2 . This is a necessary simplification which assumes that the allocation of time remains the same across weekdays and across weekends. 
FIGURE 1.2 PROPORTION OF WOMEN IN HOME DUTIES 1998-2017 (15 YEARS AND OVER)

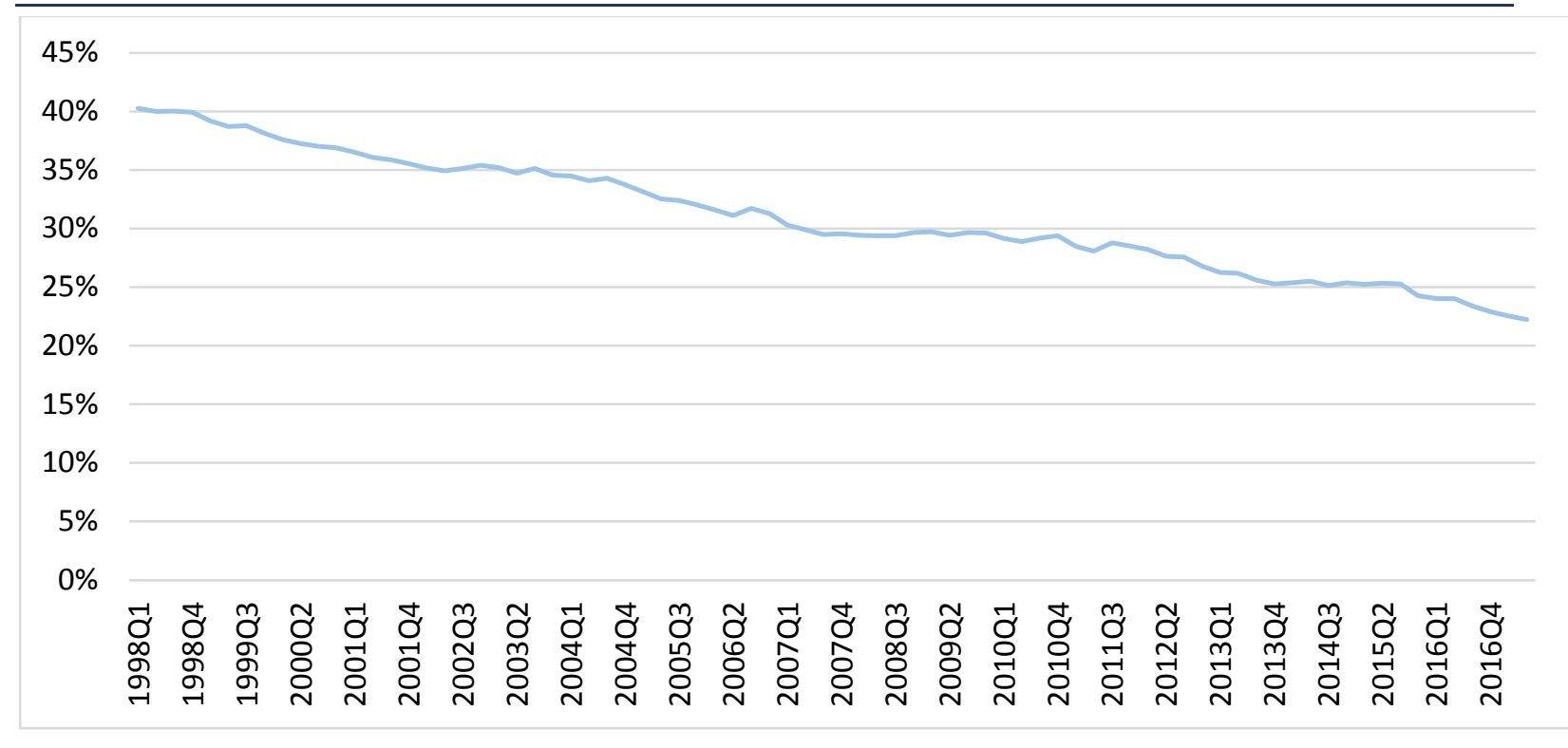

Source: QNHS data, CSO website, based on self-reported principal economic status.

Questions on adult care have been included in the Census since 2006. The latest figures for 2016 show that 4.2 per cent of men and 6.2 per cent of women aged 15 and over provide 'regular unpaid personal help for a friend or family member with a long-term illness, health problem or disability'. The time commitments recorded among this group of carers are shown in Figure 1.3. Among female carers 47 per cent report spending between one and 14 hours of care, while 26 per cent report spending 43 hours or more per week (more than the average for a full-time job). Similar proportions are recorded by male carers; 52 per cent spend one to 14 hours and 21 per cent record 43 hours or more. 


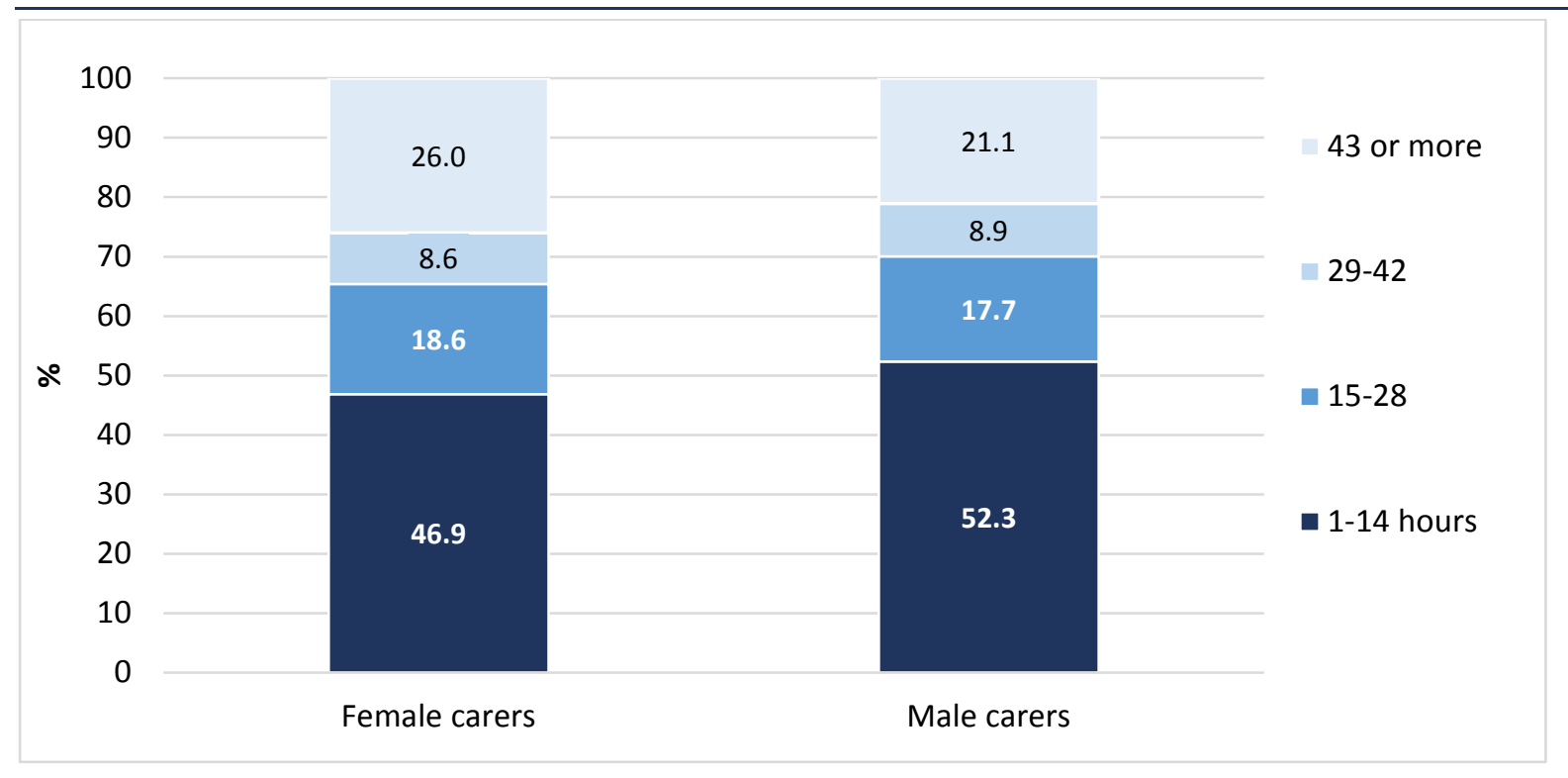

Source: Census 2016 published figures. Note the figures include carers of all ages including a small proportion of children aged under 15 $(3,800$ out of 195,200 carers $)$.

\subsection{OUTLINE OF REPORT}

This report is structured in the following way. In Chapter 2 we describe the data and methodology used in the study, including the questions used to measure unpaid work. In Chapter 3, we present detailed descriptions of participation in care and housework, and the weekly time spent on these activities. Chapter 3 also includes descriptions of trends over time and compares the Irish results to those found in the other EU28 countries.

In Chapter 4, we estimate models of unpaid work, which allow us to examine a wider array of influences, including age of children, presence of partner, and paid employment participation. The models also provide an insight into the factors behind the gender and time period effects noted in the descriptive results. We consider how the findings for Ireland reflect the policy configuration in place, labour market development and changes in the attitudinal climate. Chapter 5 presents a summary of the findings and a reflection on some policy implications. 



\section{CHAPTER 2}

\section{Methods and measurement}

\section{$2.1 \quad$ INTRODUCTION}

In this chapter we first outline the central concepts and measures and discuss the challenges to accurately measuring the extent of unpaid labour. Secondly we describe the data used for the analysis in subsequent chapters

\subsection{DEFINING AND MEASURING UNPAID LABOUR}

Unpaid labour is not routinely measured or made visible; as a result, it is often undervalued. National and international statistics agencies regularly produce labour market statistics measuring paid labour, including hours of paid work. While these include counts of those who are 'economically inactive' and record their principal status and reasons for not engaging in paid work, little information is collected on the nature of their activities or the productive value of these activities. Oakley (1974) was amongst the first to point out that caring and housework is rendered less visible and measurable for three reasons. First, it is carried out in the private sphere; second, it is unpaid; and third, it does not have discrete boundaries which mark a beginning and end time. A further challenge is distinguishing between activities that are unpaid work, leisure or relational activity (Lynch and Lyons, 2008).

In order to define unpaid work it is useful to examine first what counts as 'work' or economic activity generally. Economic acts can be defined as those which are carried out for pay, or which one can envisage being carried out for pay even if they are not so at present, or an activity that produces a tradeable output (Fahey, 1992). By this definition housework and childcare are economically productive since their output can be (and often is) bought and sold (in the form of domestic and childcare services, for example). Non-economic acts do not produce tradeable outcomes, for example eating, sleeping, self-care and leisure have to be consumed by the producer in order to be of utility. Elsewhere it has been argued that if paying someone else to do the activity for you would not diminish its value then the task 
should be considered as work, which is sometimes termed the 'third person criterion' (Gershuny, 2018). However, this 'test' does not resolve the dilemma entirely. For example, the emotional element of caring and the strong norms surrounding it mean that it may not be substituted by paid care without some loss in value. However, while measurement difficulties remain, estimates using these definitions still go a long way to quantifying caring and housework. Much emotional or 'love labour', in Lynch's (1989) sense, count as noneconomic acts.

Folbre (2006) notes that care work can also be conceptualised in terms of who benefits and argues that 'work directed toward meeting the needs of children, the elderly, and the sick and disabled is particularly important, because these "consumers" often lack political voice' (p186). However Folbre (2006) also notes that care time, broadly defined, includes providing for the needs of healthy adults, such as cooking meals.

A substantial part of the literature on unpaid work is based on time-use data (Hook 2006; Sayer 2005). This method requires respondents (and sometimes the spouse/partner) to fill out a time-use diary, which accounts for his/her time for a 24-hour period, usually broken into a series of short time intervals e.g. 15 minutes. The diary can consist of long-hand open entries (as in a traditional diary) or in the case of the short-form time diary, respondents are required to record activities from a pre-coded choice over a 24-hour period. Time-use diaries produce reliable and valid estimates of unpaid work time (Robinson and Godbey, 2010). In addition, time-use diaries facilitate a detailed assessment of time spent on particular tasks, such as childcare, adult care, cooking, cleaning, etc., and also when these tasks occurred. Time-use diaries are seen as the gold standard for measuring unpaid labour, and are carried out on a regular basis in most European and developed countries (see Fisher et al., 2012 for an introduction to the Multinational Time Use Study). However, they are not without limitations. Activities performed simultaneously are difficult to record and analyse. At a practical level, time-use data involve a 'high response burden' in that respondents must spend a significant time completing the diary and there is need for respondent 'training' so that they understand how to complete the diary correctly. Time-use diaries are relatively expensive to administer because they require a stand-alone survey and interviewer involvement (though short-diaries can be added to existing longitudinal surveys as was done in the GUI survey for nine-year-olds). Only one national time-use survey has been carried 
out in Ireland, by the ESRI funded by the Department of Justice and Equality (McGinnity et al., 2005). These results are discussed in Chapter 1.

Due to the absence of any recent time-use data for Ireland, the current analysis is based on self-estimates of time spent on care and housework collected as part of the European Quality of Life Survey (EQLS). Individuals are asked direct questions about how much time they spend either daily or weekly on housework and caring. The survey specifically asks how often respondents are involved in the caring of children, and separately in the caring of older adults and those with a disability. Such data are collected in a range of international surveys as in, for example, the European Community Household Panel survey and the European Social Survey.

These questions have three key advantages: they are collected regularly; they are asked in a uniform and harmonised way across countries, allowing for cross-national comparison; and they are asked as part of a broad survey on quality of life, which includes a range of other interesting measures. However, these data have two relevant limitations. First, they rely on respondents' recall, which can lead to inaccuracy. Second, self-reported accounts of domestic labour and caring can sometimes reflect aspirations rather than time actually spent leading to response biases (Hochschild, 1990; Shelton and John, 1996; Marini and Shelton, 1993). This tendency of over-estimation should be kept in mind in the interpretation of the results.

\section{$2.3 \quad$ DATA}

The analyses in the report draw on four waves of the EQLS, which is carried out every four to five years by the European Foundation for Living and Working Conditions (Eurofound, 2017). The survey is fielded in all European Member States and in countries that are applying to join the EU. A nationally representative sample of households is selected within each country, and one adult is randomly selected for interview within households. Further, the sample of respondents are weighted so that they are representative of the population in 
terms of gender, age, household size, region, and economic status. ${ }^{16}$ The survey was administered using face-to-face interviews in people's homes using computer-assisted personal interviewing (CAPI). In Ireland the sample size was just over 1,000 in each year except 2003 (see Table 2.1). The response rate in Ireland for the years 2007 to 2016 compared favourably to the overall response rate with EU countries.

TABLE 2.1 SAMPLE SIZE AND RESPONSE RATES EUROPEAN QUALITY OF LIFE SURVEY

\begin{tabular}{|l|c|c|c|r|}
\hline & $\mathbf{2 0 0 3}$ & $\mathbf{2 0 0 7}$ & $\mathbf{2 0 1 1 / 2 0 1 2}$ & $\mathbf{2 0 1 6}$ \\
\hline Ireland Sample N & 990 & 1,000 & 1,051 & 1,011 \\
\hline Ireland Response Rate & $32.5 \%$ & $72.2 \%{ }^{1}$ & $-{ }^{2}$ & $48 \%$ \\
\hline EU Sample N & 23,224 & 32,634 & 43,636 & 30,809 \\
\hline EU response rate & $58.4 \%$ & $57.9 \%$ & $38.4 \%$ & $34 \%$ \\
\hline
\end{tabular}

Source: Technical and overview reports.

Notes: $\quad$ 1. In 2007 the technical report records two different response rates, which differ according to how the non-contacts are treated (the alternative estimate puts the response rate in Ireland at 81.7 per cent).

2. The technical report for the third EQLS, in 2011/2012, does not report response rates for individual countries.

3. In 2003, EU=EU25 (including the ten countries which joined in 2004); in 2011 EU=EU27; in 2016 EU=EU28; in 2007 the EU figure is an average of 26 countries (EU27 without Sweden, own calculation).

The 2003 questionnaire collected information on three forms of unpaid/domestic work: caring for children; caring for elderly or disabled relatives; and housework. An initial question, asking how frequently the activity was undertaken, was followed by a question asking how many hours per week were spent on the activity. The response categories for the initial question on frequency of participation are outlined in Table 2.2. The follow-up question on hours was only asked to those who answered that they undertook the activity every day. In the subsequent waves, the question of hours was asked to all those who answered that they participated in the activity at least once a week. Due to this change the analysis of time on activities is confined to 2007, 2011 and 2016 waves.

There were a number of other wording changes to the survey in subsequent waves. In 2007, cooking was explicitly added to the question on housework. In 2011, the question on care of children was extended to include care of grandchildren. In 2016, the questions on caring were split out into more detailed categories (see Table 2.2). For the analysis we collapse these categories back down so that they are comparable with the earlier years, and add the

16 EQLS weights consider the above measures. However, weights for Round 3 (2012) do not consider economic status. More information is available in the European Quality of Life Survey 2016: Technical and field-work report (Eurofound, 2017, p. 60). 
time together for the sub-categories. Nevertheless, the inclusion of explicit questions for separate forms of care may prompt respondents to recall more care than in the previous waves of the survey or record the amount of time more accurately. We see in Chapter 3 that there is a small increase in adult care between 2011 and 2016 which may be a consequence of the change in question wording (Figure 3.6).

\section{TABLE 2.2 TYPES OF UNPAID/DOMESTIC LABOUR MEASURED IN THE EQLS}

\begin{tabular}{|c|c|c|}
\hline & Frequency & Hours \\
\hline $\begin{array}{l}\text { 2003: } \\
\text { How often are you involved in any of the following } \\
\text { activities outside of paid work? } \\
\text { - Caring for and educating children } \\
\text { - Caring for elderly/disabled relatives } \\
\text { - Housework }\end{array}$ & $\begin{array}{l}\text { Every day } \\
\text { Three or four times week } \\
\text { Once or twice a week } \\
\text { Once or twice a month } \\
\text { Less often } \\
\text { Never }\end{array}$ & $\begin{array}{l}\text { How many hours a day? } \\
\text { No. of hours } \\
\text { Collected only for every } \\
\text { day frequency }\end{array}$ \\
\hline
\end{tabular}

\section{7:}

How often are you involved in any of the following activities outside of paid work?

- Caring for and educating children

- Caring for elderly/disabled relatives

- Cooking and housework

\section{1:}

In general, how often are you involved in any of the following activities outside of paid work?

- Caring for your children, grandchildren

- Caring for elderly or disabled relatives

- Cooking and/or housework

2016:

In general, how often are you involved in any of the

following activities outside of paid work?

- caring for and/or educating your children

- caring for and/or educating your grandchildren

- caring for disabled or infirm family members, neighbours or friends under 75

- caring for disabled or infirm family members, neighbours or friends 75 or over

- cooking and/or housework
Every day

Several times a week

Once or twice a week

Less often than once a week

Never

Every day

Several days a week

Once or twice a week

Less often

Never

How many hours per

week?

No. of hours

Collected only for those up to once or twice a week

How many hours per week?

No. of hours

Collected only for those up to once or twice a week

\section{Every day}

Several days a week

Once or twice a week

Less often

Never
How many hours per

week?

No. of hours.

Collected only for those up to once or twice a week

Source: EQLS questionnaires, 2003, 2007, 2011, 2016.

In 2011, the questionnaire documents note that where respondents gave high estimates of the time (relative to the frequency of involvement category) they were prompted to reconsider the estimate by the interviewer. In the case of those involved in the activity every day, the cut-off for this prompt was over 50 hours. It is not recorded whether this 
check was carried out in other years. We can reasonably assume it was also applied in 2016. This interviewer check should help to reduce over-estimation of hours. As an additional check, we limit the time to 168 hours (24/7) in cases of single activities and total unpaid work (caring plus housework).

\subsection{CONTROLS}

How can we explain individual differences in time spent caring for others? We focus on five sources of variance in caring. First we consider personal characteristics; gender and age. The theories outlined in Chapter 1 place gender central stage in explaining variation in domestic and care work. Age too has been invoked as a potential explanatory variable. Age may operate as a proxy for life stage effects (though where possible these are considered separately), or age may capture cohort change.

Second is the demand for care and housework in the home. This is conditional upon life stage and the composition of the household, and so we consider the number of children in the home, and whether the respondent has a partner.

Third, participation in paid employment is crucial from a variety of theoretical perspectives (see Section 1.2.1). Paid work is hypothesised to influence the time available for unpaid work, and the allocation of responsibility for care and housework within the household, either through processes of specialisation or through economic bargaining (via earning power). Theories on gender roles suggest that the influence of paid work will not be gender neutral, and are likely to have a greater influence on women's care/housework levels than men. For those who have a partner we also consider the partner's employment status.

Fourth, we test whether education plays a significant role in the unpaid work of respondents. On one hand, educational levels indicate earnings capacity, which is not directly measured in the data. On the other, theories concerning attitudes towards gender roles suggest that men and women with higher education hold more egalitarian opinions or views (see Chapter 1 for a more detailed discussion of theoretical models). As a result, they will likely display different caring commitments than couples with average education. 
Finally, we consider whether there are significant changes over time. Gershuny et al. (2005) and others predict that there will be a general change over time whereby men will increasingly undertake a greater share of unpaid work in a 'lagged adaptation' to women's increasing involvement in paid employment, and in response to policy changes that facilitate greater participation of fathers in childcare in particular (e.g. parental leave and paternity leave). ${ }^{17}$ Paid employment levels and income fluctuated sharply in this period, which encompasses boom and recession in Ireland; this may also have implications for the level and distribution of unpaid work.

The variables used to measure these factors are outlined in Table 2.3 as well as their distribution in the data.

Table 2.3 describes all of the control measures used in the report. The report draws on somewhat different samples in Chapter 3 and Chapter 4 so the distribution of the variables is shown separately for both sets of analyses. Chapter 3 draws on four waves of the EQLS; 2003, 2007, 2011 and 2016. The Chapter 4 analysis drops 2003, it also drops cases that are missing values on any of the variables used in the models.

The distribution of the three dependent variables used in this report - childcare, adult care and adult care with housework - is outlined in next chapter.

17 The timeframe in mind for this process is longer than the 11-year observation period that we can analyse, nevertheless we might expect to see an underlying upward trend according to this theory. 
TABLE 2.3 SUMMARY AND DISTRIBUTION OF CONTROL MEASURES

\begin{tabular}{|c|c|c|c|c|}
\hline Measure & $\begin{array}{c}\text { Chapter } 3 \\
\text { (unweighted) } \\
\text { Frequency }\end{array}$ & $\begin{array}{c}\text { Chapter } 3 \\
\text { (weighted) } \\
\% \\
\end{array}$ & $\begin{array}{c}\text { Chapter } 4^{1} \\
\text { (unweighted) } \\
\text { Frequency }\end{array}$ & $\begin{array}{c}\text { Chapter } 4 \\
\text { (weighted) } \\
\%\end{array}$ \\
\hline \multicolumn{5}{|l|}{ Year } \\
\hline 2003 & 990 & 24.4 & - & - \\
\hline 2007 & 1,000 & 24.7 & 743 & 28.5 \\
\hline 2011 & 1,051 & 25.9 & 976 & 35.5 \\
\hline 2016 & 1,011 & 25.0 & 982 & 36.0 \\
\hline \multicolumn{5}{|l|}{ Sex of respondent } \\
\hline Male & 1,779 & 49.1 & 1,187 & 49.5 \\
\hline Female & 2,273 & 50.9 & 1,514 & 50.5 \\
\hline \multicolumn{5}{|l|}{ Age classes } \\
\hline 18-34 years old & 1,148 & 33.7 & 645 & 32.0 \\
\hline $35-49$ years old & 1,206 & 29.3 & 842 & 31.1 \\
\hline $50-64$ years old & 939 & 21.1 & 659 & 21.6 \\
\hline Over 65 & 759 & 15.9 & 555 & 15.3 \\
\hline \multicolumn{5}{|l|}{ Weekly paid work hours } \\
\hline None & 1,441 & 35.0 & 1,180 & 40.0 \\
\hline 1-30 hours & 639 & 15.6 & 431 & 15.3 \\
\hline $31-40$ hours & 1,124 & 29.9 & 696 & 27.6 \\
\hline Over 40 hours & 667 & 19.5 & 394 & 17.2 \\
\hline \multicolumn{5}{|l|}{ Education: } \\
\hline Primary (ISCED 0/2) & & & 732 & 23.4 \\
\hline Secondary (ISCED 3/4) & & & 1,192 & 46.8 \\
\hline Tertiary (ISCED 5/8) & & & 777 & 29.8 \\
\hline \multicolumn{5}{|l|}{ Partner's employment } \\
\hline Single & & & 1,171 & 41.7 \\
\hline Partner not employed & & & 533 & 19.2 \\
\hline Partner employed & & & 997 & 39.1 \\
\hline \multicolumn{5}{|l|}{ Age of youngest child } \\
\hline No child aged 0-18 & & & 1,870 & 68.5 \\
\hline Children aged 0-4 & & & 312 & 12.3 \\
\hline Children aged 5-12 & & & 336 & 12.0 \\
\hline Children aged 13-18 & & & 183 & 7.2 \\
\hline Total & 4,052 & & 2,701 & \\
\hline $\begin{array}{l}\text { European Quality of Lif } \\
{ }^{1} \text { These figures refer to } \\
\text { (time spent on care/ho } \\
\text { in Chapter } 3 .\end{array}$ & $\begin{array}{l}\text { selected for analys } \\
\text { rk) or the explanatc }\end{array}$ & $\begin{array}{l}\text { excludes resp } \\
\text { bles. Education }\end{array}$ & $\begin{array}{l}\text { vith missing values } \\
\text { 's employment an }\end{array}$ & $\begin{array}{l}\text { dependent vari } \\
\text { n's age are not }\end{array}$ \\
\hline
\end{tabular}




\section{CHAPTER 3}

\section{Level of involvement in unpaid activities in Ireland}

\subsection{INTRODUCTION}

This chapter uses EQLS data to answer four questions tied to caring, housework and unpaid work. First, who is doing unpaid work in Ireland? Second, how much unpaid work are they doing? Third, how have levels of unpaid work changed over time? Fourth, we consider how Ireland compares to other EU countries in measures of unpaid work, and more specifically gender differences in unpaid work.

Throughout, we focus on three different forms of unpaid work; childcare, adult care and housework. Our approach in this chapter is primarily descriptive, showing patterns in unpaid work between gender and age groups. We also explore group differences between employed and non-employed respondents, and households with and without children.

We pool four waves of the EQLS together because of the small sample size of respondents involved in adult care (an average of 68 per year for daily involvement). Increasing the number of observations reduces the errors around the estimates, and allows us to explore meaningful differences between groups. Regarding changes over time, we describe patterns in Figures 3.6 and 3.9 but do not formally test these changes until Chapter 4.

In Section 3.8, we compare levels of unpaid work in Ireland to other EU countries in the latest survey wave, 2016. We examine how total unpaid work (caring plus housework) and the gender gap in unpaid work in Ireland compares to elsewhere in the EU. In these analyses we control for some key compositional differences between the countries to make the results more similar. 


\subsection{WHO IS CARING? INVOLVEMENT IN CARING ACTIVITIES}

This section compares a respondent's likelihood of providing any care, regardless of hours. We consider those who provide childcare, adult care, and both care activities together. We later consider the amount of care, in terms of hours, that respondents provide.

Figure 3.1 presents the involvement of men and women in childcare. Taking all four waves of the survey together, we find that 40 per cent of women are involved in childcare compared to 26 per cent of men; this is a significant difference. Involvement in childcare also differs between age groups. Those aged 35 to 49 years are most likely to care for children; 70 per cent of women and 48 per cent of men provide care for children on a daily basis in this age bracket. The gender difference in childcare is widest among the 18 to 34 age group and is narrowest in the 65 plus age group. In this older group, 5 per cent of men and 6 per cent of women provide childcare on a daily basis for children/grandchildren.

\section{FIGURE 3.1 DAILY CHILDCARE BY GENDER AND AGE IN IRELAND, 2003-2016 POOLED}

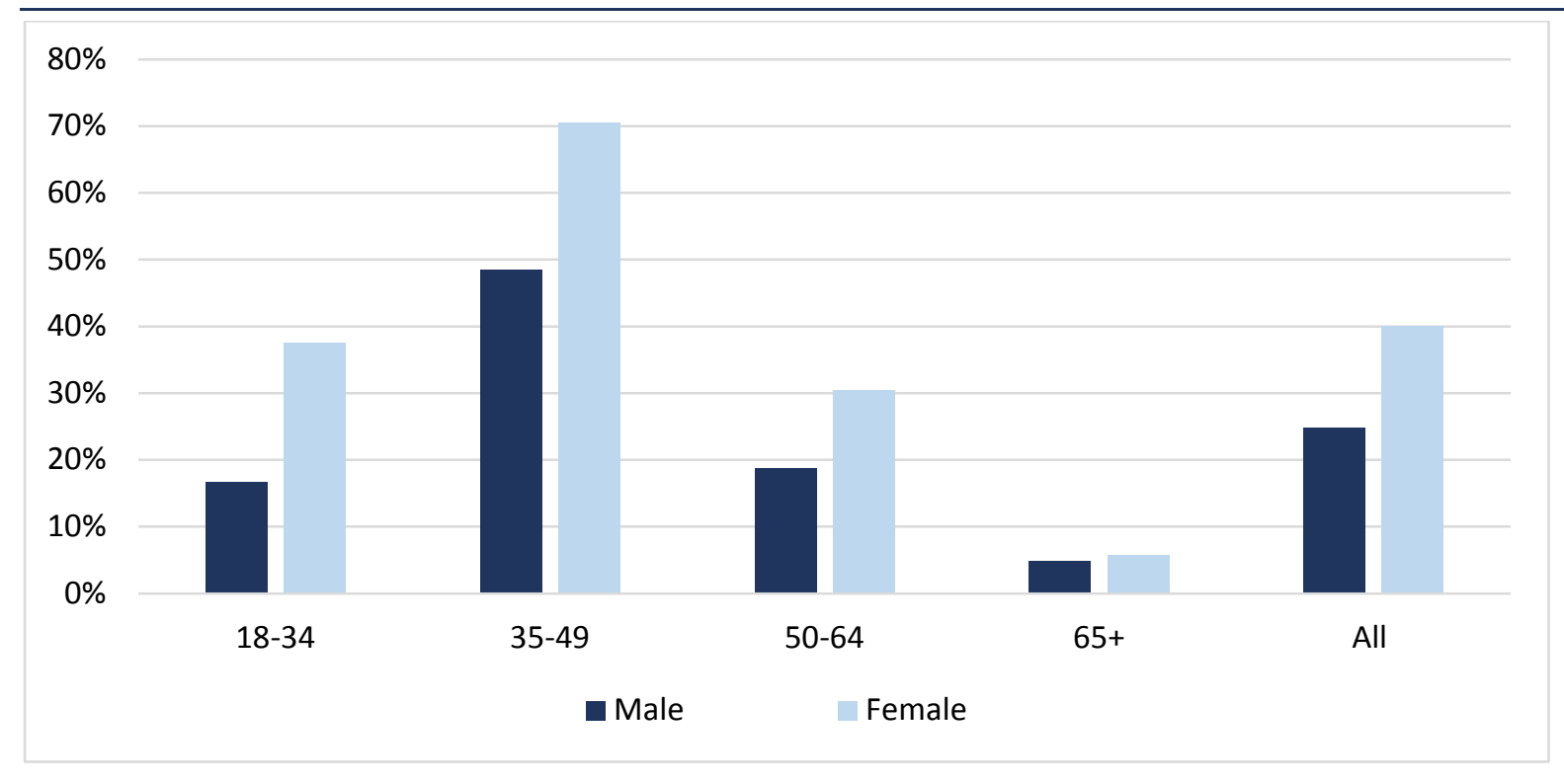

Source: Authors' analysis of the European Quality of Life Survey (2003 - 2016 pooled). Notes: Childcare refers to care of children and grandchildren.

Daily adult care, for an older person or a person with a disability, ${ }^{18}$ is much less common than care for children (see Figure 3.2). As the data are weighted to be representative of the population in age terms, this is not due to an over-representation of younger respondents.

18 In the first three waves 2003 to 2011, the adult had to be a relative of the carer but the nature of the relationship is not recorded. In 2016 the measure was expanded to include non-relatives (see Chapter 2). 
The gender differences in adult care are less pronounced than in the case of childcare. Figure 3.2 shows that over the period as a whole, 9 per cent of women and 7 per cent of men were involved in adult care on a daily basis. For women, involvement in adult care peaks among the 50 to 64 age group, when 13 per cent of women provide such care on a daily basis. For men the peak age for involvement is 65 and over; among this age cohort 9.3 per cent of men provide care on a daily basis compared to 8.5 per cent of women.

If we consider the age profile of those providing regular adult care we find that 19 per cent are aged 18 to 34 years; 35 per cent are aged 35 to 39; 27 per cent are aged 50 to 64; and 18 per cent are aged over 65.

\section{FIGURE 3.2 DAILY ADULT CARE BY GENDER AND AGE IN IRELAND, 2003-2016 POOLED}

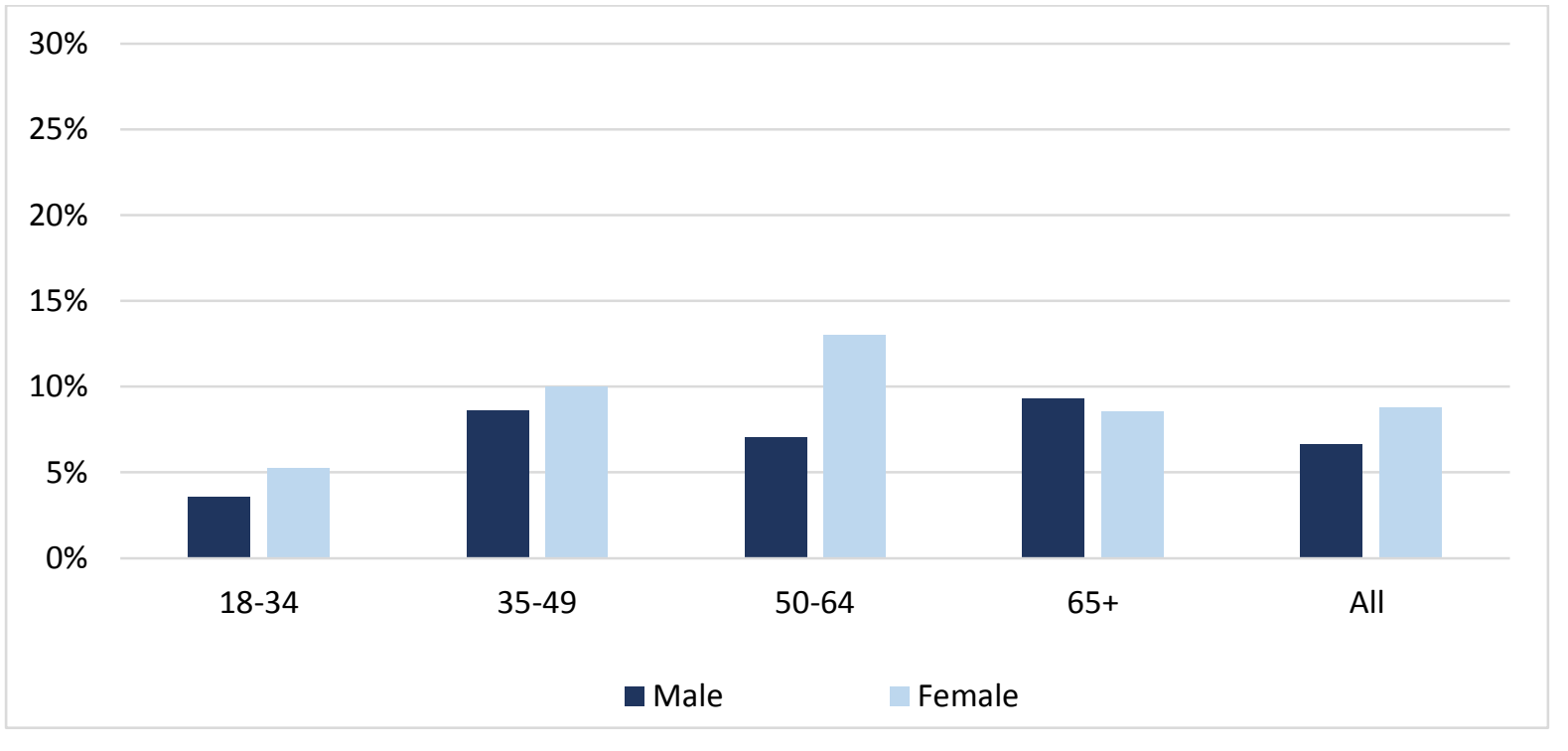

Source: Authors' analysis of the European Quality of Life Survey (2003-2016 pooled).

Figure 3.3 presents the rates of daily involvement in any care. We note that 45 per cent of women and 29 per cent of men provide care for others on a daily basis. Involvement in care labour peaks at the 35 to 49 age group for both sexes, when just over half of men and almost three-quarters of women provide care on a daily basis. 
FIGURE 3.3 DAILY INVOLVEMENT IN ANY CARE ACTIVITY BY GENDER AND AGE, 2003-2016 POOLED

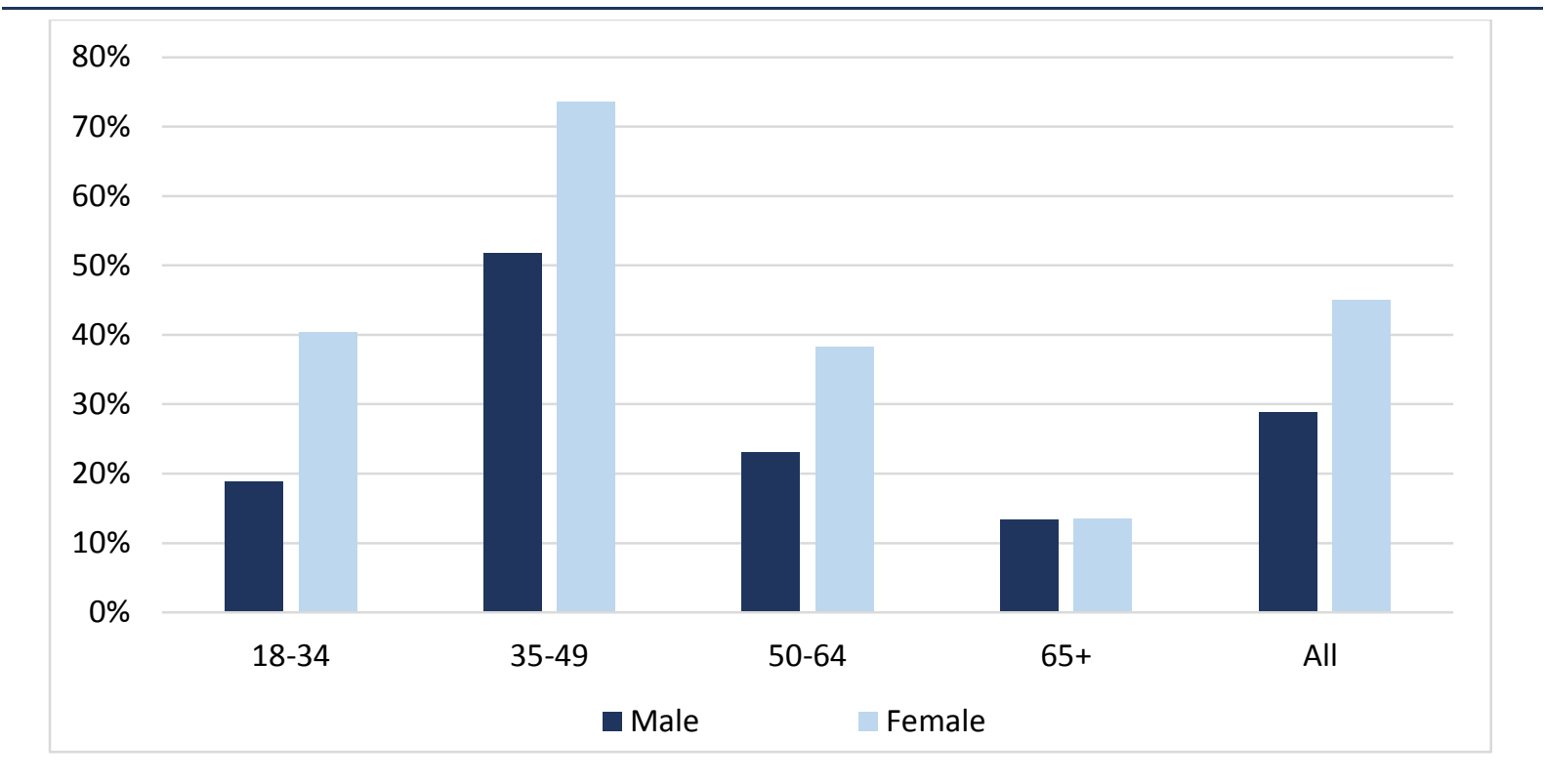

Source: Authors' analysis of the European Quality of Life Survey (2003-2016 pooled).

In general, daily involvement in care is structured by gender and age. We next consider the extent of this responsibility, exploring the variance in hours spent caring.

\subsection{WEEKLY HOURS SPENT ON CARING ACTIVITIES}

The daily participation rates in care is a useful headline figure, however it does not quantify the amount of time involved, which likely depends on the characteristics of the carer and the needs of the person being cared for. We therefore consider weekly hours spent on caring activities. Estimates of time spent on caring activities are subject to error, as discussed in Chapter 2. Nevertheless, in the absence of up-to-date time-use data, these estimates provide some indication of group differences in care activity over time. ${ }^{19}$ In Section 3.7 we compare our results from the European Quality of Life Survey to the earlier time-use figures for Ireland.

Estimates will differ substantially depending on whether we include or exclude those who are not regularly involved in any care. The EQLS only records hours of care for those who

19 In the analysis of hours we exclude 2003 data because of differences in the questionnaire for that year. It is possible that those with very high levels of care responsibility will not respond to surveys, this would apply equally to those caring for children or caring for an older persons/person with a disability. However, the survey does include respondents who record very high hours. 
report involvement in care activity at least once a week. Across the three surveys, 56 per cent of women and 69 per cent of men record no regular involvement in the care of children or grandchildren. ${ }^{20}$ If we include this group as having zero hours of childcare per week, the average number of hours spent on childcare would be 13.8 hours per week whereas if we exclude them, the average rises to 35.2 hours. ${ }^{21}$ These figures, broken down by gender and care type, are displayed in Figure 3.4. Among those regularly involved in childcare, the average weekly hours spent caring are significantly higher for women (42.6 hours) than for men ( 25.2 hours); this suggests that even among carers, a significant gender disparity exists in time spent caring.

Hours of childcare also differ widely depending on the age of the youngest child (not shown). Those with a child under the age of five spend an average of 50 hours per week on childcare compared to 41 hours for those whose youngest child is primary school age (5 to 12 years). Parents whose youngest child is aged 13-18 spend an average of 30 hours per week on childcare.

While we saw above that the proportion of the population providing adult care is lower than childcare, the time commitment for those providing adult care regularly is substantial, standing at 19.4 hours per week. ${ }^{22}$ Women caring for adults spend an average of 19.8 hours per week on this type of care, one hour more than men who spend an average of 18.8 hours (see Figure 3.4). Men's hours of adult care observed in 2007 were unusually high. The gap between men and women for adult care is wider if we look at the two more recent surveys only: 14.6 hours for men compared to 20.1 hours for women; this also suggests a gender gap in care, even among those who provide care.

If we calculate the mean hours across the whole population, including those doing no regular adult care (see Figure 3.4), the figures drop dramatically to 2.7 hours overall: this represents a mean of three hours for women and 2.4 hours for men.

20 Those in the 'not applicable' category, because they have no children or grandchildren, account for the majority of this group. It also includes those who answered 'never' or 'don't know' to the question on involvement. 
FIGURE 3.4 AVERAGE TIME SPENT ON CARE WORK, FOR WHOLE POPULATION AND REGULAR CARERS, IRELAND $(2007,2011,2016$, POOLED)

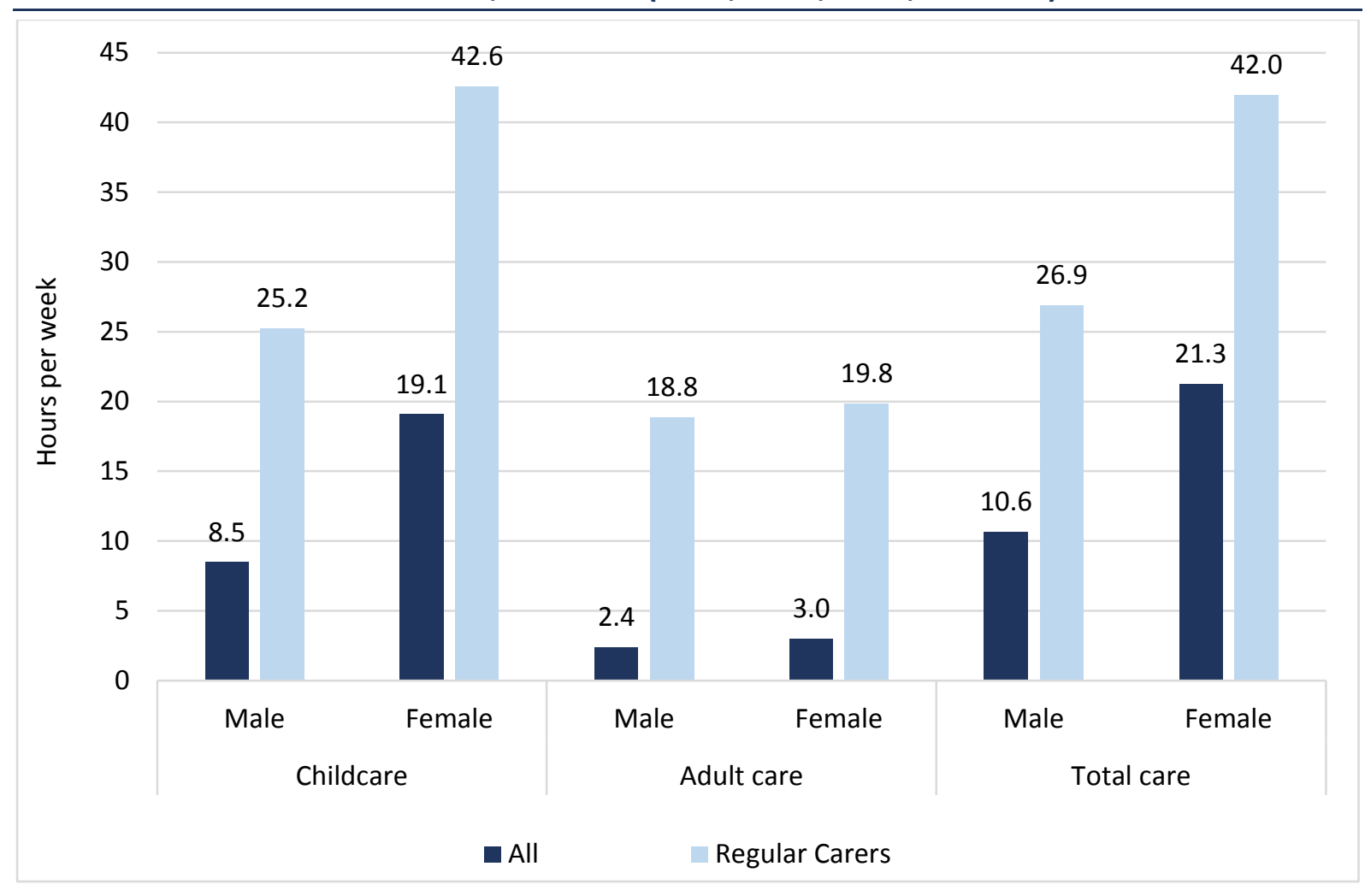

Source: Authors' analysis of the European Quality of Life Survey (2007-2016 pooled).

Notes: Time on activities is only available in a consistent format from 2007; 2003 data are excluded.

Some respondents report very high numbers of hours, up to 168 hours, which is 24 hours a day seven days a week. These outliers can pull up the mean scores. Therefore, as a check, we also report the median hours i.e. the midway point of the distribution of hours (see Figure 3.5). The median childcare hours stand at 30 hours for women and 20 hours for men. As we shall see in the next chapter, there is a great deal of variance in childcare time depending on the child's age and the parent's employment status. 
FIGURE 3.5 MEAN AND MEDIAN HOURS SPENT ON CHILD AND ADULT CARE FOR THOSE REGULARLY CARING (2007, 2011 AND 2016 POOLED)

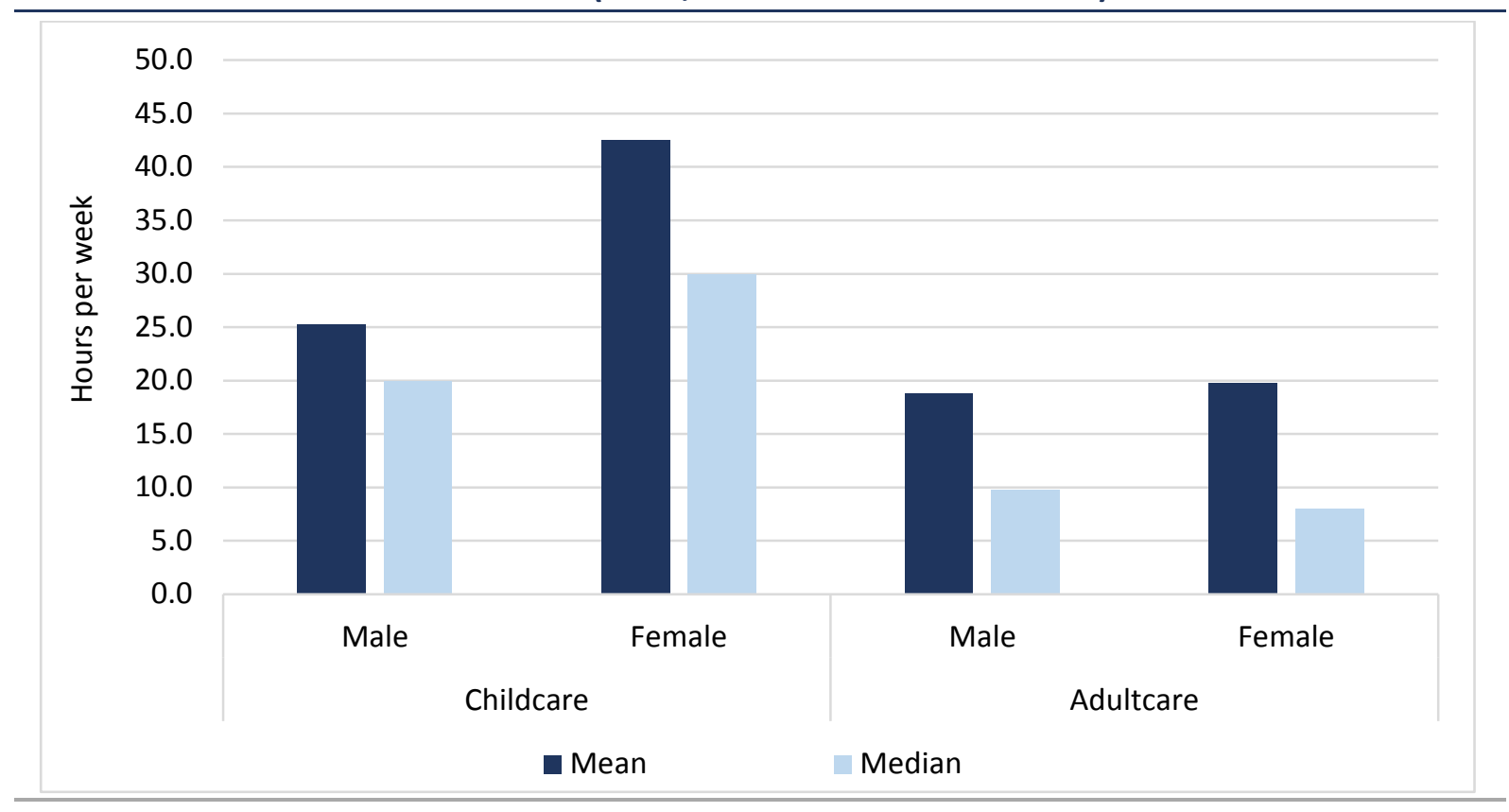

Source: Authors' analysis of the European Quality of Life Survey (2007-2016 pooled).

Notes: Hours of care are only collected for those who provide care at least once a week.

The analysis above pools all of the available survey years together, but authors suggest that differences in care and housework obligations between men and women have been narrowing over time (Gershuny et al., 2005). We consider this relationship below.

\subsection{TRENDS IN CARE ACTIVITY}

The preceding discussion presented figures on care pooled across the surveys. Here we examine whether there has been any change in care involvement over that period. Theories on the gender division of labour suggest that there should be some adjustment in men's take-up of caring and other domestic work activity over time in response to women's increased participation in the labour force and their increased bargaining power in the distribution of unpaid labour (see Chapter 1).

Considering childcare, Figure 3.6 suggests that men's participation increased from 21 per cent in 2003 to 29 per cent in 2011, but subsequently fell again to 26 per cent in 2016 . The trend in women's daily participation in childcare is much flatter, but there is a noticeable fall from 43 per cent in 2011 to 37 per cent in 2016. Female employment was increasing in Ireland from 2003 to 2007, but the onset of the severe recession in 2008 meant that employment for women and particularly men fell in the following years (Russell et al., 2014). 
In Chapter 4, we use statistical models to examine the relationship between time spent on caring/housework and paid employment. These models allow us to test how changes in employment levels influence trends over time. They also allow us to investigate whether the change in care over the period stems from the composition of the samples, for example through changes in the proportion of respondents with children.

Considering adult care, there is less variation over time in daily participation in adult care, though both sexes report a slight increase in involvement in 2016 compared to 2011. There are two possible reasons for this. The first reason involves the survey; a change in the question's wording occurred in 2016, which we outlined in Chapter 2 . The second is tied to macro changes and trends; this may be due to a genuine increase in the need for care, stemming from the ageing population. There is some evidence of a sharp increase in the number of those claiming adult care related benefits, as presented in Table 1.1.

FIGURE 3.6 PROPORTION OF MEN AND WOMEN INVOLVED IN CARE ACTIVITY EVERY DAY, IRELAND, 2003 TO 2016

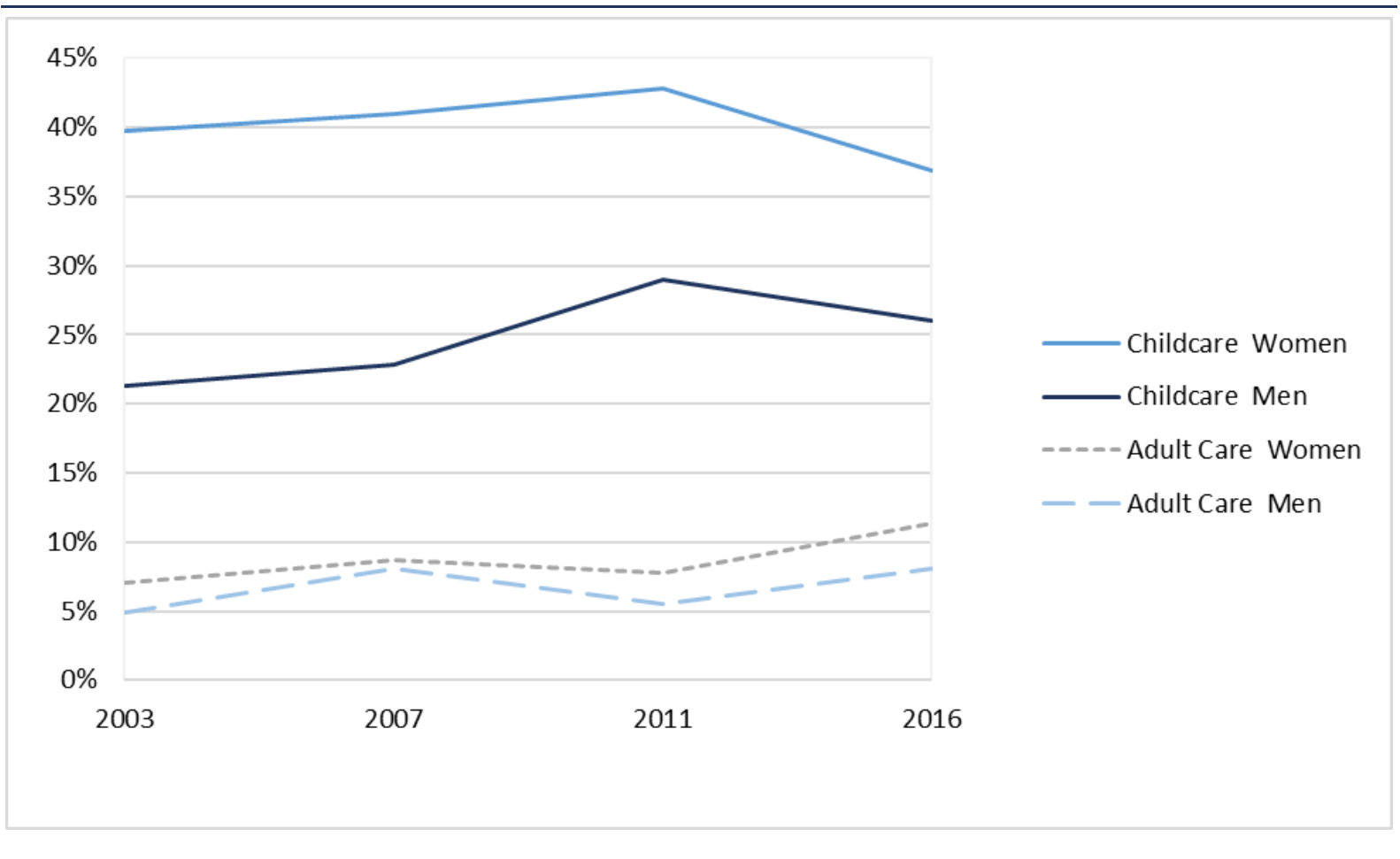

Source: Authors' analysis of the European Quality of Life Survey (2003-2016). 


\subsection{HOUSEWORK ACTIVITIES}

This section shifts the focus to housework. As outlined in Chapter 1, housework constitutes a significant element of non-market work and, alongside care, contributes to substantial gender differences in the distribution of unpaid (and paid) work. The EQLS does not explicitly define the tasks that are encompassed in 'housework', but from 2007 onwards it asks about housework and cooking specifically (see Chapter 2). We use the term housework to cover both.

\subsubsection{Participation in housework activities}

Figure 3.7 shows the proportions of women and men involved in housework on a daily basis by age group, pooled across the four survey waves. Once again there is a significant gender disparity: 81 per cent of women record daily involvement in housework, compared to 44 per cent of men.

An interesting effect emerges between age groups. Those aged 18-34 are significantly less likely to do housework on a daily basis compared to those aged over 35 . Age differences in housework after the age of 35 are minor. The gender difference in housework also persists across all age groups, and provides no evidence of a narrowing of the gap among the younger cohorts. However, to properly assess whether there is a cohort effect (and separate it from a life cycle or age effect) we need to assess whether the behaviour of the youngest groups changes over time. We consider this in Chapter 4 through statistical models. 


\section{FIGURE 3.7 DAILY INVOLVEMENT IN HOUSEWORK BY GENDER AND AGE GROUP}

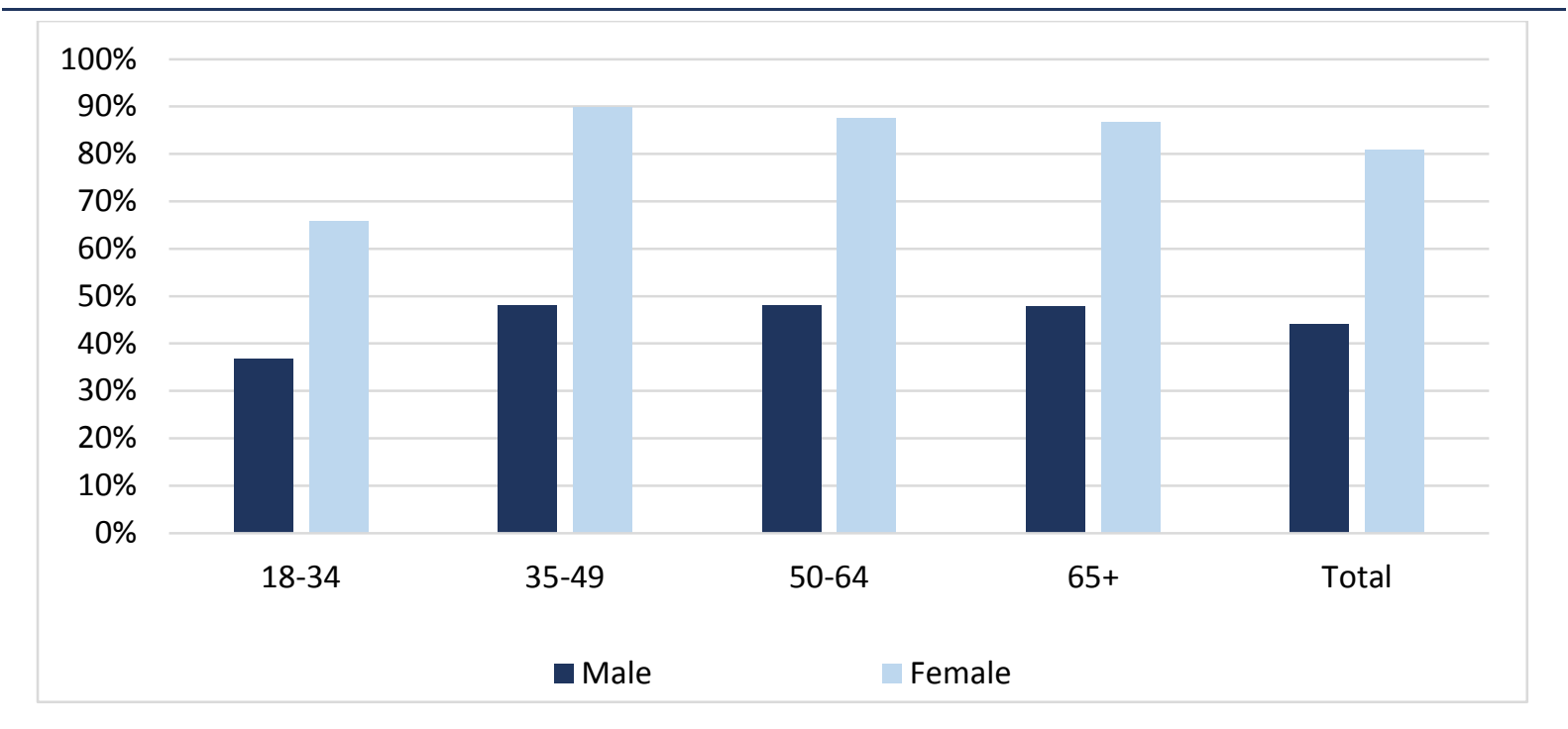

Source: Authors' analysis of the European Quality of Life Survey (2003 to 2016 pooled).

\subsubsection{Time spent on housework activities}

The gender differences in housework participation are mirrored in the amount of time spent on housework. Respondents who indicate that they do housework less than once per week are given a value of zero for hours normally spent on housework.

Figure 3.8 shows that women spend just under 20 hours per week, on average, on housework tasks. This figure is more than double the average amount of time spent on housework by men ( 9.2 hours). The average across the whole adult population is 14.5 hours per week.

In an effort to avoid outliers, Figure 3.8 also reports the median hours spent on housework, which is also 20 hours for women and seven hours for men. These figures suggest that the data on housework are less prone to outliers than the data on childcare. ${ }^{23}$

23 Excluding those with no regular involvement leads to a mean score of 21 hours for women and 12 hours for men. 
FIGURE 3.8 MEAN AND MEDIAN HOURS SPENT ON HOUSEWORK ACROSS WHOLE POPULATION (IRELAND, 2007, 2011 AND 2016 POOLED)

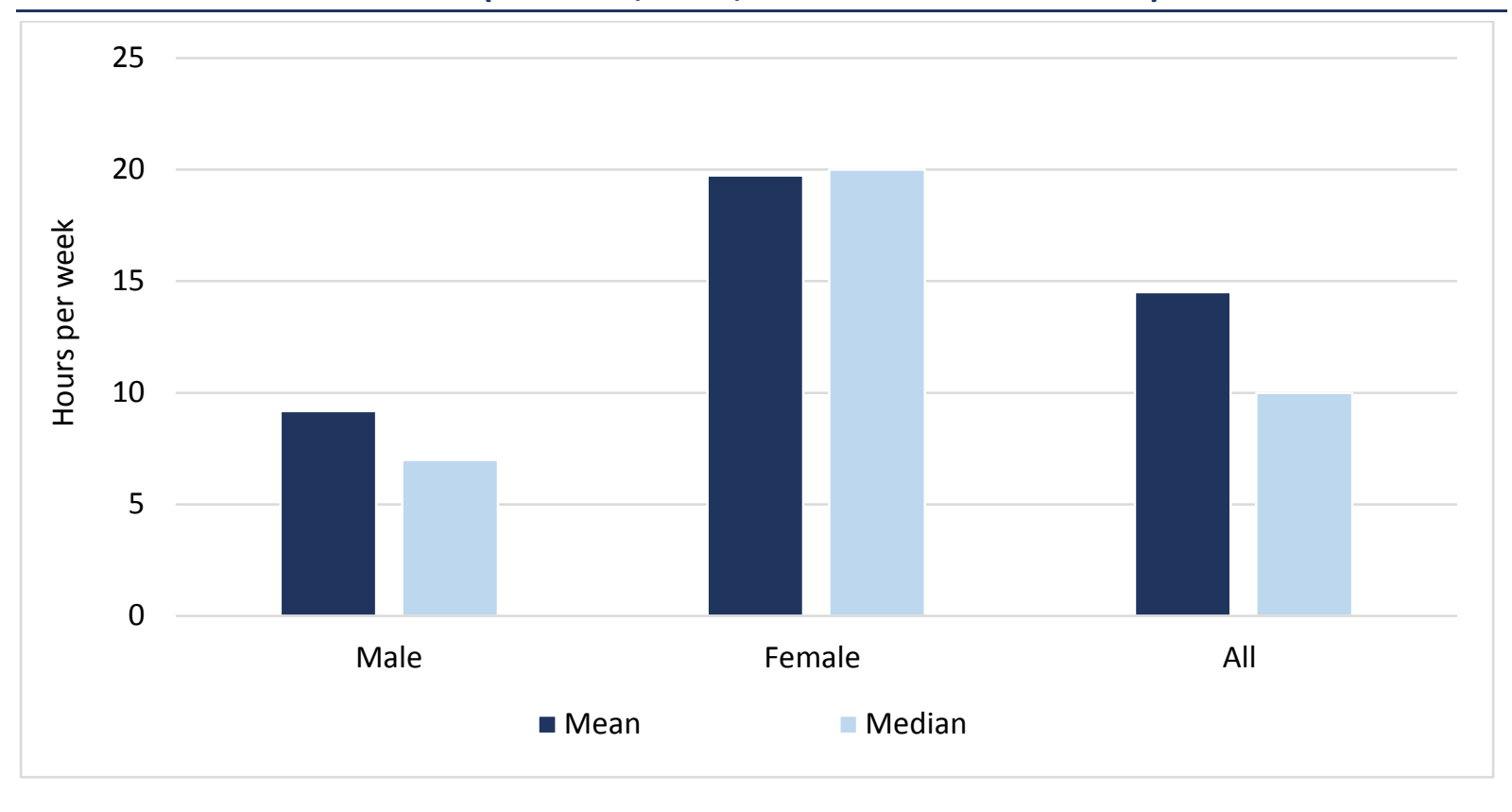

Source: Authors' analysis of the European Quality of Life Survey (2003 to 2016 pooled).

Focusing on the trend in housework over time, we see a distinct step change in participation in between 2007 and 2011 (see Figure 3.9). As mentioned above, this period encompassed a large shift in employment levels as the Irish economy moved from boom to recession. It is likely that the decline in paid employment meant that both women and men had additional time that they could devote to household work. Self-provisioning of meals and domestic work is also likely to have become a financial necessity in a period of falling household incomes. 
FIGURE 3.9 DAILY INVOLVEMENT IN HOUSEWORK IN IRELAND: CHANGE OVER TIME

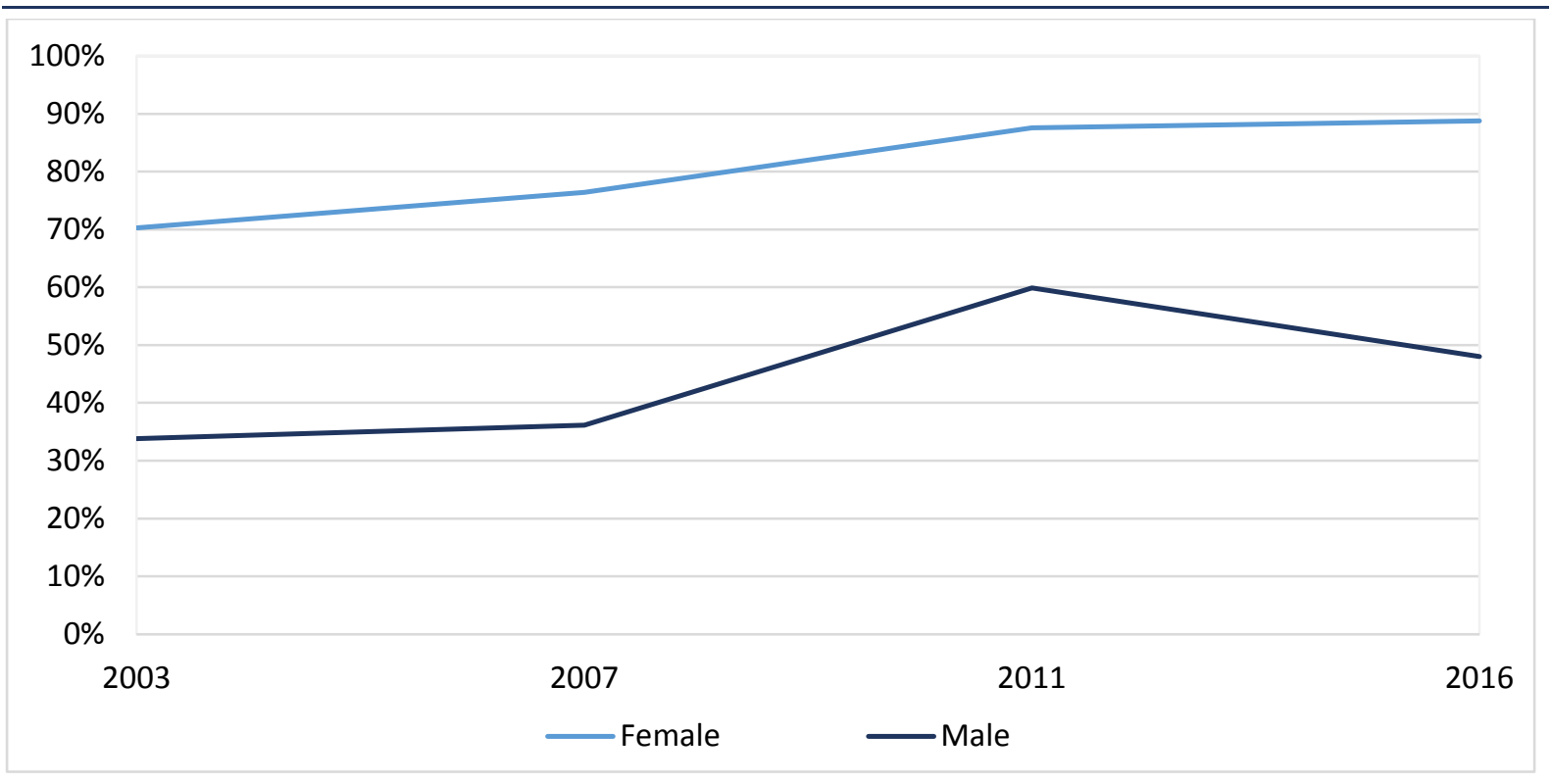

Source: $\quad$ Authors' analysis of the European Quality of Life Survey (2003 - 2016).

\subsection{EMPLOYMENT}

The previous sections focused on unpaid activity, but an individual's total workload will often consist of both paid and unpaid work. The hours spent on paid work are also an important constraint on the amount of care and housework that a respondent can provide. In this section, we look at the relationship between paid employment and unpaid work.

Employment status in the survey is self-defined ('which best describes your situation: employed; on leave; unemployed; retired; full-time homemaker' etc.). In Table 3.1 we present the proportion of each sex that are in employment. The small number of respondents who described themselves as 'on childcare or other leave' are not included with the employed in case this would distort the estimates of care/housework. ${ }^{24}$ Across all four waves of the survey, 42 per cent of women and 60 per cent of men were in employment. Consequently, the average number of paid working hours for all women (19.6 hours per week) is significantly lower than for all men (31 hours). Even among those in employment, men's hours are significantly longer than women's; 44 hours and 33 hours respectively (see Table 3.1).

24 The numbers involved are very small so they are unlikely to affect the results either way. For example in 2011 only 1.4 per cent of respondents were on leave. 
The trend figures show that male employment grew between 2003 and 2007 and then dropped sharply in 2011 during the recession, before recovering in 2016. For women, the employment rate increased gradually between 2003 and 2011 and then dropped in 2016. The decline in employment for women between 2011 and 2016 is not consistent with the trends shown in the much larger Quarterly National Household Survey, which shows a slight rise in employment rates for women between 2011 and 2016 (see Appendix Table A3.1). This suggests some sampling error that is not fully corrected by the weights. The EQLS weights control for household size, age, gender, region and employment status (see Chapter 2).

The wider difference between the EQLS and QNHS in 2016 means that we should be cautious of over-interpreting any changes in unpaid work in that year at the descriptive level, and rely on the modelled results. Moreover, for the international comparisons, which use the 2016 data (Section 3.8), the modelled results controlling for employment are preferred.

TABLE 3.1 EMPLOYMENT RATE AND HOURS OF PAID WORK BY GENDER (IRELAND 2003-2016)

\begin{tabular}{|l|c|c|c|c|}
\hline & \multicolumn{2}{|c|}{ Employment Rate (\%) } & \multicolumn{2}{c}{ Paid Hours (Employed) } \\
\hline & Male & Female & Male & Female \\
\hline $\mathbf{2 0 0 3}$ & $60.1 \%$ & $41.9 \%$ & 45.5 & 35.6 \\
\hline $\mathbf{2 0 0 7}$ & $68.5 \%$ & $42.1 \%$ & 43.7 & 32.9 \\
\hline $\mathbf{2 0 1 1}$ & $51.0 \%$ & $45.7 \%$ & 44.4 & 31.0 \\
\hline $\mathbf{2 0 1 6}$ & $61.1 \%$ & $38.8 \%$ & 42.6 & 32.3 \\
\hline All & $60.1 \%$ & $42.1 \%$ & 44.0 & 32.9 \\
\hline Base N & 1,990 & 2,062 & 1,168 & 852 \\
\hline
\end{tabular}

Source: Authors' analysis of the European Quality of Life Survey (2003-2016).

Note: The employment rate refers to the percentage of all men or all women in the survey that are employed.

We examine the relationship between working hours and unpaid working hours in the next chapter. Figure 3.10 shows the employment profile of carers. Here it is worth noting that 55 per cent of those providing care on a daily basis are in employment. This rises to 70 per cent for male daily carers and falls to 45 per cent for female daily carers. As a comparison, we also show the proportion of all respondents that are in employment (49 per cent). 
Figure 3.10 suggests that men are more likely to combine care and paid employment, although a significant portion of women also attempt to combine both care and employment.

\section{FIGURE 3.10 EMPLOYMENT STATUS OF THOSE PROVIDING CARE EVERY DAY}

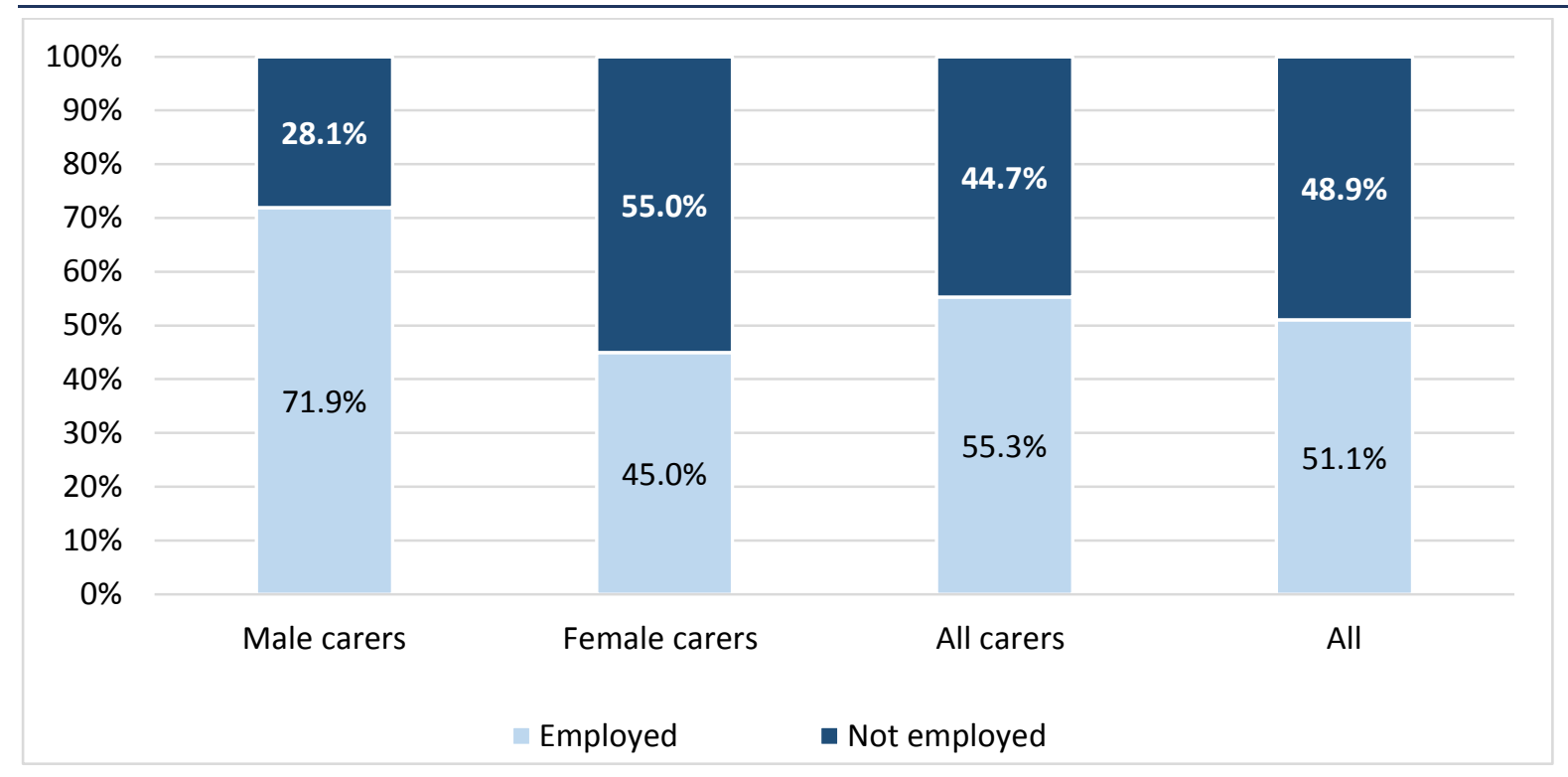

Source: Authors' analysis of the European Quality of Life Survey (2003-2016 pooled).

\subsection{COMPARISON WITH 2005 TIME-USE SURVEY}

Here we compare the EQLS figures on care and housework activities to the earlier 2005 ESRI National Time-use Survey. Table 3.1 lists both samples. The pooled EQLS figures show higher values for time spent on care than the time-use survey. The difference is 3.9 hours per week for women (21.3-17.4) and 6 hours per week for men (10.6-4.6). However, the figures for housework have fewer differences; no more than 1.5 hours per week.

Differences between the two sources may reflect differences in the timing of the survey, differences in sample (households in the time-use survey versus individuals in the EQLS), as well as the methods of data collection (time-use diaries rather than direct questions on time spent on care and housework). The comparison is provided for illustrative purposes only. 
TABLE 3.2 ESTIMATES OF MEAN WEEKLY HOURS SPENT ON CARE AND HOUSEWORK, EQLS AND NATIONAL TIME-USE SURVEY COMPARED

\begin{tabular}{|l|c|c|}
\hline & EQLS (2007 2016) & Time use survey (2005) \\
\hline Women weekly care hours & 21.3 & 17.4 \\
\hline Men weekly care hours & 10.6 & 4.6 \\
\hline All weekly care hours & 16.0 & 11.1 \\
\hline Women weekly housework & 19.7 & 18.2 \\
\hline Men weekly housework & 9.2 & 8.7 \\
\hline All weekly housework & 14.5 & 13.6 \\
\hline
\end{tabular}

Source: ESRI Time-Use Survey (2005) and European Quality of Life Survey (2007-2016).

\subsection{HOW DOES IRELAND COMPARE TO ELSEWHERE IN EUROPE?}

In this section, we draw on the comparative element of the EQLS to consider how the patterns of time spent on unpaid care in Ireland compare to other EU countries. For this analysis, we focus on the most recent wave of the survey carried out in 2016.

As discussed in Chapter 1, national variation in caring time is structured by differences in institutions and gender culture which shape how care obligations are shared between the family, the State and the market. We suggest this variation stems from a variety of sources. First, differences in taxation, welfare and social services (for example provision of care services by the State) affect the extent to which care is 'familialised' within countries and the degree to which this is shared between women and men.

Second, national differences in labour market institutions such as working time regulation, wage regulation, employment protection legislation and unionisation will influence paid working hours and how these are distributed across the population. This indirectly affects the amount of time available for care, and the availability of care in the home.

Third, gender culture or gender norms differ across countries. These expectations define the socially accepted division of caring responsibilities and paid work between men and women (Pfau-Effinger, 1998; 2004). Fourth, all else being equal, national differences in family structure and fertility will influence national caring demands. 
It is beyond the scope of the current study to undertake a detailed comparative analysis of these processes; instead, we provide a descriptive analysis that compares the level of involvement in unpaid work among women and men in Ireland relative to others in the EU, holding a set of relevant factors constant. We also explore the size of the gender gap in unpaid activities across countries.

\subsubsection{Unpaid work across Europe}

This section considers country differences in unpaid work hours (care and housework combined) in 2016. Given our concerns that the 2016 EQLS underestimates women's employment in Ireland to a greater extent than in other countries, ${ }^{25}$ we compare countries using modelled results only. These modelled results are the estimated level of unpaid work for men and women in each country if the distribution of observed characteristics (age, education, paid employment hours, partner, partner's employment, age of children) was the same in each country i.e. holding constant all of these characteristics. ${ }^{26}$ The country differences are therefore net of differences that might arise due to differing levels of female employment or differences in the distribution of children. We do not discuss the effects of each of these control variables on unpaid work as this is discussed in detail for Ireland in the following chapter.

Figure 3.11 shows the modelled values for women. Controlling for composition, women in Ireland are estimated to undertake 38.2 hours of unpaid work per week. This places women in Ireland amongst the three countries with the highest levels of unpaid work time along with Romania and Malta. At the other end of the scale women in Denmark do an average of 22.5 hours of unpaid work. The other countries recording relatively low levels of female unpaid work are Portugal, Croatia, Slovakia and Finland. These patterns are not consistent with any of the country clusters/typologies discussed in Chapter 1 . These country differences are very marked even when holding paid employment hours, family structure, education and age group constant, suggesting that there are many other processes at play in structuring unpaid work levels.

25 The 2016 EQLS ranks Ireland as having one of the lowest employment rates for women, whereas the European Labour Force Survey, which uses the ILO definition of employment, places women in Ireland in the middle of the table with an employment rate close to the EU average. 
FIGURE 3.11 WOMEN: MODELLED UNPAID WORK HOURS BY COUNTRY, 2016

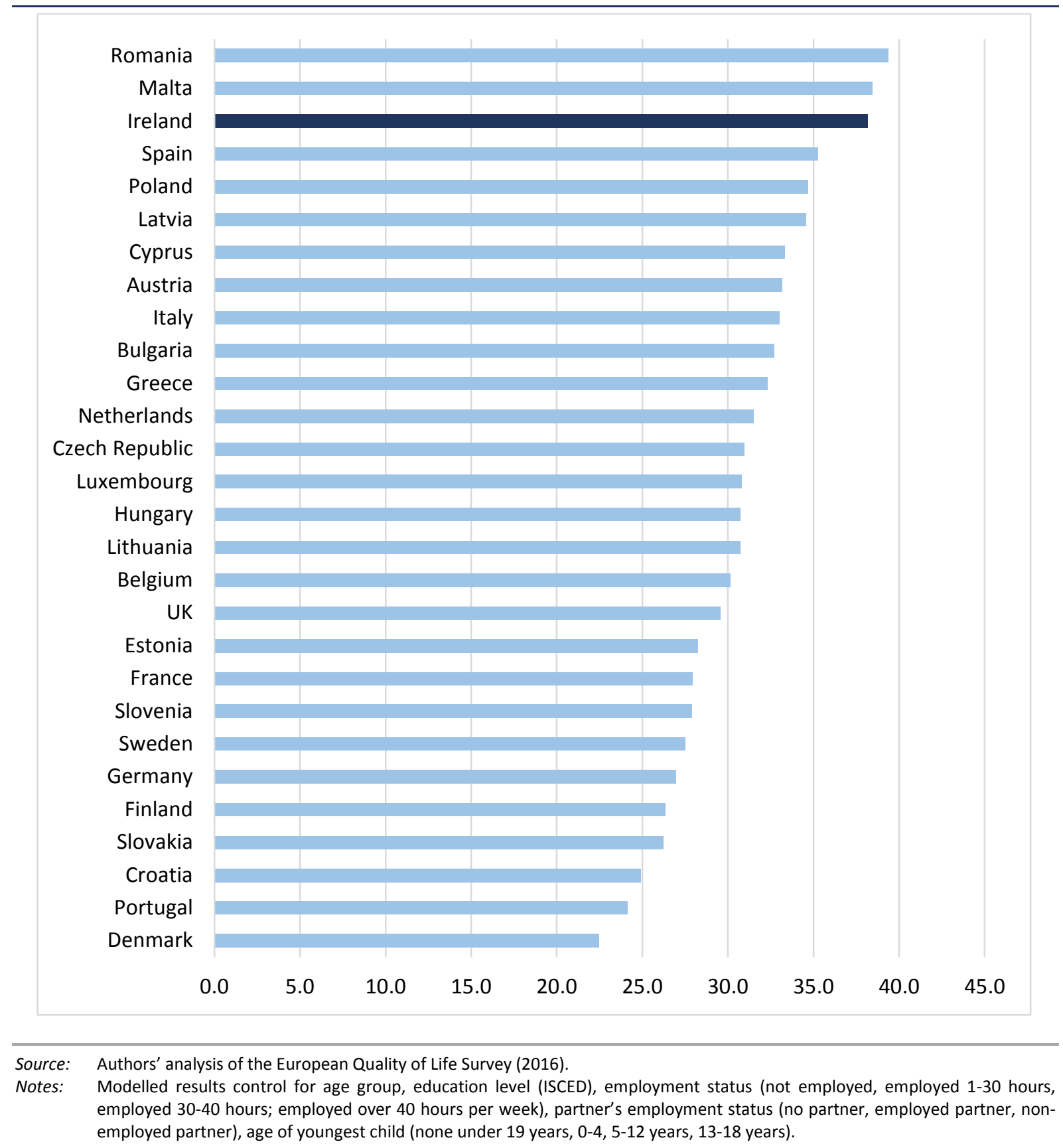

A high level of dispersion is also found in the amount of unpaid work time recorded by men across the EU28. Figure 3.12 presents the 'modelled' values for men, which are the marginal differences between countries having controlled for the factors mentioned above. This shows that men in Ireland also report some of the highest levels of unpaid work; 19.8 hours of unpaid work per week, behind only men in Latvia and Romania where men do 24 hours and 22.4 hours of unpaid work respectively. The lowest unpaid work hours amongst men are found in Croatia (8.7 hours), Czech Republic (9.4 hours) and Greece (10.3 hours). 
Again, it is important to note that compositional factors have their own effects on unpaid working time, but these factors explain little of the difference between Irish unpaid care and unpaid care in other EU countries.

FIGURE 3.12 MEN: MODELLED UNPAID WORK HOURS BY COUNTRY, 2016

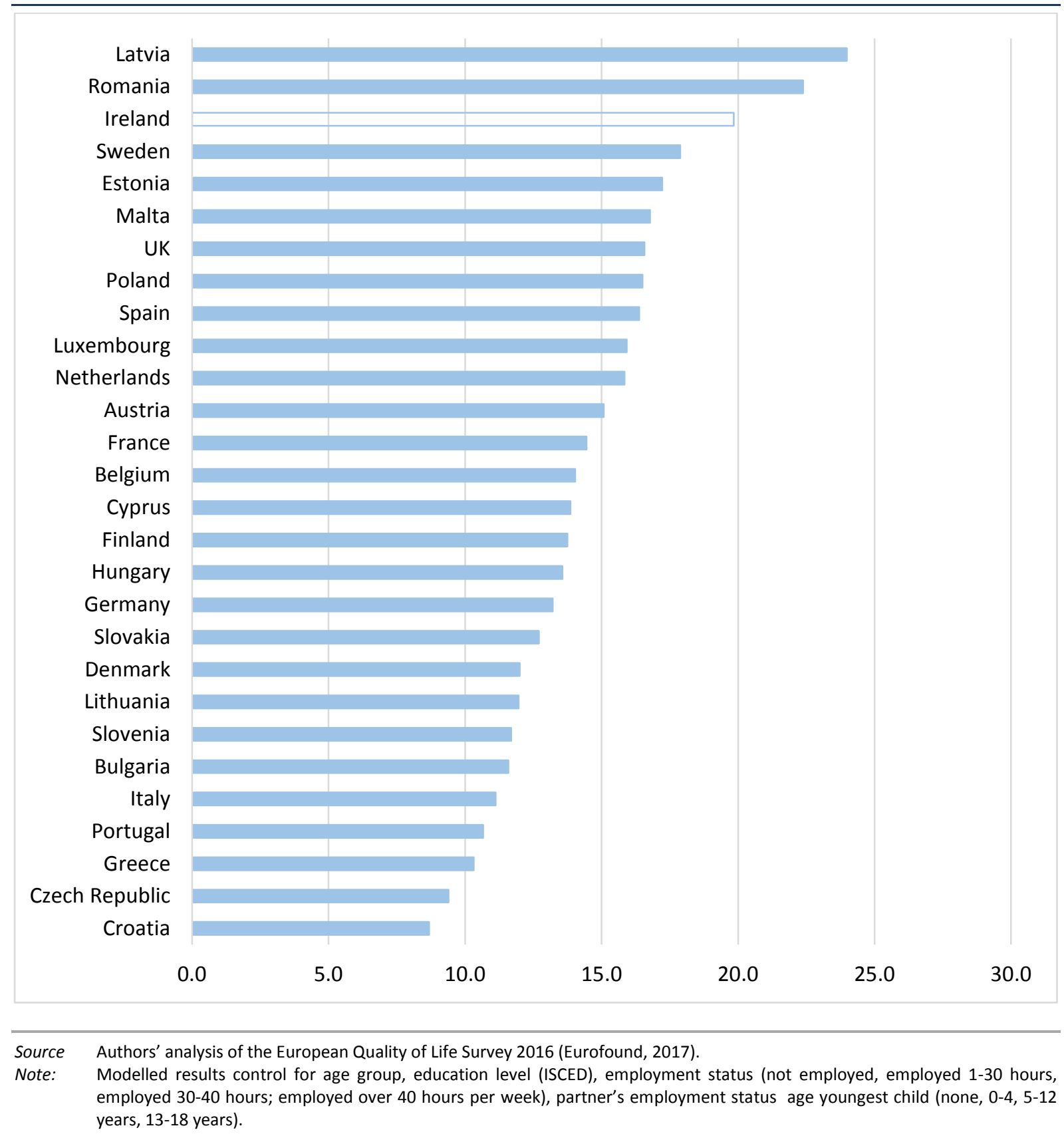

Both men and women in Ireland report notably high levels of unpaid work, but is the gender gap in unpaid hours in Ireland narrower or wider than elsewhere in Europe? In the final analysis, we compare the differences between men and women's hours of unpaid labour across the EU28. While the difference between countries in the absolute hours reported 
may be subject to cultural differences in responses, this should not affect the relativities within each country between the sexes.

In Figure 3.13, we again present the modelled results controlling for age, paid employment hours, partnership status, partner's employment, education and presence/age of children, gender and the interaction between gender and country. Figure 3.13 shows that the gap between men and women in unpaid work ranges from 7.2 hours in Sweden to 20.2 hours per week in Greece.

Ireland rates highly on the measure. It has the seventh highest gender gap in unpaid hours across the EU28. It is notable that the Scandinavian countries are among those with the lowest gender gap in unpaid work. As discussed in Chapter 1, these countries have welfare/gender regimes that are closer to the dual earner/dual caregiver model, and offer the most consistent policy configuration for promoting gender equality (Lewis 1992; Saraceno and Keck, 2011).

The largest gap is evident in the Southern states like Malta, Italy and Greece. These countries demonstrate familialist welfare models, or 'familialism by default', where provision of 'social services' falls mainly on families (Ferrera, 1996; González, 2006; Saraceno and Keck, 2011). These welfare models frame women as the primary providers of unpaid care and household labour in a context of low state provision of services and transfers. 
FIGURE 3.13 MODELLED GENDER GAP IN UNPAID WORK HOURS ACROSS EUROPE

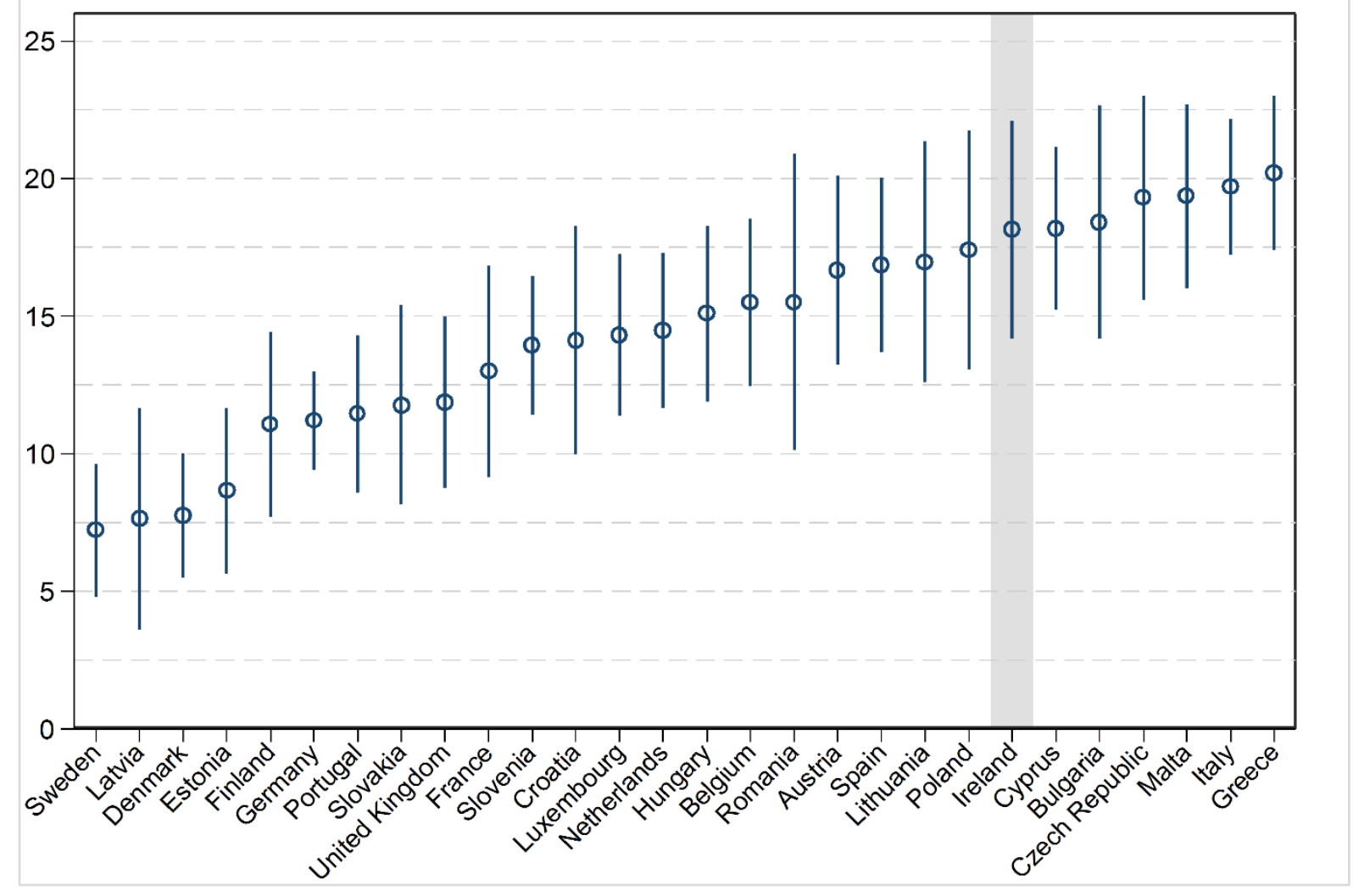

Source: $\quad$ Authors' analysis of the European Quality of Life Survey 2016 (Eurofound, 2017).

Note: $\quad$ Model controls for gender, country, age, education, paid employment hours, partners employment, and age of children. An interaction effect between gender and country is included.

Vertical lines indicate 95 per cent confidence intervals.

\subsection{SUMMARY}

In this chapter, we examined the levels of involvement in caring and housework by women and men in Ireland both in terms of regular involvement and in the estimated time spent on these activities. The analysis shows that these patterns are strongly gendered but are also affected by age. Time spent in these activities fluctuated over the period observed with an increase in participation between 2007 and 2011. It is possible that these time trends reflect changes in the paid employment due to the onset of recession, which is also described.

In the following chapter we will use statistical models to test whether changes between the years of the survey are accounted for by shifts in the employment status of respondents. The models will also allow us to test a range of influences beyond gender and age, for example family status. 
This chapter also highlighted the comparative position of Ireland in Europe. Results show that Ireland has some of the highest levels of unpaid work in Europe, even when important compositional differences between countries are taken into account. This is consistent with the relatively low State support in Ireland for care, particularly childcare as discussed in Chapter 1, which results in high individual informal and unpaid work time.

This chapter also showed that while in all countries women do more unpaid work than men, in Ireland the gap between men and women, at 15 hours, is wide in comparative terms. The gender gap in unpaid work is lowest in the Scandinavian countries, and highest in Southern European countries like Greece. This is broadly consistent with how policy configurations in these countries support care work and promote gender equality. A full investigation of cross-national differences in unpaid work is beyond the scope of the current study - such research would require further consideration of the specific policy arrangements in countries, employment practices, and gender culture.

What is clear is that this gender gap in unpaid work in Ireland is likely to have significant implications for gender inequalities in the labour market, and potentially gender inequalities in general well-being. 



\section{CHAPTER 4}

\section{Modelling the factors that influence time spent on caring, housework and total unpaid labour}

\subsection{INTRODUCTION}

In the previous chapter we considered how time spent on different unpaid tasks varied by age and by gender. There are however many other factors that influence the amount of unpaid work that an individual will undertake. As discussed in Chapter 2 these additional factors include: the demand for care and housework as captured by the composition of the household; participation in paid work; educational attainment (which is indicative of income level and may be correlated with gender role attitudes); and change over time or period effects.

Running statistical models means that we can take account of these different factors and look at the net effect of each. For example, the trend data presented in the previous chapter showed an increase in men's and women's involvement in housework and caring between 2007 and 2011. We speculate that this was due to the sharp drop in employment over the period of the recession. With models we can test whether the year effects are accounted for by changes in employment levels, i.e. does the year effect disappear when we take paid employment status into account.

We estimate models for three different outcomes: care time, housework time and total unpaid work time. In each case the dependent variable is hours per week spent on the task. For each variable there is a reference category, for example for children the reference category is 'no children 0-18 years'. The models show the influence of each group relative to the reference category. As noted in the preceding chapter, due to inconsistencies in the way information on housework and caring time was measured in 2003 , the analysis is restricted to three waves of data, 2007, 2011 and 2016.

The dependent variables include a significant proportion of zeros. This is particularly the case for time spent caring where 56 per cent of women and 69 per cent of men record no 
care time. This poses a challenge for the statistical models so we conducted tests to establish the most appropriate model. For each outcome (time caring, time on housework and total unpaid time), we use a zero-inflated negative binomial (ZINB) regression model, which is designed for count variables that include multiple zero values (Cameron and Trivedi, 2013). ZINB models are particularly suitable for the outcomes we are interested in because of the high number of zeros, and because the process that determines whether an individual undertakes no hours of unpaid work or any hours, may differ somewhat from the process that determines how many hours they work if they record a non-zero value. ${ }^{27}$ These models involve two steps, the first step takes account of the factors associated with recording a zero value (e.g. no care). The second step uses the calculations from the first step to adjust the estimates of the time spent on each activity (Long and Freese, 2006). ${ }^{28}$ In the tables and graphs we present the marginal effects from these two-step models, which show the effect of each characteristic when all the other variables are held constant (at the average value). The full model coefficients for both steps are available from the authors.

\subsection{TIME SPENT ON CHILDCARE}

The first set of models in Table 4.1 examine time spent on caring (child plus adult care) across the whole sample, including those who do no regular care work. In a model that controls only for period (Model 1), women do an average of 10.8 hours more care work than men. The year effects show that in 2011, respondents did more hours of care per week compared to 2007, but the average hours returned to the 2007 level in 2016 .

In Model 2 when age, family status, education and employment hours are controlled, the gender gap in care hours narrows somewhat to 7.3, but remains substantial. The increase in care time in 2011 is reduced and becomes insignificant as soon as paid employment is included in the model, suggesting that this rise was mainly driven by a drop in paid work hours. The models for men and women separately show that there was a significant

27 For example, in the case of care work, those aged 50-64 are more likely to be involved in any paid care (compared to the under 35s) but record lower time involvement, primarily because they are providing adult care rather than child care. 
increase in care hours for men in 2011 (even when employment was controlled), suggesting a narrowing of the gender gap in caring during recession.

Focusing on the other factors in Model 2 we find that, all else being equal, those aged 35-49 spend 4.7 hours longer on caring activities compared to those in the 18-34 reference group. As the age of children is controlled in the model, this is influenced by other factors, such as having a combination of older parents to care for as well as children, the so called 'sandwich generation'. The separate models for men and women (Models 3 and 4) show that this age/life-course effect is only significant for women. The model for women also shows that women aged 65 and over spend less time on care activities than the 18 to 34 group.

The presence of young children is the single most important influence on time spent caring. Having a pre-school child adds 34.9 hours to care time on average compared to those with no child aged 18 years or younger. The effect of pre-school children is even greater for women (+ 39.2 hours) than for men (+ 27.7 hours). ${ }^{29}$ The presence of primary school children, aged five to 12 , is associated with an additional 34.6 hours of care for women and 19.2 hours for men compared to those with no children aged 0-18 years. The additional care time drops for parents whose youngest child is 13 to 18 years but remains substantial: they provide an average of 12 hours more care per week compared to those without children.

29 The interaction effects confirm that the effect of children on care time is significantly greater for women. 
TABLE 4.1 ZERO-INFLATED NEGATIVE BINOMIAL MODEL OF CARE HOURS, MARGINAL EFFECTS ${ }^{1}$

\begin{tabular}{|c|c|c|c|c|c|}
\hline & & $\begin{array}{c}\text { Model } 1 \\
\text { All }\end{array}$ & $\begin{array}{c}\text { Model } 2 \\
\text { All }\end{array}$ & $\begin{array}{l}\text { Model } 3 \\
\text { Men }\end{array}$ & $\begin{array}{l}\text { Model } 4 \\
\text { Women }\end{array}$ \\
\hline Sex (ref. Male) & Female & $10.75^{* * *}$ & $7.25 * * *$ & & \\
\hline \multirow{2}{*}{ Year (ref. 2007) } & 2011 & $4.63^{* *}$ & 2.33 & $2.88^{*}$ & 3.02 \\
\hline & 2016 & 2.52 & -1.29 & 0.01 & -1.00 \\
\hline \multirow{3}{*}{ Age (ref. 18-34) } & $35-49$ & & $4.79 * * *$ & 2.72 & $4.932 *$ \\
\hline & $50-64$ & & -0.18 & -1.89 & 1.614 \\
\hline & $65+$ & & -1.48 & -0.78 & $-7.961 * *$ \\
\hline \multirow{2}{*}{$\begin{array}{l}\text { Education } \\
\text { (ref. Lower } \\
\text { secondary or less) }\end{array}$} & Upper secondary/PLC & & -0.94 & -0.13 & -0.962 \\
\hline & Third-level education & & -1.65 & -1.36 & -0.266 \\
\hline \multirow{3}{*}{$\begin{array}{l}\text { Children (ref. No } \\
\text { child aged } 0-18 \text { ) }\end{array}$} & Children 0-4 & & $34.68 * * *$ & $27.93 * * *$ & $38.71 * * *$ \\
\hline & Children 5-12 & & $26.39 * * *$ & $19.45^{* * *}$ & $34.71 * * *$ \\
\hline & Children $13-18$ & & $11.91^{* * *}$ & $7.645^{* *}$ & $18.43 * * *$ \\
\hline \multirow{3}{*}{$\begin{array}{l}\text { Employment (ref. } \\
\text { Over } 40 \text { hours) }\end{array}$} & No paid work & & $5.35^{*}$ & 2.42 & $13.41 * * *$ \\
\hline & $1-30$ hours & & 2.19 & -0.67 & $9.145^{* * *}$ \\
\hline & 31 to 40 hours & & -0.37 & 0.21 & $4.831^{*}$ \\
\hline \multirow{3}{*}{$\begin{array}{l}\text { Partner's } \\
\text { employment } \\
\text { (ref. Single) }\end{array}$} & Partner not employed & & 2.42 & 1.57 & 4.470 \\
\hline & Partner employed & & $3.09 *$ & 1.85 & $4.079 *$ \\
\hline & Observations & & 2,700 & 1,187 & 1,513 \\
\hline
\end{tabular}

Source: Authors' analysis of the European Quality of Life Survey 2007-2016.

Note: $\quad * \mathrm{p}<0.05, * * \mathrm{p}<0.01, * * * \mathrm{p}<0.001$.

1 . Average marginal effects are the difference in the expected hours of the group compared to the reference category with all other variables held to the average value. Zero-inflated negative binomial models involve two stages, the first stage adjusts for the high number of zeros i.e. those who record no regular care time. The variables in Stage 1 are: gender, age, children, and partners employment. The interactions between gender and age of youngest child, between gender and paid employment hours, and between gender and partner are statistically significant in a joint model. The interactions between gender and year, and gender and education level are not significant.

Employment status has a significant impact on hours of care, however this effect is confined to women. We make a distinction between those not employed, employed part-time (less than 30 hours per week), full-time (31 to 40 hours) and long hours (over 40 hours per week). Women not in paid employment do an average of 13 more hours of care per week compared to those women in long hours employment with the same family status, age etc. Women working part-time do an average of eight hours more care work compared to women employed more than 40 hours per week. The absence of an employment effect for men suggests that gender role expectations play a part, and that time availability in itself is not enough to lead to an increase in men's care hours. In order to illustrate the different influence of paid employment on care time for men and women, we present the model results graphically (Figure 4.1). This shows that at the lower levels of paid work (none or 
part-time) there is a large and significant difference in men and women's care hours. Among those working full-time and long hours there is no significant gender difference.

FIGURE 4.1 MODELLED WEEKLY CARE TIME (CHILD AND ADULT CARE) BY GENDER AND HOURS OF PAID WORK

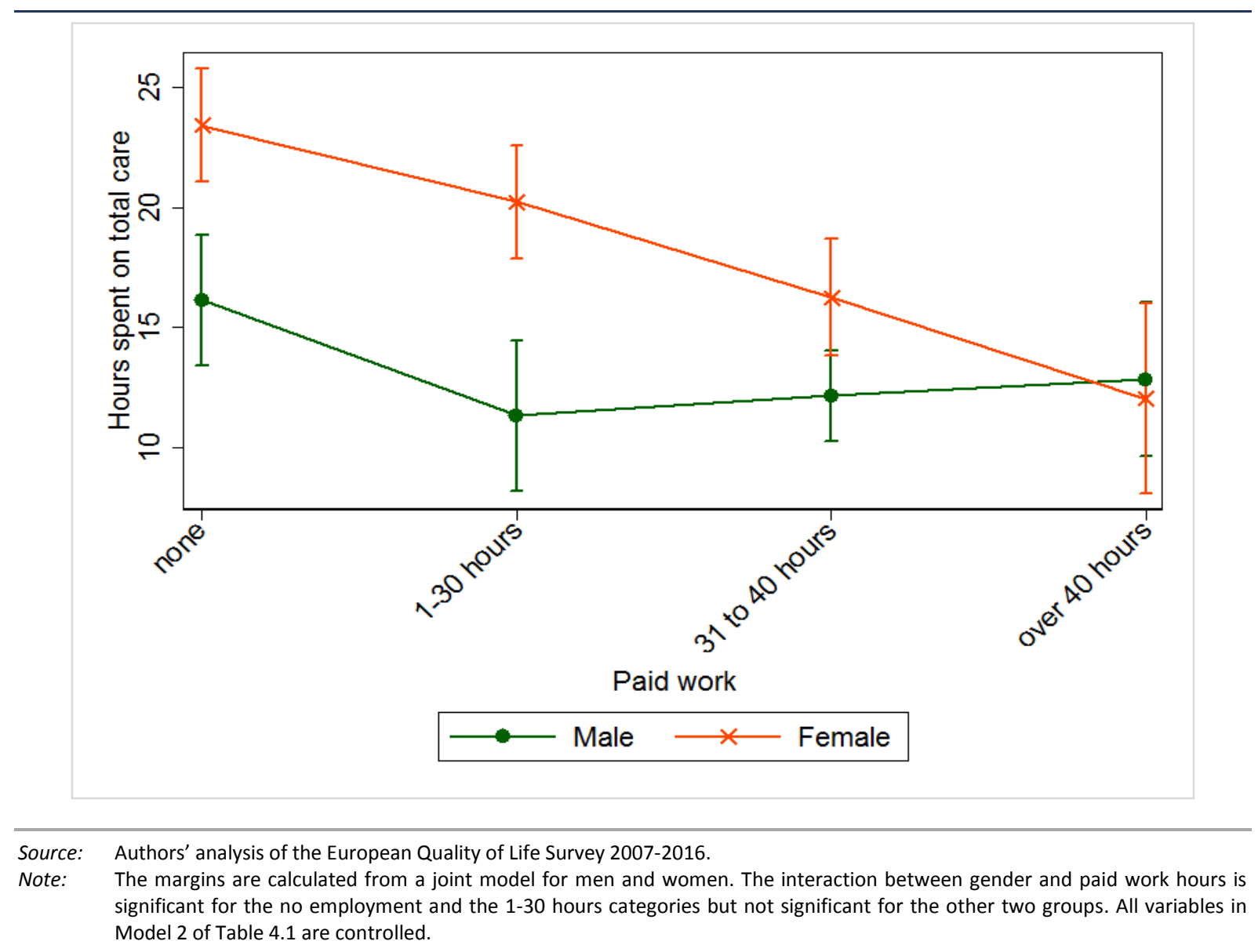

The employment status of one's partner is also relevant but again only for women. Having an employed partner increases women's care time by 4.3 hours compared to individuals that do not have a partner. These results suggest an unequal division of caring labour within couples, however to properly test theories of specialisation and bargaining would require information on both partners' care time within couples. The EQLS contains information on care time for only one person in the household.

Net of employment and family status and the other factors controlled in the model, education has no statistically significant effect on care time either overall or for men and women separately. 
The type of models used here do not report statistics on 'goodness of fit', i.e. the amount of variation in the outcome variable that is explained by the model. However, as a guide, OLS regressions show that a model with just gender and year explains only 4 per cent of variation in care hours whereas the variables in Model 2 explain almost one-third of variance. This suggests that variation in care time across the population is much more influenced by care demands (captured by the presence and age of children) than gender per se. However once these care demands are present, their allocation is strongly gendered, as shown in Models 3 and 4.

\subsection{TIME SPENT ON HOUSEWORK}

In the next set of models we consider the factors that influence the number of hours per week spent on housework. In Model 1 of Table 4.2 we see that before controlling for any factors except year, women do an average of 10.5 more hours of housework per week than men. Gender and year alone account for 16 per cent of variation in housework hours in an OLS model, significantly more than in the care models. ${ }^{30}$

In Model 2, when a range of factors relating to family structure, employment status and education are controlled, the size of the coefficient for women decreases but is still substantial at 8.4 hours. Overall there is no significant period effect. However there are different patterns for men and women. For men only we see a small increase in housework in 2011 net of the other factors in the model. For women, we see a decline in housework hours in 2016, net of other changes. While the increase for men in 2011 is not accounted for by a drop in paid work, the effect may nevertheless be related to the recession. For example, housework time may be affected by financial constraints which are not included in the model, or by adjustments in job demands not captured by the hours of paid work alone. The absence of such an increase for women in the recession period may be because their housework hours are more strongly responsive to employment hours and this is captured in the model.

Net of life-course effects (e.g. presence of children) there is evidence that younger cohorts do less housework. Hours of housework are highest in the 50 to 64 age group for both

30 The full model explains 27.5 per cent of variance when run as an OLS. 
women and men when other relevant factors are controlled, but are particularly high for women in this age group who do 8.6 hours more housework per week than women aged 18-34 years. Lower housework time among the youngest group does not change over the period $^{31}$ which means this is unlikely to indicate a cohort/generational change.

\section{TABLE 4.2 ZERO-INFLATED NEGATIVE BINOMIAL MODEL OF HOUSEWORK HOURS, MARGINAL EFFECTS}

\begin{tabular}{|c|c|c|c|c|c|}
\hline & & $\begin{array}{l}\text { Model } 1 \\
\text { All }\end{array}$ & $\begin{array}{c}\text { Model } 2 \\
\text { All }\end{array}$ & $\begin{array}{l}\text { Model } 3 \\
\text { Men }\end{array}$ & $\begin{array}{l}\text { Model } 4 \\
\text { Women }\end{array}$ \\
\hline Sex (ref. Male) & Female & $10.54 * * *$ & $8.36 * * *$ & & \\
\hline \multirow{2}{*}{ Year (ref. 2007) } & 2011 & 1.22 & 0.30 & $2.06^{* *}$ & -1.29 \\
\hline & 2016 & 0.44 & -1.00 & 0.69 & $-2.78^{*}$ \\
\hline \multirow{3}{*}{ Age (ref. 18-34) } & $35-49$ & & $3.93^{* * *}$ & $2.49 * * *$ & $4.76 * * *$ \\
\hline & $50-64$ & & $5.43^{* * *}$ & $2.99 * * *$ & $8.63^{* * *}$ \\
\hline & $65+$ & & $3.85^{* * *}$ & $2.52^{* *}$ & $5.60 * * *$ \\
\hline \multirow{2}{*}{$\begin{array}{l}\text { Education } \\
\text { (ref. Lower secondary } \\
\text { or less) }\end{array}$} & Upper secondary/PLC & & $-1.73^{* *}$ & $-1.52 *$ & -1.80 \\
\hline & Third-level education & & $-3.34 * * *$ & $-1.86^{*}$ & $-4.58 * * *$ \\
\hline \multirow{3}{*}{$\begin{array}{l}\text { Children } \\
\text { (ref. No child aged 0-18) }\end{array}$} & Children 0-4 & & $7.89 * * *$ & $6.49 * * *$ & $10.98 * * *$ \\
\hline & Children 5-12 & & $6.09 * * *$ & $4.53 * *$ & $10.10 * * *$ \\
\hline & Children 13-18 & & $2.94 * *$ & 1.78 & $5.33 * * *$ \\
\hline \multirow{3}{*}{$\begin{array}{l}\text { Employment } \\
\text { (ref. Employed >40 } \\
\text { hours p.w. }\end{array}$} & No employment & & $5.21 * * *$ & $3.28 * * *$ & $6.04 * * *$ \\
\hline & Employed 1-30 hours & & $3.70 * * *$ & $2.22 *$ & $3.93^{*}$ \\
\hline & Employed 31-40 hours & & 0.89 & 0.94 & -0.10 \\
\hline \multirow{3}{*}{$\begin{array}{l}\text { Partner's employment } \\
\text { (ref. Single) }\end{array}$} & Partner not employed & & 0.659 & $-2.24 * * *$ & $5.87 * * *$ \\
\hline & Partner employed & & $3.27^{* * *}$ & 0.71 & $5.93 * * *$ \\
\hline & Observations & 2,701 & 2,701 & 1,187 & 1,514 \\
\hline
\end{tabular}

Source: Authors' analysis of the European Quality of Life Survey 2007-2016.

Notes: $\quad * p<0.05, * * p<.01, * * * p<0.001$.

Those who do not participate in housework at least once a week are recorded as zero hours. 287 cases have a value of zero. Therefore we again run a zero-inflated negative binomial model. The interaction between education and gender is significant as are the interactions between gender and age of youngest child, between gender and year, and gender and partner's employment status. The interaction between sex and paid employment hours is not significant.

Age of children and presence of a partner in the household increase the amount of time spent on housework, though the effect of children is much less pronounced than in the case of care hours (Table 4.1). It is interesting to note that a partner (whether employed or nonemployed) increases housework for women, whereas for men having a non-employed partner reduces their housework by 2.2 hours per week regardless of their own employment status. These results suggest a persistent gendered division of housework within couples.

31 The interaction between age and year is insignificant. 
Hours of paid employment are associated with housework time for both men and women. Non-employed men do 3.4 hours more housework per week than men in paid employment of more than 40 hours per week. Non-employed women do six hours more housework than women in full-time jobs of more than 40 hours per week. Nevertheless, at each level of paid employment, women do significantly more housework than men as is illustrated in Figure 4.2.

\section{FIGURE 4.2 MODELLED HOUSEWORK TIME FOR MEN AND WOMEN BY EMPLOYMENT HOURS}

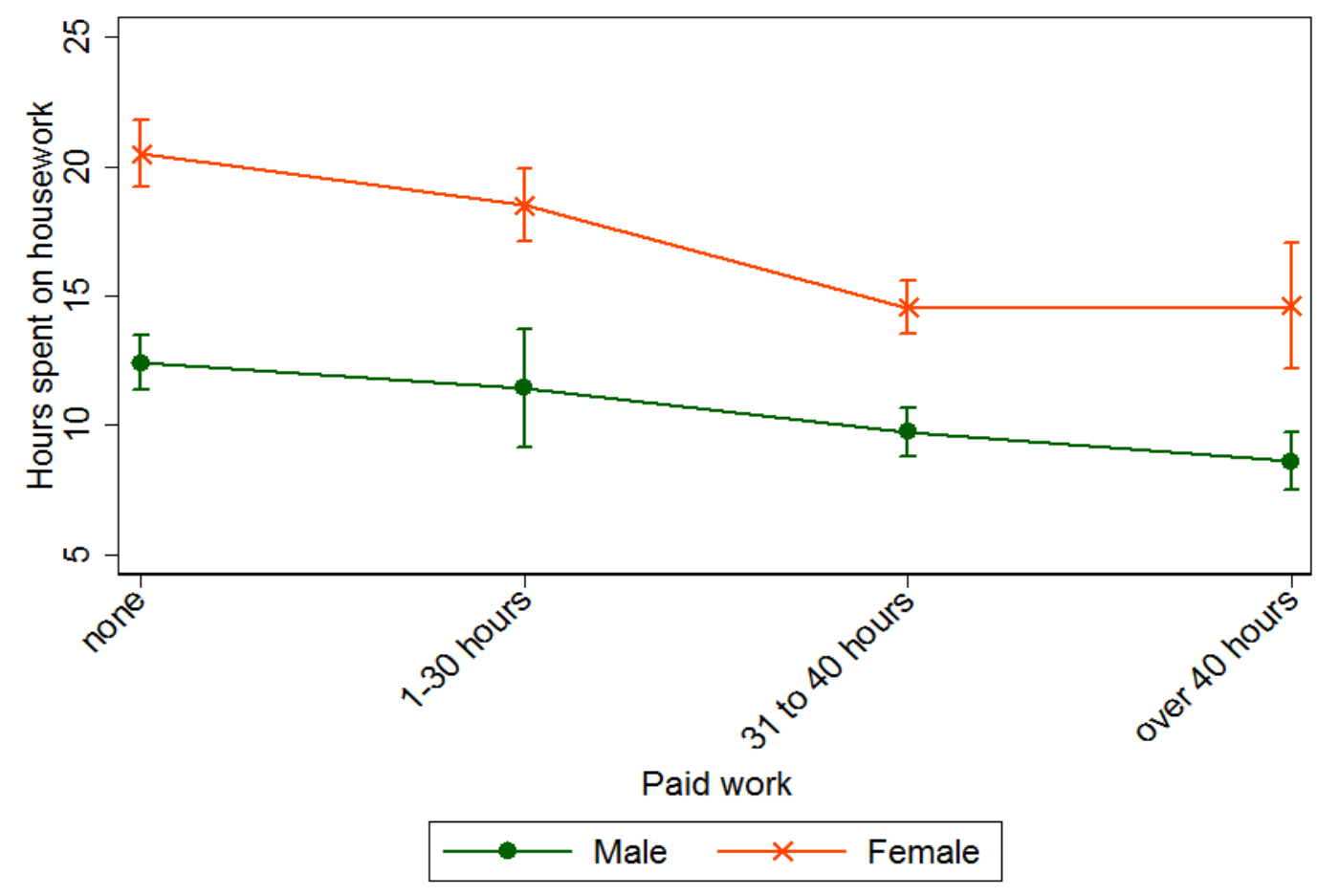

Source: $\quad$ Authors' analysis of the European Quality of Life Survey 2007-2016.

Note: $\quad$ The margins are calculated from a joint model for men and women. The interaction between gender and paid work hours is not significant showing that the gender gap is the same in all categories. All the other variables in Model 2 are controlled.

Finally we see that higher levels of education decrease housework time. This reduction is particularly pronounced among women with third-level education who do an average of 4.6 hours less housework than women with lower secondary or less even after controlling for higher levels of employment and differences in age. This could reflect outsourcing of domestic work by higher income women, or less adherence to traditional gender norms relating to domestic work. 


\subsection{TIME SPENT ON TOTAL UNPAID WORK}

In the final set of models we investigate the factors that are associated with the total unpaid workload variable i.e. caring labour and housework combined (Table 4.3). These largely reproduce the findings of the previous models but are useful to show the difference between groups in total unpaid workload.

Model 1 of Table 4.3 shows that controlling only for year, women spend an average of 21.4 hours more than men on unpaid work. In Model 2, when we hold age, hours of paid work, family structure and education constant, this drops to an average difference between women and men of 15.9 hours per week, which is still large and statistically significant.

TABLE 4.3 ZERO-INFLATED NEGATIVE BINOMIAL MODEL OF UNPAID HOURS, MARGINAL EFFECTS

\begin{tabular}{|c|c|c|c|c|c|}
\hline & & $\begin{array}{c}\text { Model } 1 \\
\text { All }\end{array}$ & $\begin{array}{c}\text { Model } 2 \\
\text { All }\end{array}$ & $\begin{array}{l}\text { Model } 3 \\
\text { Men }\end{array}$ & $\begin{array}{l}\text { Model } 4 \\
\text { Women }\end{array}$ \\
\hline Sex (ref. Male) & Female & $21.39 * * *$ & $15.92 * * *$ & & \\
\hline \multirow{2}{*}{ Year (ref. 2007) } & 2011 & $5.57^{* *}$ & 2.31 & $3.54^{*}$ & 1.81 \\
\hline & 2016 & 2.87 & -3.78 & -0.45 & -5.51 \\
\hline \multirow{3}{*}{ Age (ref. 18-34) } & $35-49$ & & $11.41 * * *$ & $7.14^{* * *}$ & $12.40 * * *$ \\
\hline & $50-64$ & & $9.59 * * *$ & $3.42 *$ & $18.16 * * *$ \\
\hline & $65+$ & & 5.86 & 2.76 & 3.64 \\
\hline \multirow{2}{*}{$\begin{array}{l}\text { Education (ref. Lower } \\
\text { secondary or less) }\end{array}$} & Upper secondary/PLC & & -3.39 & -2.34 & -3.39 \\
\hline & Third-level education & & $-7.68 * *$ & $-4.03 *$ & $-7.80^{*}$ \\
\hline \multirow{3}{*}{$\begin{array}{l}\text { Children (ref. No child } \\
\text { aged } 0-18 \text { ) }\end{array}$} & Children 0-4 & & $46.39 * * *$ & $35.35^{* * *}$ & $59.35^{* * *}$ \\
\hline & Children 5-12 & & $32.47^{* * *}$ & $22.47^{* * *}$ & $47.34 * * *$ \\
\hline & Children 13-18 & & $13.98 * * *$ & $8.47^{* *}$ & $24.40 * * *$ \\
\hline \multirow{3}{*}{$\begin{array}{l}\text { Employment (ref. Paid } \\
\text { work }>40 \text { hours } p / w \text { ) }\end{array}$} & No paid employment & & $10.07^{* * *}$ & $6.21 * * *$ & $19.90 * * *$ \\
\hline & $1-30$ hours $\mathrm{p} / \mathrm{w}$ & & $8.76^{* *}$ & 2.71 & $17.39 * * *$ \\
\hline & 31 to 40 hours $p / w$ & & 0.29 & 1.20 & 4.45 \\
\hline \multirow{3}{*}{$\begin{array}{l}\text { Partner's employment } \\
\text { (ref. Single) }\end{array}$} & Partner not employed & & $5.63^{*}$ & -0.97 & $14.98 * * *$ \\
\hline & Partner employed & & $8.98 * * *$ & 2.93 & $13.93 * * *$ \\
\hline & Observations & & 2,701 & 1,187 & 1,514 \\
\hline
\end{tabular}

Source: Authors' analysis of the European Quality of Life Survey 2007-2016.

Note: $\quad * \mathrm{p}<0.05,{ }^{*} \mathrm{p}<.01,{ }^{* * *} \mathrm{p}<0.001$.

In Model 1 there is a significant increase in unpaid work time of 5.6 hours in 2011 in the period of economic recession. The addition of controls for paid employment time and other 
compositional factors in Model 2 reduces this effect to non-significance. For men (Model 3), an increase in unpaid work is still observed in 2011.

The presence and age of children is very strongly associated with the total unpaid workload, which is not surprising given the scale of caring time and housework for those with younger children noted in the analysis above. As in the housework and care models, the association between hours of unpaid labour and children is considerably stronger for women.

Hours of paid work are also strongly linked to weekly hours of unpaid work. When separate models are estimated for women and men (Models 3 and 4) we see that women's unpaid work hours are much more responsive to their hours of employment than men's unpaid work hours. In fact, men's unpaid work hours do not differ significantly depending on their paid hours. Figure 4.3 shows that women's unpaid work hours are substantially higher than men's within each category of paid work hours, until paid work hours exceed 40 hours per week: among this group there is no gender difference.

For women, having a partner significantly increases their unpaid workload, by 15 hours if the partner is not employed and by 14 hours if the partner is employed. Men's unpaid work hours do not vary between those with and without a partner, nor by partner's employment status. 
FIGURE 4.3 MODELLED HOURS OF TOTAL UNPAID WORK BY GENDER AND PAID EMPLOYMENT

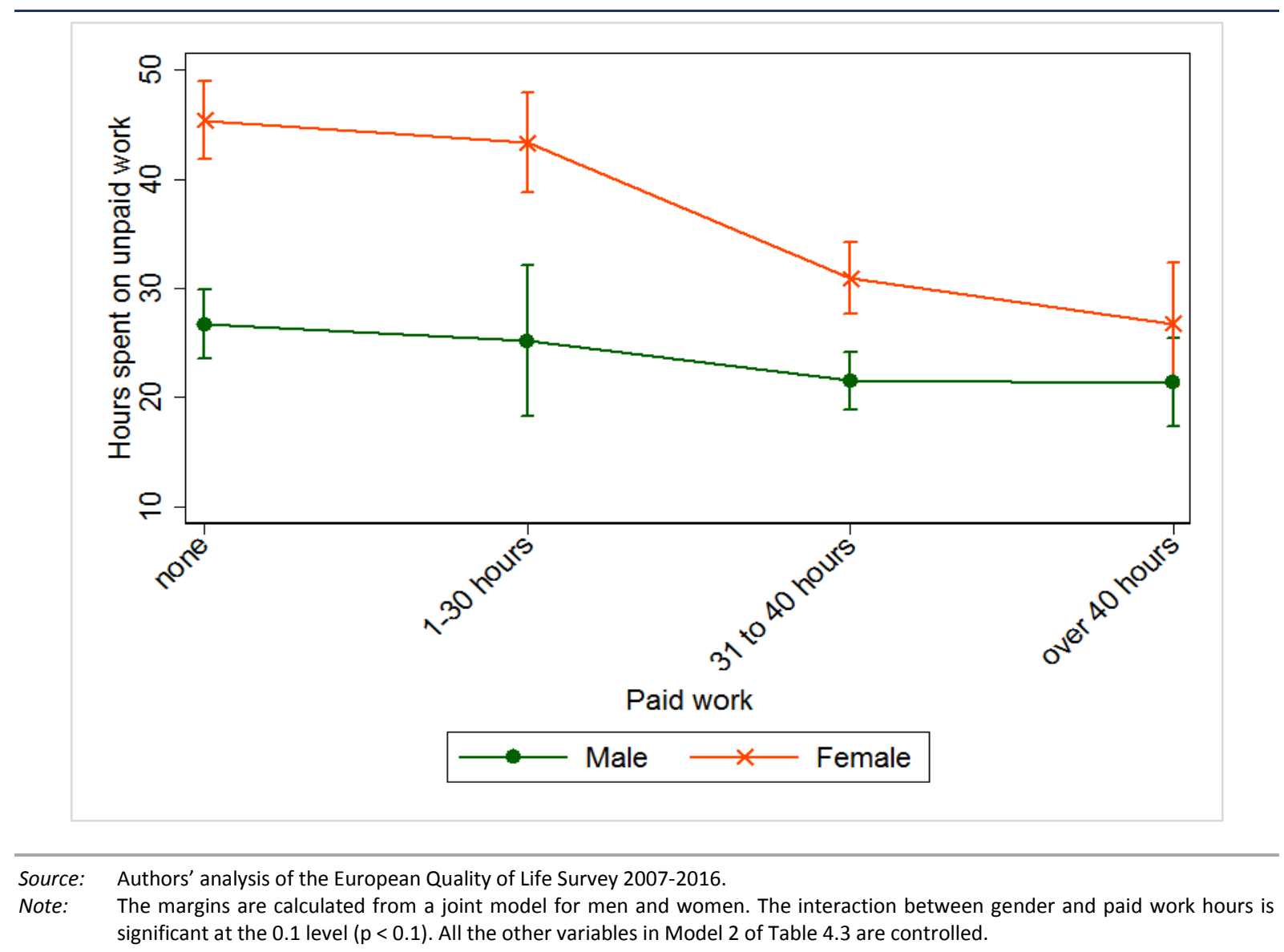

\subsection{SUMMARY}

In this chapter we examine how time spent on caring (adult plus childcare), housework, and total unpaid work in Ireland is influenced by a range of factors; gender, age, presence and age of children, partnership status, employment, education and year. These multiple influences are examined through statistical models, which allow us to examine the effect of each factor net of other characteristics and to compare like with like.

The models confirm the strong influence of gender on the time spent on caring, housework and total unpaid work time. The gender effect cannot be accounted for by differences in paid work hours, so a simple time availability or gender specialisation explanations will not suffice, though they may account for some of the association. Gender role explanations seem better able to account for why men's time on caring and total unpaid care does not alter with their employment status while women's unpaid time is strongly linked to their employment. Men's housework time is related to employment status, though the 
association is weaker than for women. Housework time may be easier to adjust than care time, given that the demand for such work occurs in all households. Our findings about the extent of the overall gender gap and the differential influence of paid work for men and women mirror the findings of McGinnity and Russell (2007) based on time-use data for Ireland.

The presence of young children is the strongest predictor of care time and of total unpaid work time for both men and women. However the effect sizes are even larger for women than men. Interestingly the presence of a partner increases the domestic workload for women but not for men. The data do not contain information on need for care among adults either inside or outside the household. It is possible that the age coefficients in caretime and total unpaid time models are picking up some of this demand. Care time peaks for women aged 35-49 years; housework peaks for men and women in the 50-64 age group. Total unpaid work is highest for women in the 35-49 age group and in the 50-64 age group, while it peaks for men aged 35-49 years. These age results are net of the effect of having younger children.

Education level has no independent impact on hours of care or total unpaid work, but it is associated with housework. Net of employment status, women with the highest education level do almost five hours less housework per week than those with the lowest level of education. This may be due to higher incomes which lead to outsourcing or more egalitarian attitudes about the division of housework - we cannot disentangle these effects with the current data. If higher education was associated with greater sharing of the domestic workload in couples we might expect higher educated men to do more housework. Instead we find that men's housework time also decreases with higher education. Data that contain information on the housework levels of both partners within couples are needed to fully test these hypotheses.

We initially observed an increase in care and total unpaid work between 2007 and 2011 with a subsequent return to 2007 levels in 2016. For women (and overall), this trend could be accounted for by the drop in paid work hours during the recession and other compositional changes. However, the significant rise in men's unpaid work, housework and caring between 2007 and 2011 was not accounted for by changes in paid employment. We 
nevertheless argue that this is a recession effect since the rise was not maintained in 2016. It is possible for example, that falls in income during the recession led to an increase in selfprovisioning of services, for example preparing meals rather than buying take-away or eating out. This change in men's unpaid work did not therefore indicate a longer term trend towards greater gender equality in this domain. Similar patterns have been observed in the paid work domain where a narrowing of the employment gap between men and women in the recession period began to widen again in the recovery (Russell et al., 2017a). 



\section{CHAPTER 5}

\section{Summary and conclusions}

\section{$5.1 \quad$ INTRODUCTION}

In this study we set out to examine the level of unpaid work in Ireland using data from the European Quality of Life Survey (EQLS), which is carried out across Europe every five years, most recently in 2016. We investigate the participation and time committed to both care work (care of children and of elderly/disabled adults) and housework/cooking. The conceptual discussion in Chapter 2 highlights that housework and preparing meals can also be seen as providing care in a broad sense, including for healthy adults. Moreover both sets of activities produce potentially tradeable outputs and can be purchased on the market, and so can be conceived of as work.

The outputs of care work and housework are essential for the well-being of the family and society. The time spent on unpaid activities also has implications for participation and position in the labour market and financial position. The gendered allocation of unpaid work has been identified as a significant source of gender inequalities in employment, pay, poverty and lifetime income (see Chapter 2).

\subsection{EXTENT AND DISTRIBUTION OF CARE WORK}

Care work encompasses care for both children and for older/disabled adults. Demographic change in the form of the ageing population and policy shifts towards greater care in the community for older people and those with disabilities, create a greater demand for informal care. At the same time social and economic changes, such as the greater participation of women in paid employment, and the economic cycle of boom and recession, have implications for the availability of someone within the home to provide for these needs. These societal changes are likely to create new pressures and needs for supports for those providing care. The long-term rise in female employment also has implications for the sharing of care (and other household work) within couples. 
We find that the extent of care work in Ireland is substantial: 45 per cent of women and 29 per cent of men provide care for others on a daily basis (childcare and/or adult care). Involvement in care peaks in the 35 to 49 age group for both sexes, when just over half of men and almost three-quarters of women provide care on a daily basis. We find that 55 per cent of regular carers are in employment: 45 per cent of female carers and 72 per cent of male carers.

Across the whole population the average time spent on care per person is 16 hours per week; 10.6 hours for men and 21.3 hours for women. A much higher proportion of the population is involved regularly in childcare than adult care. Therefore mean childcare hours per person across the whole population are five times as high (13.8 hours per week) as adult care hours (2.7 hours per week).

The time commitments involved are considerably higher if we focus on regular carers i.e. those involved in caring at least once a week. For those providing regular care for their children or grandchildren, the mean number of hours rises to 35.2 hours per week; 42.6 hours for women and 25.2 for men. Among those providing regular care for older/disabled adults the mean weekly time involved is 19.4 hours per week. The gender difference is much narrower among adult carers. Women caring for adults spend an average of 19.8 hours per week, while male carers spend an average of 18.8 hours (this gender difference is not statistically significant).

The models presented in Chapter 4 show that differences in paid employment hours and other relevant characteristics do not fully explain the gender difference in care work. On average, women still provide 7.2 more hours of care per week than men, when these factors are held constant. In addition to gender, the strongest predictors of care time are presence and age of children, and participation in paid employment. For example, the difference in care hours between women in long hours of paid employment (over 40 hours per week) and those not in employment is 13.4 hours per week. Hours of care do not differ by employment status for men, showing that time availability alone is not enough to explain gender differences and that gender role expectations (see Chapter 1) also play a part. We find that there are large gender difference in care hours for the non-employed and those working part-time but that the gap is not significant for men and women working full-time. This 
pattern of results shows an adaptation of unpaid work to paid work hours for women but not for men.

The persistence of gender asymmetries is also evidenced in the effects of partners' employment. Having an employed partner increases care time for women but not for men. Together these results suggest that the traditional division of care work persists within couples.

Even when age of children is controlled for, women aged 35-49 have the longest care hours. This group is likely to encompass the 'sandwich generation', who are caring for older parents as well as children.

\subsection{EXTENT AND DISTRIBUTION OF HOUSEWORK}

Involvement in unpaid housework is more pervasive than care work: 81 per cent of women and 44 per cent of men participate on a daily basis. Those aged 18 to 34 are least likely to participate daily in housework. The average time spent on this work is 14.5 hours per week: just under 20 hours for women and seven hours for men.

The models show that wide gender differences in housework time persist at all levels of paid work hours. The results also show that in addition to being gendered, housework time is strongly associated with age, presence/age of children and employment status. Housework time peaks for those aged 50 to 64 years. In general those aged 35 and older do considerably more housework than the youngest age group. Lower housework time amongst the youngest age group is present in each year of the survey, which suggests that it is not indicative of a cohort/generational change but rather a life-course effect.

Having a partner, whether employed or non-employed, increases housework for women but not for men. All else being equal, women with the highest educational qualifications do less housework. Differences in hours of paid work are already taken into account so there are two potential explanations for this. First, educated women are likely to have more resources and may be better able to outsource this work. Second, more educated women may be more likely to share this work with partners either due to more egalitarian gender role 
attitudes in better educated couples or to the greater bargaining power of the woman (see Chapter 1).

\subsection{CHANGE OVER TIME}

The descriptive figures suggest that participation in unpaid work increased during the recession in 2011, when levels of paid work dropped significantly. This trend was most discernible for childcare and housework among men. This change was also noted in the average time spent on both care and housework. The models show that changes in paid employment hours account for this trend for women but for men, even controlling hours of employment and other relevant factors, there is an increase in unpaid work between 2007 and 2011. By 2016 the figures returned to 2007 levels, which suggests that it is a recessionary effect rather than a structural ${ }^{32}$ or long-term change in men's time in unpaid work. We speculate that this effect is linked to a rise in self-provisioning in response to falls in household income or changes in job demands that are not captured fully by hours.

\section{$5.5 \quad$ INTERNATIONAL COMPARISONS}

A comparison to other countries across the EU28 (in 2016) shows that Irish respondents record some of the highest levels of unpaid work in Europe. Even when we hold relevant compositional factors constant, including paid work hours, family structure and education, women and men in Ireland report the third highest level of unpaid work in the EU.

The gender gap in unpaid work was universal across all 28 countries; however, it varied in size from 7.2 hours (in Sweden) to 20.2 hours in Greece. Ireland has the seventh highest gender gap in paid hours across the EU28.

Exploring the factors behind these remaining country differences is beyond the scope of the current study. The literature on welfare and employment regimes suggests that differences in the institutional settings will play a significant role in shaping these patterns as well as differences in the prevailing attitudinal or cultural context (see Chapter 1). It is significant that the gender gap in unpaid work is narrowest in the Scandinavian countries where

32 The pattern of change over time is inconsistent with a rising demand due to population ageing but the time-period examined may be too short to observe such a trend. 
policies have attempted to promote gender equality in both paid work and unpaid work. The literature suggests these countries are closest to the dual earner/dual caregiver model.

\subsection{LIMITATIONS AND IMPLICATIONS FOR DATA COLLECTION}

Measuring the extent of care or unpaid work is challenging for two reasons. First, difficulties can arise in defining what should be included and excluded in measures of care. Second, in the case of self-reported data of the type used in this study, it is challenging for respondents to recall and calculate how much time they spend on caring and housework activities. Unpaid activities of this sort lack the clear time schedule boundaries or contractual obligations that apply to paid employment, making it more difficult for individuals to estimate. Qualitative research shows that accounts of the time spent on unpaid work and its division within couples may also be influenced by ideologies of sharing within the couple (Hochschild, 1990). There is some empirical evidence that unpaid hours are overestimated in self-reports (Shelton and John, 1996), which suggests that results on hours may be upperbound estimates. Nevertheless, consistently measured self-reported time estimates allow for important comparisons between groups, over time, and across countries. Results on daily involvement are less likely to be affected by errors of recall or calculation.

While the EQLS provides a much needed update on caring and housework, there are nevertheless limits to the data relevant to the current study. We consider three important limitations below.

First, the information on who is being cared for is for the most part limited to children, grandchildren and relatives who are older or have a disability. The latest survey in 2016 provided a more detailed breakdown of the recipients of care; however the small sample size within these groups means that the scope for further exploration of the beneficiaries is limited.

Second, only one respondent is sampled per household so questions about how caring and household tasks are negotiated within couples, which has been the central focus of much theoretical discussion, cannot be addressed. 
Third, as mentioned above, self-reported estimates of time spent on activities in response to survey questions are prone to errors of recall and calculation. The EQLS follows best practice in the framing of these questions and in checking outliers; however, the literature suggests that the estimates from time-use surveys are more reliable. A comparison of mean time estimates in the EQLS and the Time-Use Survey 2005 show that mean figures for housework were very close, but the means for care are significantly higher in the EQLS. This may suggest that direct survey questions on activity times overestimate care time compared to time-use diary methods. However, there are also other differences including the timing of the surveys and the nature of the samples that could lead to variation in the results.

The development of time-use surveys have been pivotal in progressing knowledge and measurement of these non-market activities. Many European countries, the US and Australia collect national time-use survey data on a regular basis and data from 30 countries have been harmonised for international research. ${ }^{33}$ Ireland is an outlier in having collected only one such survey that is representative of the full population in 2005 , and even then, the sample size collected was small. A new time-use survey is long overdue and would provide much valuable information, not only on unpaid work but a wide range of other issues including leisure time, sports/physical activity, voluntary activities, travel time, energy usage and technology use, to name but a few.

\subsection{IMPLICATIONS FOR ECONOMIC EVALUATIONS OF CARE}

Previous international research has attempted to estimate the value of care and other housework (or 'non-market production') and in some cases to add these figures to the National Accounts (European Commission, 2003; Folbre 2015). This approach formed part of a broader debate in Europe around improving and broadening measures of social progress and economic performance beyond measures of GDP (Stiglitz et al., 2009). In Ireland, Hanly and Sheerin (2017) estimate that the value of informal adult care is between $€ 2.1$ billion and $€ 5.5$ billion depending on the valuation method used. They also note that both estimates are significantly higher than the budget for formal care, both long-term care (€988 million) and formal community based packages (€320 million) (ibid. p.359). 
Given that adult care represents only a fraction of the total unpaid work measured here, the valuation of total unpaid work will be a multiple of the figure produced by Hanly and Sheerin (2017). Recognition of the value of such work depends first on its measurement. The current research contributes to that first step. Valuation methods could be applied to these estimates as a future research exercise.

\subsection{POLICY IMPLICATIONS}

The findings we present measure behaviour and we cannot necessarily deduce preferences from behaviour, as decisions around caring are made within the constraints of the existing social and economic context. This context includes policy arrangements, employer behaviour and prevailing social attitudes around gender (the gender regime). The policy environment influences the availability of alternative care options through State provision or market provision, and affects the costs of providing care/housework informally within the household. These costs include short- and longer-term financial and labour market consequences.

The Irish welfare state has been characterised as a Liberal 'modified male breadwinner' system. In Liberal welfare states the market tends to play a larger role in service provision. The 'modified' element captures the pattern of growing female participation in the labour market, and the developments in policy that have facilitated this and changing gender role attitudes. Yet these changes are combined with a lagged policy response in other areas and persisting gender inequality in paid and unpaid work - gender inequality in unpaid work being clearly demonstrated in this report. These trends open new contradictions and pressures on working and family life, especially for women.

In order to move to a situation where caring is both valued and more equally shared between men and women, in other words closer to the dual carer/dual caregiver model or universal caregiver models, there is a need for changes in social and employment policies that support carers, facilitate the combination of care and employment and at the same time encourage greater male participation in care. 
While there have been significant policy changes in relation to leave schemes for care of children/dependent adults and in the provision of childcare supports (see Chapter 1), State support for caring remains relatively low compared to other European countries. This means that both women and men in Ireland are combining high levels of unpaid work and paid work. Greater recognition of this is needed in the organisation of employment through, for example, greater access to flexible work practices and greater access to paid leave schemes for men. In Ireland, while workers can request reduced hours for care responsibilities, there is no statutory entitlement to this as there is in several European countries. Paid leave for fathers has recently been introduced in Ireland but is limited to two weeks. International experience suggests that access to paid parental leave for fathers that is not transferable is crucial for increasing uptake among men (Blum et al., 2018) and is argued to be instrumental in leading to a less gendered division of care roles in Nordic countries (Sullivan et al., 2009).

Take-up of reduced hours options remains strongly gendered in Ireland (Russell et al., 2017b; Russell et al., 2014). Changes in organisational culture are needed to normalise parttime work among men, to reduce long hours work culture and to reduce the penalties attached to part-time work. This would also facilitate a shift towards more gender equality in paid and unpaid work. This change may also be consistent with many men's preferences. Long working hours are strongly linked to work-life conflict for both men and women (McGinnity and Russell, 2015). Moreover, research comparing actual and preferred work among couples also found that in Ireland, as in many other European countries, the male breadwinner arrangement (male employed/female not employed) was much more common than preferred: 29 per cent of working age couples had this arrangement but it was preferred by only 9 per cent. In contrast, dual earnings and modified male breadwinner and dual part-time arrangements were less common than preferred (Steiber and Haas, 2018).

Service provision also needs to recognise the reality that over half of those providing care are in employment. For example, is the timetabling of services compatible with paid employment schedules? Similarly, income supports need to be structured to allow individuals with care responsibilities to remain in employment if they choose to do so, for example through appropriate earnings disregards. Exits from employment are more costly to the individual and the State. 
Supports for full-time carers are predominantly means-tested, though the universal child benefit has in the past been conceptualised by government as childcare support, and designated an important part of the 'childcare strategy' (McGinnity et al., 2013). Tax allowances and sharing elements between partners are also seen as de facto support for full-time carers, even though they are contingent on partnership status rather caring. It is beyond the scope of the current report to consider the adequacy of welfare benefits for fulltime carers. However, ESRI poverty research consistently shows that households with one or more adults with a disability and lone parents have some of the highest poverty levels in the State (Watson et al., 2016; Russell et al., 2010). The levels of persistent deprivation among these two groups is higher in Ireland (and the UK) compared to elsewhere in Europe (Watson et al., 2018). ${ }^{34}$ Moreover, a recent study found that policy changes aimed at increasing employment among lone parents had resulted in a decline in income among employed lone parents (Regan et al., 2018).

Recent research has suggested that there is a high level of unmet need for access to formal care supports such as home-care packages and home help (Wren et al., 2017; Grotti et al., 2019) and for formal childcare supports (Grotti et al., 2019). Unmet care needs are particularly pronounced for low income households who cannot afford to source these services in the private market. Therefore a shift away from a Liberal modified breadwinner system to a system within increased care provision by the State would therefore reduce social class inequalities as well as gender inequalities. This was demonstrated by the ECCE scheme where free pre-school places increased participation most by households that were disadvantaged in terms of social class and income (Murray et al., 2016).

The framing of care and household work and the assumptions made about the appropriate gendered allocation of such tasks are codified not only in individual policies but also in the Irish Constitution. The Oireachtas is currently considering replacement wording for Article 41.2 of the Constitution. This report presents evidence on the extent of caring and other unpaid work in the household, which provides an insight into the scale of the societal contribution, even if only in the narrow quantitative sense. It also highlights some of the complexities involved in defining and measuring care and unpaid work generally. Caring and

34 The study compares the experience of different groups across $11 \mathrm{EU}$ countries. 
other household work can be defined in terms of who is in receipt of the care, or in terms of the nature of the outputs themselves. Such issues of definition may become important in interpreting the reach of a constitutional amendment.

The study also provides up-to-date evidence on who is carrying out unpaid work and the time commitment involved; this is relevant in terms of reference to 'carers' in the Constitution. For example, we find that over half ( 55 per cent) of those providing care on a daily basis are also in employment; therefore, a definition based on providing full-time care would exclude a great many of those providing care and substantial proportion of the care provided.

Bodies representing carers, such as the Family Carers Association, as well as organisations engaged in promoting equality in society such as the National Women's Council and the Irish Human Rights and Equality Commission have acknowledged the symbolic importance of recognising the value of care work in a gender neutral way within the Constitution. ${ }^{35}$ The scale of care/housework endeavour highlighted in the study suggests that the value and distribution of this work is an important question for Irish society to consider.

35 Oireachtas Joint Committee on Justice and Equality (2018). 


\section{REFERENCES}

Allen, S. and A. Hawkins (1999). 'Maternal Gatekeeping: Mothers' Beliefs and Behaviors that Inhibit Greater Involvement in Family Work', Journal of Marriage and Family, Vol. 61, pp. 199-212.

Becker, G. (1991). A treatise on the Family. Cambridge, Mass: Harvard University Press.

Bergin, A., E. Kelly and S. McGuinness (2012). 'Explaining changes in earnings and labour costs during the recession', ESRI Renewal Series, Paper 9. Dublin: Economic and Social Research Institute.

Bettio, F. and J. Plantenga (2004). 'Comparing care regimes in Europe', Feminist Economics, 10(1), 85-113.

Bettio, F. and J. Plantenga (2008). 'Care regimes and the European employment rate', in Institutions for Social Well-Being (pp. 152-175). Palgrave Macmillan, London.

Bianchi, S., M. Milkie, L. Sayer and J. Robinson (2000). 'Is Anyone Doing the Housework? Trends in the Gender Division of Household Labor', Social Forces, Vol. 79, pp. 191-228.

Bianchi, S.M., J.P. Robinson and M.A. Milkie (2006). Changing rhythms of American family life. New York: Russell Sage Foundation.

Bianchi, S. and M. Milkie (2010). 'Work and Family Research in the First Decade of the $21^{\text {st }}$ Century', Journal of Marriage and Family 72:705-725.

Bittman, M., P. England, L. Sayer, N. Folbre and G. Matheson (2003). 'When Does Gender Trump Money? Bargaining and Time in Household Work', American Journal of Sociology, Vol. 109, No. 1.

Blau, F.D., M.A. Ferber and A.E. Winkler (1992). 'The Economics of Women', Men and Work, Englewood Cliffs.

Blau, F. and L. Kahn (2000). 'Gender differences in pay', Journal of Economic Perspectives. Vol 14. No 4.

Blau, F.D. and L. Kahn (2013). 'Female Labor Supply: Why Is the United States Falling Behind?', American Economic Review: Papers \& Proceedings 2013, 103(3): 251-256.

Blossfeld, H.P. and S. Drobnic (Eds.) (2001). Careers of couples in contemporary society: From male breadwinner to dual-earner families: From male breadwinner to dual-earner families. OUP Oxford.

Blum, S., A. Koslowski, A. Macht and P. Moss (2018). International Review of Leave Policies and Related Research 2018, International Network on Leave Policies and Research. 
Bolin, K., B. Lindgren and P. Lundborg (2008). 'Your next of kin or your own career?: Caring and working among the 50+ of Europe', Journal of health economics, 27(3), pp.718-738.

Breen, R. and L. Cooke (2005). 'The Persistence of the Gendered Division of Domestic Labour', European Sociological Review, Vol. 21, No. 1.

Brines, J. (1994). 'Economic Dependency, Gender and the Division of Labor at Home', American Journal of Sociology, Vol. 100, pp. 652-688.

Cameron, A.C. and P.K. Trivedi (2013). Regression analysis of count data, Vol. 53. Cambridge University Press.

Carmichael, F., S. Charles and C. Hulme (2010). 'Who will care? Employment participation and willingness to supply informal care', Journal of Health Economics, 29(1), pp.182-190.

Chesley, N. and S. Flood (2017). 'Signs of change? At-Home and breadwinner parents' housework and Child-Care time', Journal of Marriage and Family, 79(2), pp.511-534.

Ciccia, R. and I. Bleijenbergh (2014). 'After the Male Breadwinner Model? Childcare Services and the Division of Labor in European Countries', Social Politics, 21(1), 50-79.

Cooke, L.P. (2014). 'Gendered parenthood penalties and premiums across the earnings distribution in Australia, the United Kingdom, and the United States', European Sociological Review, 30(3), pp.360-372.

Correll, S.J., S. Benard and I. Paik (2007). 'Getting a job: Is there a motherhood penalty?', American journal of sociology, 112(5), pp.1297-1338.

Crompton, R. (Ed.) (1999). Restructuring Gender Relations and Employment: The Decline of the Male Breadwinner. Oxford: Oxford University Press.

Daly, M. (1996). Social Security, Gender and Equality in the European Union. Office for Official Publications of the European Communities.

Daly, M. (2000). The Gender Division of Welfare: The Impact of the British and German Welfare States, Cambridge: Cambridge University Press.

Daly, M. (2011). 'What adult worker model? A critical look at recent social policy reform in Europe from a gender and family perspective', Social Politics, 18(1), 1-23.

Department of Employment Affairs and Social Protection (n.d.). 2016 Annual report. Statistical Information on Social Welfare Services. www.welfare.ie/en/pdf/DEASP_Annual_Statistics_Report_2016.pdf.

Department of Employment Affairs and Social Protection (n.d.). 2017 Annual report. Statistical Information on Social Welfare Services. www.welfare.ie/en/Pages/Annual-SWS-Statistical-InformationReport.aspx. 
Department of Health (2014). Primary Care: A New Direction, Dublin: Stationery Office.

Doorley, K. (2018). 'Taxation, Work and Gender Equality in Ireland'. IZA Discussion Paper No. 11495. Available at SSRN: https://papers.ssrn.com/sol3/papers.cfm?abstract_id=3177369.

Duncan and Edwards (1997). 'Lone Mothers, Paid Work and Gendered Moral Rationalities', Feminist Economics, 3(2), 29-61.

England, P. (2006). 'Toward gender equality: Progress and bottlenecks', The declining significance of gender, 63, pp.245-265.

Esping-Andersen (1990). The three worlds of welfare capitalism. Cambridge: Polity Press.

Esping-Andersen (2009). The incomplete revolution: adapting to women's new roles. Cambridge: Polity Press.

Eurofound (2017). ‘European Quality of Life Survey 2016: Quality of Life, Quality of Public Services, and Quality of Society'.

European Commission (2003). Household Production and Consumption: Proposal for a Methodology of Household Satellite Accounts, Luxembourg: Office for Official Publications of the European Communities.

Fahey, T. (1992). 'Housework, the household economy and economic development in Ireland since the 1920s', Irish Journal of Sociology, 2(1), 42-69.

Family Carers Ireland (2017). Balancing Work and Care: International Challenges and Irish Perspectives.

Ferrant, G., L.M. Pesando and K. Nowacka (2014). 'Unpaid Care Work: The missing link in the analysis of gender gaps in labour outcomes', OECD Development Centre. www.oecd.org/dev/developmentgender/Unpaid_care_work. pdf. Accessed April, 20, 2016.

Ferrera, M. (1996). 'The Southern Model of Welfare in Social Europe', Journal of European Social Policy, 6 (1): 17-37.

Fine-Davis, M. (2016). Changing gender roles and attitudes to family formation in Ireland. Manchester: Manchester University Press.

Fisher, K., J. Gershuny and A. Gauthier (2012). Multinational time use study: user's guide and documentation. Centre for Time Use Research.

Folbre, N. and M. Bittman (2004). Family time: The social organization of care (Vol. 2). Psychology Press.

Folbre, N. (2006). 'Measuring care: Gender, empowerment, and the care economy', Journal of human development, 7(2), 183-199. 
Folbre, N. (2015). Valuing Non-Market Work. Background think piece for Human Development Report. UNDP Human Development Report Office, Think Piece.

Fraser, N. (1994). 'After the family wage: gender equity and the welfare state', Political Theory, 44(4), 591-618.

Gannon, B. and B. Davin (2010). 'Use of formal and informal care services among older people in Ireland and France', The European Journal of Health Economics, 11(5), 499-511.

Geist, C. and P.N. Cohen (2011). 'Headed toward equality? Housework change in comparative perspective', Journal of Marriage and Family, 73(4), 832844.

Gershuny, J., M. Bittman and J. Brice (2005). 'Exit, Voice and Suffering: Do Couples Adapt to Changing Employment Patterns?', Journal of Marriage and Family, Vol. 67 (August): pp. 656-665.

Gershuny, J. (2018). 'Gender Symmetry, Gender Convergence and Historical Work-time Invariance in 24 Countries', Centre for Time-Use Research Working Paper, University of Oxford.

González, M. (2006). 'Balancing Employment and Family Responsibilities in Southern Europe: Trends and Challenges for Social Policy Reform', Revue française des affaires sociales, 189-214.

Gornick, J.C. and M.K. Meyers (Ed.) (2009). Gender Equality: Transforming Family Divisions of Labor. New York: Verso.

Gregory, M. (2010). 'Assessing Unequal Treatment: Gender and Pay', in Bond, L., F. McGinnity and H. Russell (Eds.) Making Equality Count: Irish and International Research Measuring Equality and Discrimination. Dublin: Liffey Press.

Grotti, R., B Maître and D. Watson (2019). Technical Paper on Access to Care Services in Ireland, Social Inclusion Technical Paper No. 9, Dublin: Department of Social Protection.

Gupta, S. (2007). 'Autonomy, dependence, or display? The relationship between married women's earnings and housework', Journal of Marriage and Family, 69(2), pp.399-417.

Hakim, C. (2002). 'Lifestyle preferences as determinants of women's differentiated labor market careers', Work and occupations, 29(4), pp.428-459.

Hanly, P. and C. Sheerin (2017). 'Valuing Informal Care in Ireland: Beyond the Traditional Production Boundary', The Economic and Social Review, 48(3, Autumn), 337-364. 
He, D. and P. McHenry (2016). 'Does formal employment reduce informal caregiving?', Health economics, 25(7), pp.829-843.

Heger, D. (2014). Work and Well-Being of Informal Caregivers in Europe. Ruhr Economic Paper No. 512 Available at https://ssrn.com/abstract=2562367 http://dx.doi.org/10.2139/ssrn.2562367.

Hochschild, A. (1990). The Second Shift. London: Piatkus.

Hook, J. (2006). 'Care in Context: Men's Unpaid Work in 20 Countries, 19652003', American Sociological Review, Vol. 71, pp. 639-660.

Hoyer, S. and N. Reich (2017). Leave and financial support for family caregivers in EU member states. Observatory for Sociopolitical Developments in Europe.

Indecon (2017). 'Indecon Independent Review of the Amendments to the Oneparent Family Payment since January 2012' Presented to: Department of Employment Affairs and Social Protection.

Kalleberg, A.L. and R.A. Rosenfeld (1990). 'Work in the Family and in the Labor Market: A Cross-National, Reciprocal Analysis', Journal of Marriage and the Family, Vol. 52, pp. 331-346.

Kelly, E., G. Kingston, H. Russell and F. McGinnity (2015). 'The equality impact of the unemployment crisis', Journal of the Statistical and Social Inquiry Statistical Society of Ireland, Vol.44, 2014-5, pp.71-85.

King, D. and L. Pickard (2013). 'When is a carer's employment at risk? Longitudinal analysis of unpaid care and employment in midlife in England', Health \& Social Care in the Community, 21(3), 303-314.

Leira, A. and C. Saraceno (2002). 'Care: actors, relationships and contexts', in Hobson, B., J. Lewis, and B. Siim (Eds.), Contested Concepts in Gender and Social Politics. Cheltenham: Edward Elgar, 55-83.

Lewis, J. (1992). 'Gender and the development of welfare regimes', Journal of European Social Policy, 2(3), 159-73.

Lewis, J. and S. Giullari (2005). 'The adult worker model family, gender equality and care: the search for new policy principles and the possibilities and problems of a capabilities approach', Economy and Society, 34, 76-104.

Long, J.S. and J. Freese (2006). Regression models for categorical dependent variables using Stata. Stata press.

Lynch, K. (1989). 'Solidary labour: its nature and marginalisation', The Sociological Review, 37(1), 1-14.

Lynch, K. and M. Lyons (2008). 'The gendered order of caring', in Barry, U. (Ed.). Where are we now?: new feminist perspectives on women in contemporary Ireland. Tasc at New Island Press. 
Maître, B., H. Russell and C.T. Whelan (2014). 'Trends in Economic Stress and the Great Recession in Ireland - An Analysis of the CSO Survey on Living and Income Conditions', Social Inclusion Technical Paper No. 5, Dublin: Department of Social Protection.

Marini, M.M. and B.A. Shelton (1993). 'Measuring household work: Recent experience in the United States', Social Science Research, 22(4), 361-382.

McGinnity, F., H. Russell, J. Williams and S. Blackwell (2005). Time Use in Ireland, 2005: Survey Report. Dublin: ESRI and Department of Justice, Equality and Law Reform.

McGinnity, F. and H. Russell (2007). 'Work Rich, Time Poor? Time Use of Men and Women in Ireland', The Economic and Social Review, Vol. 38, No. 3.

McGinnity, F. and H. Russell (2008). Gender Inequalities in Time Use: The Distribution of Caring, Housework and Employment Among Women and Men in Ireland. Dublin: Equality Authority/ESRI.

McGinnity, F., A. Murray and S. McNally (2013). Mothers' Return to Work and Childcare Choices for Infants in Ireland. Dublin: Stationery Office.

McGinnity, F. and H. Russell (2015). 'Work-life balance, working conditions and the Great Recession', in The changing worlds and workplaces of capitalism (pp. 201-220). Palgrave Macmillan, London.

McGuinness, S., E. Kelly, T. Callan and P.J. O'Connell (2009). The gender wage gap in Ireland: Evidence from the National Employment Survey 2003. Dublin: Equality Authority/ESRI.

Michaud, P.C., A. Heitmueller and Z. Nazarov (2010). 'A dynamic analysis of informal care and employment in England', Labour Economics, 17(3), pp.455-465.

Morris, L. (1995). Social Divisions: Economic Decline and Social Structural Change. London: UCL Press.

Murphy, M. (2011). 'Making Ireland a caring and equal society', Studies: An Irish Quarterly Review, 100(397), 43-53.

Murray, A., F. McGinnity and H. Russell (2016). 'Inequalities in Access to Early Care and Education in Ireland', in Williams, J., E. Nixon, E. Smyth and D. Watson (Eds.) Cherishing all the Children Equally? Cork: Oak Tree Press.

Nizalova, O. (2012). 'The wage elasticity of informal care supply: Evidence from the health and retirement study', Southern Economic Journal, 79(2), pp.350-366.

Oakley, A. (1974). Woman's work: The housewife, past and present. Vintage.

OECD (2017). OECD Family Database Charts PF3.4.B and PF3.4.C, Available: www.oecd.org/els/family/database.htm (Updated 27.08.2017). 
Oireachtas Joint Committee on Justice and Equality (2018). Report on prelegislative scrutiny of the General Scheme of the 38th Amendment of the Constitution (Role of Women) Bill. Dublin: Houses of the Oireachtas.

Orloff, A.S. (1993). 'Gender and the social rights of citizenship: The comparative analysis of gender relations and welfare state', American Sociological Review 58(3): 303-328.

O'Sullivan, S. (2007). 'Gender and attitudes to women's employment: 19882002', in Hilliard, B. and M. Nic Ghiolla Phádraig (Eds.), Changing Ireland in Comparative Perspective. Liffey Press.

Pepin, J.R., L.C. Sayer and L.M. Casper (2018). 'Marital Status and Mothers' Time Use: Childcare, Housework, Leisure, and Sleep', Demography, 55(1), pp.107-133.

Pfau-Effinger, B. (1998). 'Gender Cultures and the Gender Arrangement - A Theoretical Framework for Cross-National Gender Research', Innovation: The European Journal of Social Sciences, Vol. 11, Issue 2.

Pfau-Effinger, B. (2004). Development of Culture, Welfare States and Women's Employment in Europe. Aldershot: Ashgate.

Regan, M., C. Keane and J.R. Walsh (2018). Lone-Parent Incomes and Work Incentives. ESRI Budget Perspectives 2019, Paper 1, ESRI.

Robinson, J. and G. Godbey (2010). Time for life: The surprising ways Americans use their time. Penn State Press.

Russell, H., P.J. O'Connell and F. McGinnity (2009a). 'The impact of flexible working arrangements on work-life conflict and work pressure in Ireland', Gender, Work \& Organization, 16(1), 73-97.

Russell, H., F. McGinnity, T. Callan and C. Keane (2009b). A Woman's Place? Female Participation in the Irish Labour Market. Dublin: Equality Authority/ESRI.

Russell, H., B. Maître and B. Nolan (2010). 'Monitoring poverty trends in Ireland 2004-2007: key issues for children, people of working age and older people', Economic and Social Research Institute (ESRI) Research Series.

Russell, H., F. McGinnity and G. Kingston (2014). Gender and the Quality of Work: From boom to recession. Dublin: Equality Authority/ESRI.

Russell, H., F. McGinnity and P.J. O'Connell (2017). 'Gender Equality in the Irish Labour Market 1966-2016: Unfinished Business?', The Economic and Social Review. 48 (4).

Russell, H., E. Smyth, S. McCoy, R. Grotti, D. Watson and O. Kenny (2017b). A study of gender in senior civil service positions in Ireland. Dublin ESRI and Department of Justice and Equality, 
Russell, H., F. McGinnity, É. Fahey and O. Kenny (2018). Maternal employment and the cost of childcare In Ireland. Research Series No. 73. Dublin: ESRI.

Saraceno and Keck (2011). 'Towards an integrated approach for the analysis of gender equity in policies supporting paid work and care responsibilities', Demographic Research, Vol. 25, pp. 371-406.

Sarasa, S. (2007). 'Do welfare benefits affect women's choices of adult care giving?', European Sociological Review, 24(1), 37-51.

Savage, M., T. Callan, B. Nolan and B. Colgan (2015). The Great Recession, Austerity and Inequality: Evidence from Ireland, ESRI Working Paper No. 499, April 2015.

Sayer, L., S. Bianchi and J. Robinson (2004). 'Are Parents Investing Less Time in Children? Trends in Others' and Fathers' Time with Children', American Journal of Sociology 110(1):1-43.

Sayer, L.C. (2005). 'Gender, time and inequality: Trends in women's and men's paid work, unpaid work and free time', Social forces, 84(1), 285-303.

Schwartz, C.R. and R.D. Mare (2005). 'Trends in educational assortative marriage from 1940 to 2003', Demography, 42(4), 621-646.

Shelton, B.A. and D. John (1996). 'The Division of Household Labor', Annual Review of Sociology, Vol. 22, pp. 299-322.

Steiber, N. and B. Haas (2018). 'Too much or too little work? Couples' actual and preferred employment patterns and work hours mismatches in Europe', Zeitschrift fur Damilienforschung, 30 Jahrg., Journal of Family Research, pp269-292.

Stiglitz, J.E., A. Sen and J.P. Fitoussi (2009). Report by the Commission on the Measurement of Economic Performance and Social Progress. https://ec.europa.eu/eurostat/documents/118025/118123/Fitoussi+Co mmission+report.

Sullivan, O., S. Coltrane, L. McAnnally and E. Altintas (2009). 'Father-friendly policies and time-use data in a cross-national context: Potential and prospects for future research', The Annals of the American Academy of Political and Social Science, 624(1), pp.234-254.

Sullivan, O., J. Gershuny and J.P. Robinson (2018). 'Stalled or Uneven Gender Revolution? A Long-Term Processual Framework for Understanding Why Change Is Slow', Journal of Family Theory \& Review, 10(1), pp.263-279.

Watson, D., B. Maître, C.T. Whelan and H. Russell (2016). Social Risk and Social Class Patterns in Poverty and Quality of Life in Ireland, 2004-2013. Department of Social Protection.

Watson, D., B. Maître, R. Grotti and C.T. Whelan (2018). 'Poverty Dynamics of Social Risk Groups in the EU: an analysis of the EU Statistics on Income 
and Living Conditions, 2005 to 2014', Economic and Social Research Institute (ESRI) Research Series.

West, C. and D. Zimmerman (1987). 'Doing Gender', Gender and Society, Vol. 1, No. 2, pp.125-151.

Wren, M, C. Keegan, B. Walsh, A. Bergin, J. Eighan, A. Brick, S. Connolly, D. Watson and J. Banks (2017). Projections of Demand for Healthcare in Ireland, 2015-2030: First Report From The Hippocrates Model, Dublin: ESRI. 



\section{APPENDIX}

In Table A3.1 we compare the employment rates (percentage of population employed) in the European Quality of Life Survey sample to those reported in the Quarterly National Household Survey for the relevant year.

We would expect the two sources to differ because they use different definitions of employment - the EQLS uses self-defined employment status whereas the QNHS uses the ILO definition (i.e. anyone recording one hour or more of paid work is counted as employed). Self-defined main status will tend to produce a lower employment rate for women and younger people, who combine employment with another status, for example study or care. There is also a lower age cut-off for the QNHS figures. Excluding those aged 15-17 years from the QNHS would likely make the employment rate even higher for that source.

Comparing EQLS figures pooled across the four waves and the QNHS employment rates for the same year we see that the estimate is 5.5 percentage points lower for men and 8.7 percentage point lower for women. The gap between the two sources is particularly wide for women in 2016 and 2007 and for men in 2003. While we expect differences between the two sources, the divergent trend between 2011 and 2016 for women means that we should treat the 2016 figure with some caution.

TABLE A3.1 EMPLOYMENT RATES BY GENDER OVER TIME (IRELAND 2003-2016)

\begin{tabular}{|l|c|c|c|c|}
\hline & \multicolumn{2}{|c|}{$\begin{array}{c}\text { \% Employed in EQLS Survey } \\
\text { (18 and over) }\end{array}$} & \multicolumn{2}{c}{$\begin{array}{c}\text { \% Employed in QNHS survey } \\
\text { (15 and over) }\end{array}$} \\
\hline & Male & Female & Male & Female \\
\hline $\mathbf{2 0 0 3}$ & $60.1 \%$ & $41.9 \%$ & $70.3 \%$ & $49.8 \%$ \\
\hline $\mathbf{2 0 1 1}$ & $68.5 \%$ & $42.1 \%$ & $72.6 \%$ & $54.2 \%$ \\
\hline $\mathbf{2 0 1 6}$ & $51.0 \%$ & $45.7 \%$ & $57.0 \%$ & $48.1 \%$ \\
\hline All & $61.1 \%$ & $38.8 \%$ & $62.8 \%$ & $51.4 \%$ \\
\hline Base N & $60.1 \%$ & $42.1 \%$ & $65.54 \%$ & $50.8 \%$ \\
\hline
\end{tabular}

Base N

1,990

2,062

Source: Authors' analysis of the European Quality of Life Survey (2003-2016) and Quarterly National Household Survey, average for four quarters. Labour Force Survey quarterly series QLF01.

www.cso.ie/px/pxeirestat/Statire/SelectVarVal/Define.asp?Maintable=QLF01\&Planguage=0. 
TABLE A3.2 MEAN WEEKLY HOURS SPENT ON CHILDCARE ACTIVITY

\begin{tabular}{l|c|c|c|c|c|c|c}
\hline & \multicolumn{3}{|c|}{ Women } & \multicolumn{3}{c}{ Men } & \multicolumn{3}{c}{ All } \\
\hline & Carers only $^{\mathbf{1}}$ & All & Carers only $^{\mathbf{1}}$ & All & Carers only $^{\mathbf{1}}$ & All \\
\hline $\mathbf{2 0 0 7}$ & 41.5 & 16.6 & 20.1 & 5.1 & 33.0 & 10.7 \\
\hline $\mathbf{2 0 1 1}$ & 43.5 & 22.5 & 27.2 & 10.7 & 36.6 & 16.7 \\
\hline $\mathbf{2 0 1 6}$ & 42.1 & 17.8 & 26.3 & 9.3 & 35.1 & 13.6 \\
\hline $\mathbf{2 0 0 7 - 2 0 1 6}$ & 42.6 & 19.1 & 25.2 & 8.5 & 35.2 & 13.8 \\
\hline
\end{tabular}

Source: Authors' analysis of the European Quality of Life Survey 2007, 2011 and 2016.

${ }^{1}$ Only those who are involved at least once a week.

TABLE A3.3 MEAN WEEKLY HOURS SPENT ON ADULT CARE

\begin{tabular}{|c|c|c|c|c|c|c|}
\hline & \multicolumn{2}{|c|}{ Women } & \multicolumn{2}{|c|}{ Men } & \multicolumn{2}{|c|}{ All } \\
\hline & Carers only $^{1}$ & All & Carers only ${ }^{1}$ & All & Carers only $^{1}$ & All \\
\hline 2007 & 19.1 & 2.1 & 29.8 & 2.9 & 23.9 & 2.5 \\
\hline 2011 & 14.5 & 2.4 & 12.4 & 1.8 & 13.6 & 2.1 \\
\hline 2016 & 25.8 & 4.4 & 16.8 & 2.3 & 21.9 & 3.4 \\
\hline Total & 19.8 & 3.0 & 18.8 & 2.4 & 19.4 & 2.7 \\
\hline
\end{tabular}

Source: Authors' analysis of the European Quality of Life Survey 2007, 2011 and 2016.

${ }^{1}$ Only those who are involved at least once a week.

TABLE A3.4 INVOLVEMENT IN HOUSEWORK ACTIVITY EVERY DAY

\begin{tabular}{|c|c|c|c|c|c|c|c|c|c|c|}
\hline \multicolumn{3}{|c|}{ All } & \multicolumn{2}{|c|}{1834} & \multicolumn{2}{|c|}{3549} & \multicolumn{2}{|c|}{5064} & \multicolumn{2}{|c|}{$65+$} \\
\hline & $\begin{array}{c}\text { Male } \\
\%\end{array}$ & $\begin{array}{c}\text { Female } \\
\%\end{array}$ & $\begin{array}{c}\text { Male } \\
\%\end{array}$ & $\begin{array}{c}\text { Female } \\
\%\end{array}$ & $\begin{array}{c}\text { Male } \\
\%\end{array}$ & $\begin{array}{c}\text { Female } \\
\%\end{array}$ & $\begin{array}{c}\text { Male } \\
\%\end{array}$ & $\begin{array}{c}\text { Female } \\
\%\end{array}$ & $\begin{array}{c}\text { Male } \\
\%\end{array}$ & $\begin{array}{c}\text { Female } \\
\%\end{array}$ \\
\hline 2003 & 34 & 70 & 25 & 56 & 39 & 81 & 43 & 74 & $33^{*}$ & 81 \\
\hline 2007 & 36 & 76 & 31 & 58 & 35 & 90 & 48 & 87 & 36 & 82 \\
\hline 2011 & 60 & 88 & 54 & 74 & 64 & 96 & 58 & 93 & 64 & 93 \\
\hline 2016 & 48 & 89 & 43 & 80 & 52 & 92 & 45 & 94 & 55 & 91 \\
\hline
\end{tabular}

Source: Authors' analysis of the European Quality of Life Survey 2007-2016, 2003 excluded due to lack of comparability. *indicates that there are fewer than 50 cases in the denominator for this cell. 
16-22 Sráid na Faiche,

Baile Átha Cliath 7, D07 CR20 16-22 Green Street,

Dublin 7, D07 CR20

Guthán/Phone + 353 (0) 18589601

Ríomhphost/Email info@ihrec.ie

Idirlíon/Web www.ihrec.ie
Whitaker Square,

Sir John Rogerson's Quay Dublin 2

Phone +35318632000

Fax +35318632100

Email admin@esri.ie

Web www.esri.ie 